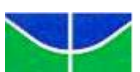 \\ UNIVERSIDADE DE BRASÍLIA \\ FACULDADE DE MEDICINA \\ PROGRAMA DE PÓS-GRADUAÇÃO EM CIÊNCIAS MÉDICAS
}

ANA PAULA MONTEIRO GOMIDES REIS

\section{PREVALÊNCIA E FATORES ASSOCIADOS A ENTEROPARASITOSES EM PACIENTES COM ARTRITE REUMATOIDE}

Dissertação apresentada como requisito parcial para a obtenção do título de Mestre em Ciências Médicas pelo Programa de Pós-Graduação em Ciências Médicas da Universidade de Brasília.

Orientadora: Licia Maria Henrique da Mota Co-orientadora: Caliandra Maria Bezerra Luna Lima

Brasília, 2016 
Reis Gomides Monteiro, Ana Paula

Prevalência e fatores associados a enteroparasitoses em pacientes com artrite reumatoide. / Ana Paula Monteiro Gomides Reis; orientador Licia Maria Henrique da Mota. -- Brasília, 2016. $124 \mathrm{p}$.

Dissertação (Mestrado - Mestrado em Ciências Médicas) -- Universidade de Brasília, 2016.

1. Artrite reumatoide. 2. Brasil. 3. Parasitoses.

4.Protozooses. I. Henrique da Mota, Licia Maria, orient. II. Título. 


\title{
PREVALÊNCIA E FATORES ASSOCIADOS A ENTEROPARASITOSES EM PACIENTES COM ARTRITE REUMATOIDE
}

\begin{abstract}
Dissertação apresentada como requisito parcial para a obtenção do título de Mestre em Ciências Médicas pelo Programa de Pós-Graduação em Ciências Médicas da Universidade de Brasília.
\end{abstract}

Data da defesa da dissertação: 05/09/2016

\section{BANCA EXAMINADORA}

Dra Licia Maria Henrique da Mota (Presidente)

Universidade de Brasília

Dra. Cíntia Mendes Clemente

Universidade de Brasília

Dra. Lenora Gandolfi

Universidade de Brasília

Prof. Sandor Balsamo (Suplente)

UNIEURO 
Dedico este trabalho à minha família: sustentação e melhor razão. 


\section{AGRADECIMENTOS}

\section{AOS MESTRES}

À minha querida orientadora, Licia Maria Henrique da Mota, que com seu brilhantismo e carisma, inspira todos ao seu redor. Você é um exemplo concreto de como um grande mestre pode influenciar o destino de seus alunos. Serei eternamente grata pela confiança e oportunidades.

Ao Prof. Dr. Leopoldo Luiz dos Santos Neto, modelo de excelência acadêmica, que nos incentiva ao crescimento contínuo. Obrigada pelo apoio, ensinamentos e oportunidade de convivência.

À Caliandra Maria Bezerra Luna Lima, minha co- orientadora, que com sua disponiblidade conseguiu encurtar distâncias e fazer toda diferença neste trabalho.

À querida Janice Sepúlveda Reis, minha grande amiga, cunhada, e maior incentivadora para a realização deste mestrado. Obrigada por tantos ensinamentos acadêmicos e de vida.

Ao Dr. Paulo Madureira de Pádua e a toda equipe de Reumatologia da Santa Casa de Belo Horizonte, responsáveis por minha formação na área da Reumatologia. 
Aos meus pais, Gilberto e Marília, a quem devo tudo o que sou, todo o meu amor.

Ao meu esposo e companheiro de vida, Bruno Sepúlveda Reis, pelo apoio e compreensão. Sem você mais este projeto não seria possível.

Aos meus filhos, Laura e Gabriel, fontes de amor incondicional e razões para viver.

À minha irmã Heloísa, minha melhor amiga, e aos meus irmãos, Jorge Augusto e Geandré, pelo companheirismo e carinho.

Às minhas amadas sobrinhas Luísa e Isabela, motivos de grande alegria.

À toda a minha família: querida vovó Fiíca, tias e tios, primos. Ter vocês é um grande privilégio.

À equipe de Reumatologia do HUB em especial Dr. Cleandro Albuquerque, Dra. Luciana Muniz, Dra. Talita Yokoy, Dra. Sandra Maximiano e Edivânia, pelo apoio durante a pesquisa.

Ao acadêmico, Alex Luiz, pela ajuda e participação ativa nesta pesquisa.

Ao Laboratório Sabin pelo apoio ao projeto e realização das análises em amostras fecais.

Aos amigos: Beatriz Amélia Monteiro de Andrade, Cíntia Leitão Braga, Flávia de Cássia Torres Ferreira, Flávia Leandra Monteiro Costa, 
Juliana Monteiro Corrêa, Marcelle Cordeiro Amorim, Rogério Monteiro Barbosa. Vocês me fazem ter certeza de que algumas amizades duram por toda a vida.

À minha querida amiga Tatiana Evaristo com quem compartilhei momentos felizes e momentos de grande adversidade nos últimos anos. Juntas conseguimos aprender muitas lições e fortalecer nossa amizade e crenças.

Às queridas amigas Martha, Micheline e Milene, pelo carinho e apoio em tempos de grandes desafios profissionais.

À DEUS, que me dá provas diárias do seu amor infinito e sempre nos permite recomeçar. 
"Sê todo em cada coisa. Põe quanto és. No mínimo que fazes." Fernando Pessoa 


\section{RESUMO}

Introdução: Os pacientes portadores de doenças reumáticas apresentam profundas alterações no sistema imunitário em virtude das doenças de base e dos tratamentos utilizados, o que aumenta o risco de ocorrência e a gravidade de infecções, dentre elas as enteroparasitoses. $O$ tratamento atual da artrite reumatoide envolve terapias imunossupressores potentes havendo a necessidade de rastreamento para processos infecciosos latentes. Não há na literatura estudos de prevalência de parasitoses em portadores de artrite reumatoide até o momento. O conhecimento destes dados epidemiológicos são fundamentais para fornecer elementos para o adequado manejo destes pacientes na prática clínica.

Objetivos: a) Avaliar a prevalência de parasitoses em uma população com Artrite Reumatoide; b) Determinar a prevalência das helmintíases e protozooses por espécie nos pacientes; c) Avaliar as condições socioeconômicas dos pacientes e sua relação com a ocorrência das enteroparasitoses; d) Demonstrar a possível relação entre a presença de parasitoses intestinais e parâmetros de atividade de doença.

Pacientes e Métodos: Foram coletados dados socioeconômicos demográficos e clínicos de uma amostra de conveniência de 67 pacientes acompanhados regularmente no ambulatório de AR do Hospital Universitário de Brasília no período de julho de 2015 a abril de 2016. Todos os pacientes foram submetidos ao exames parasitológico de fezes (EPF) pelo método de Hoffman, Pons e Janer (HPJ). Foram obtidas as frequências das variáveis de interesse, realizada análise bivariada e análise de regressão de Poisson múltipla com variância robusta.

Resultados: A idade média foi de 53.9 anos, com predomínio em mulheres (94\%) brancas (47.8\%). O tempo médio de doença foi de 9.2 anos e a maioria dos pacientes estava com a doença em remissão ou atividade leve. A prevalência de parasitoses foi de $11.9 \%$, sendo todos os casos de protozoários das seguintes espécies: Endolimax nana, Entamoeba histolytica e Entamoeba Coli. A análise multivariada final indicou que a presença de parasitose tem relação estatística significativa com ausência fadiga pela EVA $(p=0,0488)$ e com melhor índice de saúde atual pela EVA $(p=0,0012)$.

Palavras- chave: Artrite reumatoide, Brasil, parasitoses, protozooses. 


\section{ABSTRACT}

Introduction: Patients with rheumatic diseases have profound alterations in the immune system as a result of underlying diseases and the treatments used, which increases the risk of occurrence and severity of infections, among them the enteroparasitosis. The current treatment of rheumatoid arthritis involves immunosuppressive therapies powerfully needed for screening infectious processes. There are no studies in the literature on the prevalence of parasitic infections in patients with rheumatoid arthritis till date. The knowledge of these epidemiologic data are crucial to provide elements for the proper management of these patients in clinical practice.

Objectives: a) To assess the prevalence of parasitic diseases in a population with Rheumatoid Arthritis; b) To determine the prevalence of helminthiasis and protozooses by species in patients; (c) Assess the socioeconomic conditions of the patients and its relationship with the occurrence of enteroparasitosis; (d) To demonstrate the possible relationship between the presence of intestinal parasitic infections and parameters of disease activity.

Patients and methods: We collected demographic and socioeconomic data of a convenience sample of 67 patients followed up regularly at the clinic of the Hospital Universitário de Brasília in July 2015 period to April 2016. All patients were presented for parasitological examination of stools (EPF) by Hoffman, Pons and Janer (HPJ). We obtained the frequencies of the variables of interest, performed bivariate analysis and logistic regression, Poisson regression with robust variance.

Results: The mean age was 53.9 years, predominantly in women (94\%) white (47.8\%). The mean disease duration was 9.2 years and most patients had the disease in remission or light activity. The prevalence of parasitic infections was $11.9 \%$, with all cases of protozoa of the following species: Endolimax nana, Entamoeba histolytica and Entamoeba coli. The final multivariate analysis indicated that the presence of disease has significant statistical relationship with no fatigue by VAS $(p=0.0488)$ and best current health index by VAS $(p=0.0012)$. Key words: Rheumatoid arthritis, Brazil, parasites, protozoa. 


\section{LISTA DE TABELAS}

Tabela1- Características sócio-demográficas de 70 pacientes com artrite reumatoide: frequência absoluta e relativa de cada variável da amostra

Tabela 2 - Distribuição por ocupação dos 67 pacientes com artrite reumatoide

Tabela 3 - Comorbidades apresentadas pelos indivíduos com AR no estudo

Tabela 4 - Escala visual analógica (valor: 0-100) de pacientes com artrite reumatoide avaliados no estudo

Tabela 5 - Prevalência de parasitose conforme variáveis estudadas em pacientes com AR $(n=67)$

Tabela 6 - Distribuição das variáveis de estudo de acordo com as razões de prevalência bruta e ajustada conforme modelo de regressão de

Poisson com variância robusta e seus respectivos intervalos de $95 \%$ de confiança 


\section{LISTA DE ABREVIATURAS E SIGLAS}

\section{AR- Artrite reumatoide}

CCEB- Critério de classificaçãoo econômica Brasil

CDAI- Índice Clínico de Atividade da Doença

Célula NK- Célula Natual killer

CEP-FM - Comitê de Ética em Pesquisa da Faculdade de Medicina

CTPS - Carteira de Trabalho e Previdência Social

DAS 28- Escore de atividade da doença 28 articulações

EPF - Exame parasitológico de fezes

EVA- Escala visual analógica

HAQ- Health Assessment Questionnaire

HAS- Hipertensão arterial sistêmica

HUB- Hospital Universitário de Brasília

ICAD's- Índices compostos de atividade de doença

IL- Interleucina

IMC- Índice de massa corporal

INF- Interferon

LSN- Limite superior da normalidade

MMCDs- Medicamentos modificadores do curso da doença

PCR- Proteína C reativa

RANKL- Receptor activator of nuclear factor kappa ligand

RP- Razão de prevalência

SDAI- Índice simplificado de atividade da doença

TCLE- Termo de consentimento livre e esclarecido

TGF-Transforming growth factor

Th- Célula $T$ helper

TNF- Tumor necrosis factor

UNB- Universidade de Brasília

VHS- Velocidade de hemossedimentação 
ACR- American College of Rheumatology

EULAR- European League Against Rheumatism

SF 36- 36-Item short-form 


\section{SUMÁRIO}

1. INTRODUÇÃO

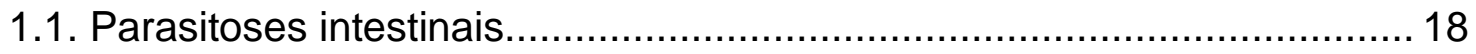

1.1.1. Histórico e prevalência ............................................................... 18

1.1.2. Considerações clínicas e diagnóstico …………….................... 19

1.2 Parasitoses intestinais e o sistema imunitário ..................................... 20

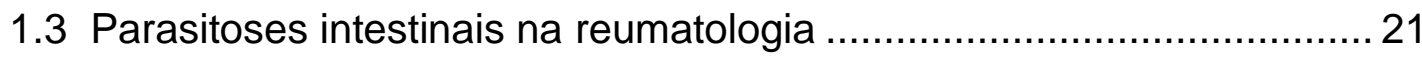

2. JUSTIFICATIVA

3. OBJETIVOS

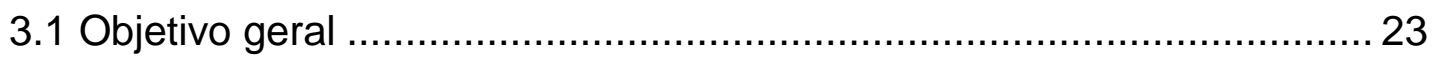

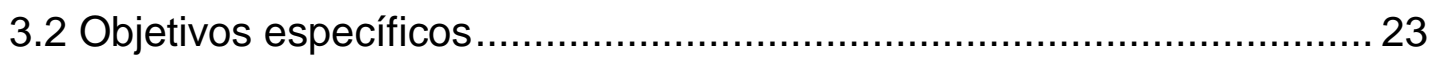

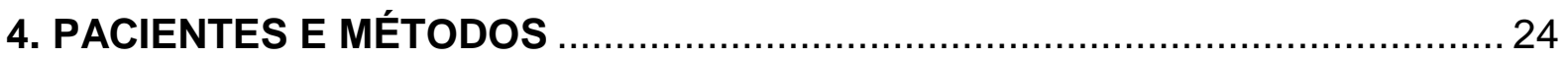

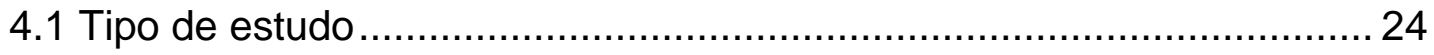

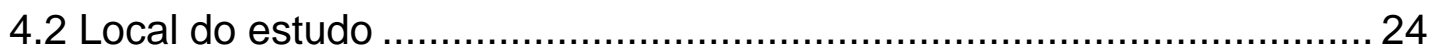

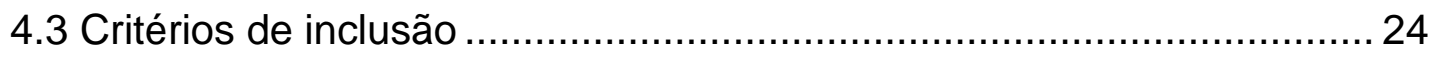

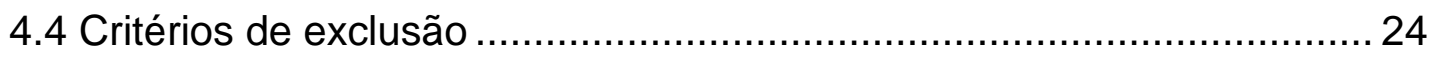

4.5 Seleção dos pacientes e duração do estudo ....................................... 25

4.6 Parâmetros avaliados e forma de avaliação ....................................... 25

4.6.1 Caracterização da população estudada .................................... 25

4.6.2 Exames laboratoriais ....................................................... 27

4.6.3 Exame parasitológico de fezes (EPF) ………....................... 27

4.6.4 Escores de atividade da ar.................................................... 28 
4.6.3 Avaliação do impacto da ar na qualidade de vida do paciente..... 28

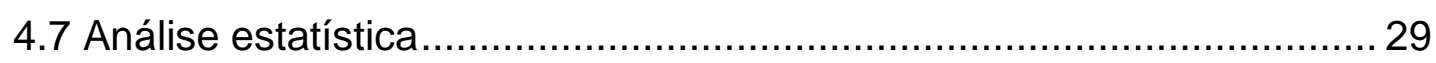

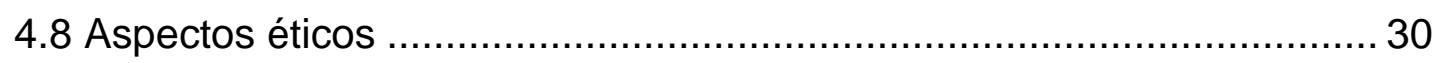

5. RESULTADOS

5.1 Características gerais da população …………………………….... 30

5.2 Características relacionadas à artrite reumatoide ................................. 35

5.3 Resultados das análises em amostra fecal ........................................ 38

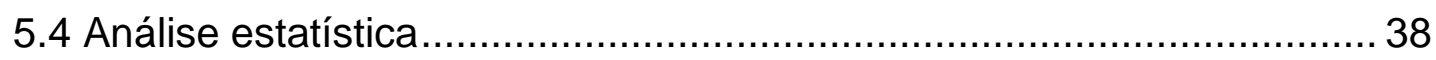

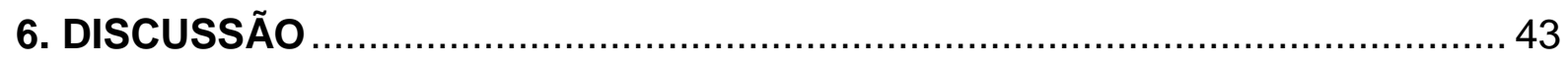

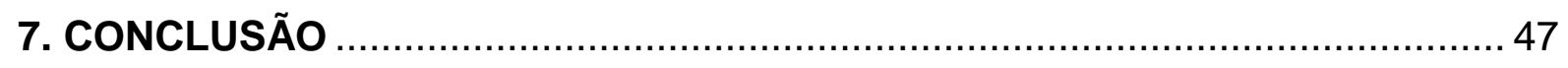

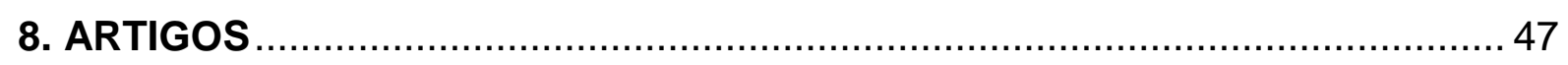

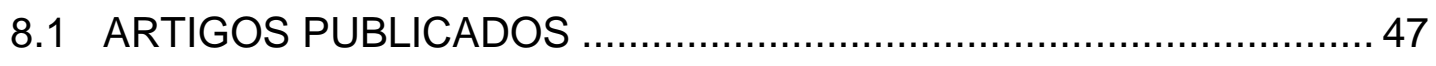

8.1.1 Parasitoses intestinais: efeito protetor na artrite reumatoide? .... 47

8.1.2 Gut parasites in rheumatoid arthritis: imminent threat or protective

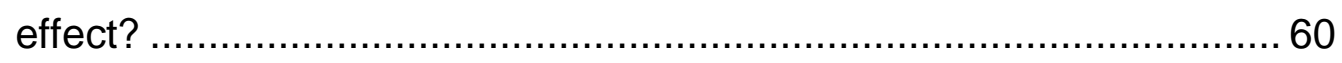

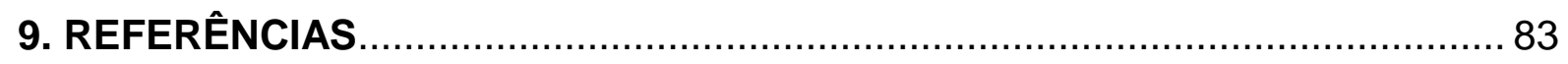

ANEXO 1 Termo de Consentimento Livre e Esclarecido ........................................ 92

ANEXO 2 Rotina para tratamento de pacientes com diagnóstico de artrite reumatoide, acompanhados na coorte brasília de artrite reumatoide ...................... 94

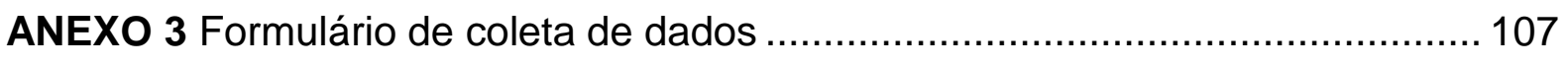

ANEXO 4 Critério de Classificação Econômica Brasil (CCEB) da Associação Brasileira de Empresas de Pesquisa (ABEP) ...................................................114

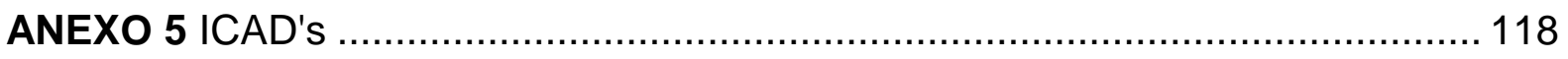

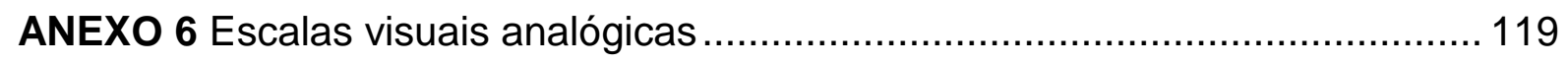


ANEXO 7 Questionário de Capacidade Funcional - HAQ............................... 120

ANEXO 8 Aprovação do Comitê de Ética ................................................... 123 


\section{INTRODUÇÃO}

\subsection{PARASITOSES INTESTINAIS}

\subsubsection{HISTÓRICO E PREVALÊNCIA}

As parasitoses intestinais figuram entre as doenças mais antigas que se tem conhecimento na humanidade. A história da parasitologia humana deu origem a um ramo de estudo conhecido como paleoparasitologia, na qual são pesquisados presença de parasitos em materiais arqueológicos, múmias, fósseis, dentre outros. Com o avanço de técnicas na área de biologia molecular e genética, esta área teve grande avanço e vem fornecendo evidências de que o surgimento dos parasitas se confunde com o próprio surgimento da raça humana. Há comprovação, através do encontro de parasitas em fósseis, de que o homem da pré- história já era acometido por parasitoses. $(1,2)$

Apesar da antiguidade destas doenças e a despeito de todo avanço da medicina, as enteroparasitoses apresentam elevada prevalência ainda nos dias de hoje. Estima-se que $25 \%$ da população mundial esteja infectada por algum tipo de parasito. (3) Calcula-se que cerca de 1 bilhão de pessoas estejam infectadas por Ascaris lumbricoides, sendo um pouco menor o número infestado por Trichuris trichiura e pelos ancilostomídeos. Estima-se, ainda, que milhões de indivíduos sejam portadores de Entamoeba histolytica e Giardia lamblia. (4)

As helmintíases e as protozooses, os dois tipos de enteroparasitoses, se distribuem de acordo com o clima, características da população e da região. São mais prevalentes em regiões tropicais e subtropicais. (5-7) 
As formas mais comuns de contaminação do hospedeiro são a ingestão de água e alimentos contaminados, além de penetração direta pela pele por penetração de larvas existentes no solo. Pode haver, embora mais raramente, transmissão por via sexual. As condições de moradia, de saneamento básico e higiene pessoal são fatores determinantes de uma maior prevalência das parasitoses em populações com condições econômicas mais precárias e piores condições de saneamento básico. (4, 8-9)

No Brasil, a real prevalência das parasitoses intestinais ainda não é conhecida. Os estudos geralmente são feitos com populações restritas como indivíduos institucionalizados, crianças e idosos, moradores de zona rural. Em 2005, o Ministério da Saúde publicou Plano Nacional de Vigilância e Controle das Enteroparasitoses com o objetivo de obter informações sobre prevalência e definir medidas de controle. Ainda assim os dados disponíveis foram insuficientes e restritos, pois eram referentes a escolares ou usuários da rede pública de saúde. (4, 9-13) Desta forma, vem sendo considerada por muitos autores como uma das doenças negligenciadas (DN) mais importantes, que são definidas como conjunto de doenças causadas que produzem importante dano físico, cognitivo e socioeconômico, principalmente, em comunidades de baixa renda. (14-16)

\subsubsection{CONSIDERAÇÕES CLÍNICAS E DIAGNÓSTICO}

As manifestações clinicas das parasitoses bem como sua intensidade e gravidade dependem de múltiplos fatores, inerentes ao parasito e ao hospedeiro. Em relação às características do patógeno, sabe-se que o número (carga parasitária), tamanho, virulência, localização e metabolismo são determinantes. No hospedeiro acredita-se que a idade, estado nutricional, doenças concomitantes, hábitos de vida, alterações do sistema imune e uso de medicamentos interferirem diretamente no quadro. Portanto, a combinação dos fatores citados determinará o indivíduo "doente" ou o portador assintomático. $(4,18)$

O quadro clínico das parasitoses é extremamente variado. Em sua maioria, os pacientes são assintomáticos ou oligossintomáticos. Entretanto, casos graves e 
até mesmo fatais são vistos ocasionalmente, principalmente em indivíduos com alterações no sistema imune e alta concentração de parasitas.

Os sintomas mais comuns dessas infecções são inespecíficos como alterações do hábito intestinal, náuseas, vômitos, anorexia e adinamia. Entretanto danos maiores podem ocorrer como desnutrição, anemia, obstrução intestinal e síndromes de má absorção . (19-21)

O diagnóstico das parasitoses intestinais é realizado pelo exame parasitológico de fezes (EPF) através da pesquisa de diferentes formas parasitárias (trofozoítos e cistos de protozoários, ovos e larvas de helmintos). Levando-se em consideração que a produção de ovos, cistos ou larvas não é uniforme ao longo do dia ou do ciclo do parasita, e que alguns protozoários apresentam o período negativo de eliminação das estruturas parasitárias, deve-se utilizar a combinação de técnicas diferentes em mais de uma amostra fecal. A coleta e conservação do material também devem ser feitas de forma adequada para minimizar o risco de resultados falso-negativos. (21-23)

\subsection{PARASITOSES INTESTINAIS E O SISTEMA IMUNITÁRIO}

A resposta imunológica do hospedeiro contra parasitos tem sido estudada há várias décadas, principalmente em modelos experimentais. Embora todos os mecanismos de defesa do organismo ainda não sejam completamente conhecidos, existem evidências de que a barreira da mucosa intestinal, a resposta humoral e celular estão presentes em graus variados na dependência do tipo de infecção. Sabe-se que há importante resposta humoral quando os parasitos passam por estágios extra celulares em seu ciclo e a resposta celular ocorre sobretudo nos estágios intracelulares dos protozoários. (24)

Por outro lado, para garantir sua sobrevivência prolongada no organismo, acredita-se que os mesmos tem habilidade de realizar uma imunomodulação da resposta imune do tipo "downregulation". Isso seria possível através da produção de substâncias biologicamente ativas: moléculas ES (excretory-secretory") que causariam mudanças na resposta inflamatória do hospedeiro. Vários estudos 
experimentais demonstraram ações diversas que culminam com uma resposta antiinflamatória. (24-34)

A predominância da resposta imune do tipo Th2, talvez seja o mecanismo mais importante neste processo. Já foi demonstrado que substâncias produzidas por helmintos, principalmente a ES-62, induzem uma modificação da resposta Th1 para Th2 culminando com elevação na produção de IL-4, IL-10 e TGF $\square \square \square$ além da redução de citocinas pró-inflamatórias (TNF- $\square$, IL-1 $\square, 6$ e 17, IFN- $\square$, RANKL). Adicionalmente, pode haver alteração da função de células dendríticas, macrófagos, células NK e células $B$, levando à expansão $T$ regulatórias responsáveis por manter a autotolerância. (25)

\subsection{PARASITOSES INTESTINAIS NA REUMATOLOGIA}

A Reumatologia é uma especialidade que abrange, tipicamente, a abordagem e tratamento de doenças nas quais há alterações complexas do sistema imunitário. Além disso, o tratamento utilizado para induzir ou manter remissão destas enfermidades também podem causar quadros de imunossupressão o que pode aumentar o risco de processos infecciosos. Diante disso, vem sendo crescente a preocupação com as doenças parasitárias em pacientes com doenças reumáticas. $(23,35)$

A artrite reumatoide $(A R)$ é uma doença inflamatória autoimune crônica na qual o tratamento medicamentoso vem evoluindo drasticamente. Nos últimos anos, além da corticoterapia e tradicionais MMCDS (medicamentos modificadores do curso de doença), novas drogas vem sendo utilizados, como por exemplo a terapia biológica que inclui inibidores de citocinas (antagonistas do TNF alfa e/ ou bloqueadores dos receptores de citocinas) e imunomoduladores. Na maioria dos casos, estas terapias vem sendo bem toleradas mas podem aumentar o risco de infecções provavelmente por inibição de moléculas essenciais na defesa do hospedeiro contra vírus, bactérias, fungos e parasitas. (36-47) Diante do exposto, desde que as novas drogas se tornaram essenciais no manejo da $A R$, vem sendo 
feitas recomendações aos profissionais para rastreamento e monitorização de processos infecciosos nesta população. $(37,48)$

Em relação ao risco específico de aparecimento ou agravamento de parasitoses nos pacientes com artrite reumatoide, existe uma escassez de informações, pois não há na literatura estudos de prevalência nesta população. Apesar disso, em virtude de um maior risco e potencial gravidade das infecções parasitárias nos pacientes reumáticos, algumas Sociedades de Reumatologia, como a Sociedade Brasileira, a Sociedade Italiana e a Sociedade Espanhola vem elaborando documentos baseados em consenso de especialistas e revisões de literatura, para orientar a investigação e tratamento destas enfermidades, principalmente nos candidatos ao uso de imunobiológicos. $(37,48)$

Um outra dificuldade encontrada na reumatologia, é que a imunossupressão secundária ao tratamento, pode causar dificuldades diagnósticas em razão de modificações em parâmetros laboratoriais. A eosinofilia, alteração comum em infecções por parasitas, pode não ocorrer ou não ser valorizada em usuários de corticóides sistêmicos. Adicionalmente, muitos sintomas das parasitoses podem mimetizar manifestações da própria doença de base, dificultando o diagnóstico das mesmas. (40)

A relação inversa entre infecções parasitárias e doenças reumáticas também vem sendo descrita na literatura. Alguns autores acreditam que a infecção por helmintos pode minimizar o aparecimento e a gravidade da artrite reumatoide. Este fato ocorreria devido a produção de substâncias capazes de atenuar o processo inflamatório da doença, principalmente pelos helmintos. Várias linhas de pesquisa tem surgido neste sentido de que alguns parasitas poderiam exercer fator "protetor" em diversas doenças autoimunes, fato que ainda necessita comprovação. (49-62)

\section{JUSTIFICATIVA}

Os pacientes portadores de doenças reumáticas apresentam profundas alterações no sistema imunitário em virtude das doenças de base e dos tratamentos 
utilizados, o que aumenta o risco de ocorrência e a gravidade de infecções, dentre elas as enteroparasitoses.

O tratamento atual da artrite reumatoide envolve terapias imunossupressores potentes havendo a necessidade de rastreamento para processos infecciosos latentes.

Não há na literatura estudos de prevalência de parasitoses em portadores de artrite reumatoide até o momento. O conhecimento destes dados epidemiológicos são fundamentais para fornecer elementos para o adequado manejo destes pacientes na prática clínica.

\section{OBJETIVOS}

\subsection{OBJETIVO GERAL}

Avaliar a prevalência de parasitoses em uma população com Artrite Reumatoide.

\subsection{OBJETIVOS ESPECÍFICOS}

a) Determinar a prevalência das helmintíases e protozooses por espécie nos pacientes.

b) Avaliar as condições socioeconômicas dos pacientes e sua relação com a ocorrência das enteroparasitoses.

c) Demonstrar a possível relação entre a presença de parasitoses intestinais e parâmetros de atividade de doença. 


\section{PACIENTES E MÉTODOS}

\subsection{TIPO DE ESTUDO}

Estudo observacional analítico com delineamento transversal.

\subsection{LOCAL DO ESTUDO}

Os dados foram coletados de pacientes com diagnóstico de AR avaliados e em tratamento regular no Ambulatório de Reumatologia do Hospital Universitário de Brasília (HUB), Universidade de Brasília (UnB).

\subsection{CRITÉRIOS DE INCLUSÃo}

- Idade maior que 18 anos.

- Capacidade de preencher o termo de consentimento livre e esclarecido (Anexo 1) e aceitar o acompanhamento em longo prazo.

- Diagnóstico de AR realizado por reumatologista preenchendo os critérios ACR 1987 ou EULAR/ACR 2010. (63,64)

- Acompanhamento e tratamento protocolar (Anexo 2) nos ambulatórios de AR do Hospital Universitário de Brasília (HUB).

\subsection{CRITÉRIOS DE EXCLUSÃO}

- Gravidez

- Pacientes que no período de até 30 dias antes do estudo fizeram uso de medicamentos antiparasitários. 
- Pacientes que não realizarem todas as avaliações necessárias para conclusão do estudo ou que abandonarem o acompanhamento.

- Doença subjacente aguda ou crônica com alta probabilidade de falecimento em um futuro próximo

\subsection{SELEÇÃO DOS PACIENTES E DURAÇÃO DO ESTUDO}

Os indivíduos avaliados foram selecionados pela pesquisadora responsável durante a rotina de atendimento dos mesmos no ambulatório de reumatologia do HUB. Foi selecionada uma amostra de conveniência de 70 pacientes, logo, sem o cálculo amostral.

Os participantes que preenchiam os critérios de inclusão, receberam informações sobre parasitoses e também uma explanação acerca do projeto. Após este procedimento, os indivíduos que expressarem interesse em fazer parte da pesquisa, assinaram o Termo de Consentimento Livre e Esclarecido (TCLE- anexo 1) e foram submetidos à avaliação clínica.

A coleta de dados ocorreu no período de julho de 2015 a abril de 2016.

\subsection{PARÂMETROS AVALIADOS E FORMA DE AVALIAÇÃO}

Os pacientes foram submetidos a avaliação clinica na qual foram pesquisados os seguintes parâmetros (Anexo 3):

\subsubsection{CARACTERIZAÇÃO DA POPULAÇÃO ESTUDADA}

4.6.1.1) Dados epidemiológicos e socioeconômicos 
- Idade

- Sexo

- Cor/ Raça

- Estado civil

- Formação educacional

- Anos de estudo

- Profissão

- Questionário para avaliação de classe econômica (Critério de Classificação Econômica Brasil : CCEB. Anexo 4)

4.6.1.2) Hábitos de vida

- Tabagismo: atual ou prévio, tempo de tabagismo.

- Etilismo: uso regular de bebidas alcoólicas (uma ou mais vezes por semana).

- Prática de atividade física regular (sim ou não, número de vezes por semana).

4.6.1.3) Dados da história clínica relacionados a AR:

- Tempo de doença.

- Fator reumatoide: positivo ou negativo. Negativo foi considerado quando valores iguais ou inferiores ou limite superior da normalidade (LSN) para o ensaio. Titulação baixa refere-se quando o valor for superior ao LSN mas inferiores a 3 vezes o LSN. Titulação alta quando o valores forem iguais ou maiores a 3 vezes o LSN.

- Doença erosiva: considerada existente quando ocorreram erosões (quebra da cortical óssea) em pelo menos três articulações.

- Manifestações extra-articulares: presença e tipo.

- Comorbidades: tipo e número.

- Infiltrações: avaliadas se o procedimentos já foi feito durante o tratamento (sim ou não), o número de vezes e local. 
- Cirurgias ortopédicas: sim ou não para a realização das mesmas.

\subsubsection{4) Exame físico}

- Exame físico geral (Anexo 3)

- Exame físico osteoarticular (Anexo 3 )

4.6.1.5) Avaliação nutricional

- Peso

- Altura

- Cálculo de índice de massa corporal (IMC): Peso/ altura $^{2}$

\subsubsection{EXAMES LABORATORIAIS}

- VHS

- PCR

\subsubsection{EXAME PARASITOLÓGICO DE FEZES (EPF)}

Todos os pacientes foram submetidos ao exames parasitológico de fezes (EPF), pesquisa de gordura e sangue oculto nas fezes. Os exames foram realizados no laboratório Sabin- DF.

As análises no material fecal foram realizadas pelo método de Hoffman, Pons e Janer (HPJ), realizando-se três leituras em cada preparação, que fundamenta-se na sedimentação espontânea em água. O método HPJ foi usado para detectar a presença de ovos e larvas de helmintos e cistos de protozoários. Trata-se de uma 
técnica amplamente utilizada em estudos epidemiológicos, pois apresenta vantagens, tais como, baixo custo, fácil execução e boa sensibilidade. (65) Para pesquisa de gordura fecal foi utilizado o método Sudan III. $(66,67)$ A avaliação de sangue oculto nas fezes foi feita pela pesquisa de anticorpo monoclonal antihemoglobina humana por método imunocromatográfico. (68)

\subsubsection{ESCORES DE ATIVIDADE DA AR}

- Escore de atividade da doença baseado na contagem de 28 articulações DAS 28. (69) (Anexo 5)

- Índice simplificado de atividade da doença - SDAl; calculado a partir da contagem das articulações inflamadas e doloridas, das escalas visuais analógicas de atividade da doença do paciente e do médico e do valor da proteína $C$ reativa $(P C R)$, através da seguinte fórmula: Escore total $=$ articulações dolorosas DAS 28 + articulações edemaciadas DAS $28+$ EVA paciente + EVA médico + PCR. O CDAl apresenta um escore de 0.1 - 86.0. (69) (Anexo 5)

- Índice clínico de atividade da doença - CDAl; calculado como o SDAI, exceto pela exclusão do PCR do seu escore total, compondo então, um escore de 0.1 - 76.0. (Anexo 5)

\subsubsection{AVALIAÇÃO DO IMPACTO DA AR NA QUALIDADE DE VIDA DO PACIENTE}

- Escala visual analógica da dor global (Anexo 6)

- Escala visual analógica de avaliação global da atividade da doença do paciente (Anexo 6)

- Escala visual analógica de avaliação global da atividade da doença do médico (Anexo 6) 
- Health Assesment Questionarie (HAQ) (versão validada em português) (70) (Anexo 7)

\subsection{ANÁLISE ESTATÍSTICA}

A análise estatística consistiu nas seguintes etapas:

a) Obtenção de frequências das variáveis de interesse.

b) Obtenção das prevalências das variáveis associadas à presença de parasitose, com os respectivos intervalos de confiança.

c) Análise bivariada empregando como medida de efeito a razão de prevalência, com seus respectivos intervalos de confiança

d) Análise de regressão de Poisson múltipla com variância robusta. (71)

No presente estudo, a presença de parasitose foi considerada a variável dependente. As variáveis independentes consideradas foram: idade, anos de estudo, classe econômica, tempo de doença, AR soropositiva, índice de massa corporal (IMC), rigidez matinal, escalas visuais analógicas (dor, fadiga, atividade hoje, atividade 6 meses, saúde hoje, EVA médico), DAS 28 (VHS e PCR), SDAI e CDAI.

Para realização da análise bivariada, as variáveis foram divididas em 2 grupos: idade ( $\leq 40$ e $>40$ ), anos de estudo ( $\leq 8$ e $>8$ ), classe econômica (B e C a $E)$, tempo de doença em anos ( $\leq 10$ e $>10$ ), AR soropositiva (não e sim), IMC (normal e alterado), rigidez matinal (não e sim), EVA dor, EVA fadiga, EVA atividade hoje, EVA atividade 6 meses, EVA saúde hoje, EVA avaliação do médico (todas com resposta do tipo ausência quando igual a zero e presença para todos os outros valores), DAS 28 VHS e PCR, SDAl e CDAl (todas com resposta do tipo remissão e não remissão). Em seguida, verificou-se a associação entre cada variável independente e o desfecho (presença de parasitose). Posteriormente, aquelas com 
$p<0,25$ foram incluídas na análise múltipla.(71) No modelo final, considerou-se significativas aquelas com $\mathrm{p}<0,05$.

testar o efeito das variáveis independentes sobre a presença de parasitose foram utilizados modelos de regressão de Poisson com variância robusta. Este modelo fornece uma melhor estimativa das razões de prevalência, que por sua vez representam de forma mais significativas as medidas de efeito para estudos transversais. (71)

Multicolinearidade entre as variáveis independentes foi avaliada. Considerou como limite da presença de multicolinearidade se o indicador de tolerância assume valores menores que 0,40. (73)

Considerou-se significativo $p<0,05$ e intervalos de confiança de $95 \%$. As análises foram conduzidas pelo aplicativo SAS 9.4.

\subsection{ASPECTOS ÉTICOS}

O projeto que deu origem ao presente trabalho foi submetido à apreciação do Comitê de Ética em Pesquisa em Seres Humanos (CEP) da Faculdade de Medicina da UnB (FM-UnB) em 15 de junho de 2007, analisado e aprovado em 22 de agosto de 2007 (Registro do projeto: CEP-FM 028/2007). (Anexo 8)

Todos os participantes assinaram um termo de consentimento livre e esclarecido. (Anexo 1)

\section{RESULTADOS}

\subsection{CARACTERÍSTICAS GERAIS DA POPULAÇÃO}


Foram avaliados 70 pacientes com AR, entretanto 3 foram excluídos da análise por não completarem todas as avaliações. Em relação ao gênero, 63 pacientes (94\% da amostra) eram do sexo feminino. Todos os participantes eram provenientes de zona urbana do Distrito Federal e alegaram receber água encanada. Os outros dados sócio demográficos desta população estão sumarizados na tabela 1.

Em relação à profissão, 29 pacientes (43,2 \%) se declararam como " Do lar "ou "donas de casa". A distribuição das ocupações pode ser vista na tabela 2 e o tipo de vínculo trabalhista atual pode ser encontrado no gráfico 1.

TABELA 1: Características sócio-demográficas de 70 pacientes com artrite reumatoide: frequência absoluta e relativa de cada variável da amostra

\begin{tabular}{clcc}
\hline \multirow{2}{*}{ Variável } & Categoria & $\mathrm{n}$ & $\%$ \\
\hline Sexo & Feminino & 63 & 94 \\
& Masculino & 4 & 6 \\
\hline Cor & Branca & 32 & 47,8 \\
& Parda & 29 & 43,3 \\
& Negra & 5 & 7,5 \\
& Indígena & 1 & 1,4 \\
\hline Estado Civil & Solteira & 23 & 34,3 \\
& Casada & 32 & 47,8 \\
& Divorciada & 7 & 10,4 \\
& Viúvo & 5 & 7,5 \\
\hline Formação & Analfabeto & 6 & 8,9 \\
& Primeiro grau & & \\
& incompleto & 17 & 25,4 \\
& Primeiro grau & & 19,4 \\
& completo & 13 &
\end{tabular}




\begin{tabular}{|c|c|c|c|}
\hline & \multicolumn{3}{|l|}{ Segundo grau } \\
\hline & incompleto & 2 & 3 \\
\hline & \multicolumn{3}{|l|}{ Segundo grau } \\
\hline & completo & 19 & 28,3 \\
\hline & Superior incompleto & 2 & 3 \\
\hline & Superior completo & 5 & 7,5 \\
\hline & Pós graduação & 3 & 4,5 \\
\hline \multirow[t]{5}{*}{ Classe social } & B1 & 3 & 4,5 \\
\hline & B2 & 14 & 20,9 \\
\hline & C1 & 23 & 34,3 \\
\hline & $\mathrm{C} 2$ & 17 & 25,4 \\
\hline & $D-E$ & 10 & 14,9 \\
\hline \multirow[t]{4}{*}{ Idade } & Média & & 53.9 \\
\hline & Desvio padrão & & 12.3 \\
\hline & Mínimo & & 26 \\
\hline & Máximo & & 80 \\
\hline \multirow[t]{4}{*}{ Anos de estudo } & Média & & 8.3 \\
\hline & Desvio padrão & & 4.6 \\
\hline & Mínimo & & 0 \\
\hline & Máximo & & 16 \\
\hline
\end{tabular}


TABELA 2: Distribuição por ocupação dos 67 pacientes com artrite reumatoide

\begin{tabular}{|c|c|c|c|}
\hline Variável & Categoria & $N$ & $\%$ \\
\hline \multirow[t]{26}{*}{ Profissão } & Atendente & 1 & 1,5 \\
\hline & Auxiliar administrativo & 2 & 3 \\
\hline & Auxiliar de serviços & & \\
\hline & gerais & 1 & 1,5 \\
\hline & Auxiliar de cozinha & 1 & 1,5 \\
\hline & Auxiliar de creche & 1 & 1,5 \\
\hline & Cantineira & 1 & 1,5 \\
\hline & Comerciante & 2 & 3 \\
\hline & Copeira & 2 & 3 \\
\hline & Costureira & 1 & 1,5 \\
\hline & Cozinheira & 1 & 1,5 \\
\hline & Diarista & 1 & 1,5 \\
\hline & Do lar & 29 & 43,2 \\
\hline & Doméstica & 2 & 3 \\
\hline & Empregada doméstica & 2 & 3 \\
\hline & Empresária & 1 & 1,5 \\
\hline & Faxineira & 2 & 3 \\
\hline & Funcionária pública & 2 & 3 \\
\hline & Funcionário público & 2 & 3 \\
\hline & Pedagoga & 1 & 1,5 \\
\hline & Pedreiro & 1 & 1,5 \\
\hline & Pescadora & 1 & 1,5 \\
\hline & Professora & 2 & 3 \\
\hline & Recepcionista & 1 & 1,5 \\
\hline & Secretária & 1 & 1,5 \\
\hline & Servidora pública & 3 & 4,5 \\
\hline
\end{tabular}




$\begin{array}{lll}\text { Tecnico de contabilidade } & 1 & 1,5 \\ \text { Trabalhadora rural } & 1 & 1,5 \\ \text { Vigilante } & 1 & 1,5\end{array}$

GRÁFICO 1: Tipo de vínculo trabalhista dos pacientes com AR avaliados no estudo

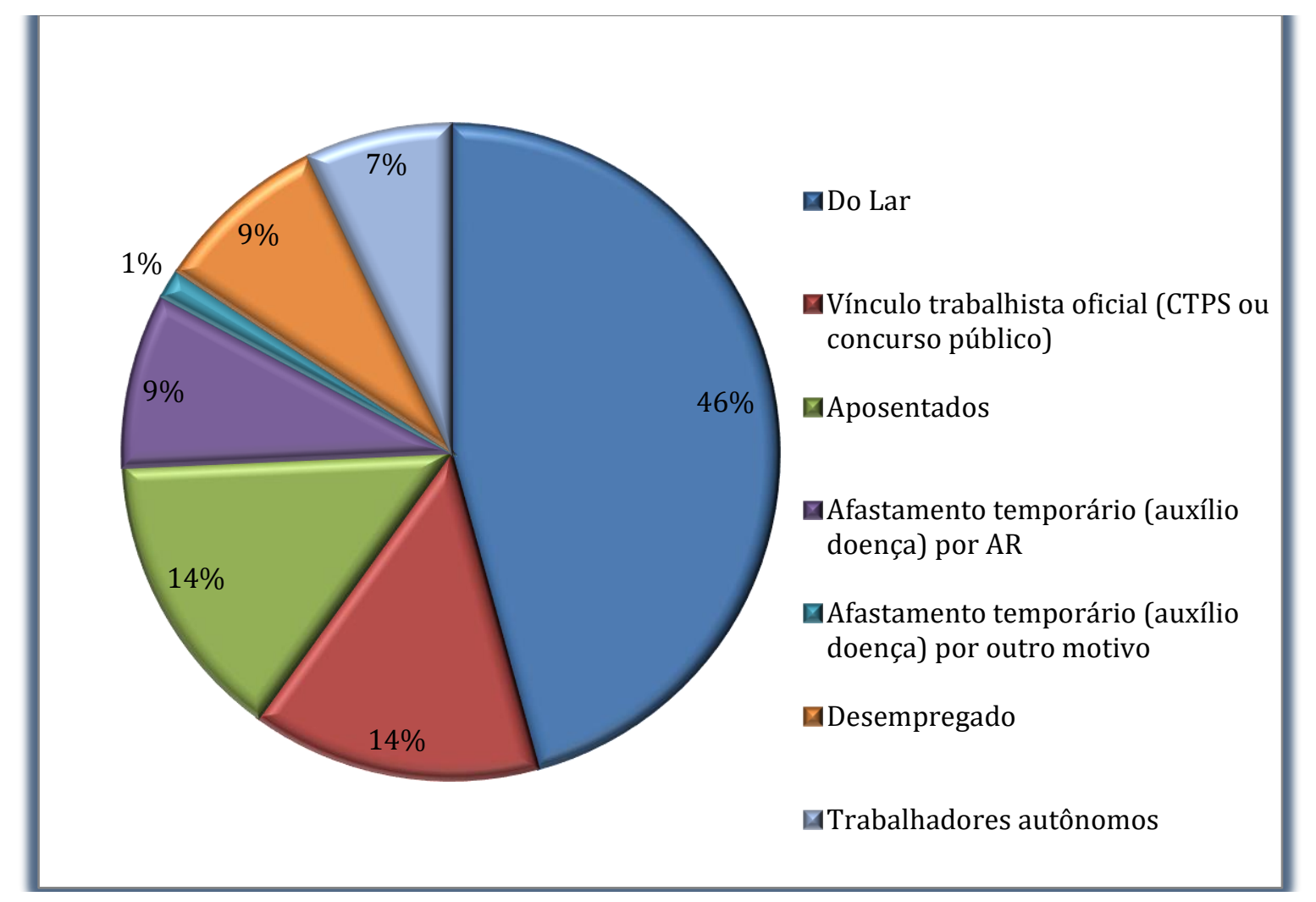

Quando analisados os hábitos de vida, 14 pacientes (20.9\%) tinham história de tabagismo prévio e 4 (6.25\%) se declararam tabagistas atualmente. A média do tempo de tabagismo entre as fumantes foi de 27.1 anos, com mediana de 30 anos e variação de 1 a 40 anos.

Em relação ao hábito de ingesta regular de bebida alcóolica apenas 1 paciente $(1.5 \%)$ se declarou usuária, relatando uso superior a 3 vezes por semana. 
A prática de exercícios físicos foi analisada e 44 participantes (65,7\%) responderam que realizam atividades regulares por 2 ou mais vezes por semana. Os outros 23 pacientes não realizavam exercícios ou o faziam apenas uma vez por semana ou menos.

A classificação do peso corporal, medido pelo IMC (peso/altura ${ }^{2}$ ), verificou que $30(44.8 \%)$ avaliados tinham índice normal, 21 (31.3\%) com sobrepeso e 16 (23.8\%) apresentaram graus variados de obesidade.

As comorbidades mais frequentes encontradas na amostra podem ser vistas na tabela 3 .Cabe ressaltar que apenas 11 pacientes (16.4\%) não apresentavam outras doenças além da AR e 17 (25.4\%) apresentavam apenas 1 comorbidade. $O$ restante (39 pacientes ou $58.2 \%$ ) apresentavam 2 ou mais comorbidades associadas.

TABELA 3: Comorbidades apresentadas pelos indivíduos com AR no estudo

\begin{tabular}{l|c|c}
\hline \multicolumn{1}{c|}{ Doença } & Número de pacientes & \% total da amostra \\
\hline HAS & 29 & 43.3 \\
\hline Diabetes Mellitus & 18 & 26.9 \\
\hline Dislipidemia & 13 & 19.4 \\
\hline Fibromialgia & 9 & 13.4 \\
\hline Osteoartrose & 4 & 6.0 \\
\hline Osteoporose & 4 & 6.0 \\
\hline
\end{tabular}

\section{2) CARACTERÍSTICAS RELACIONADAS À ARTRITE REUMATOIDE}

Em relação às características da $A R$, verificamos que 54 pacientes $(80.6 \%)$ da amostra eram soropositivas em relação ao fator reumatoide, sendo que 39 (58.2\%) apresentavam títulos altos do mesmo (valor maiores que 3 ou mais vezes do que limite superior da normalidade) e o restante (15 pacientes) apresentavam 
títulos baixos. Nove indivíduos (13.4\%) apresentavam doença erosiva e três tiveram manifestações extra articulares (2 com nódulos subcutâneos e 1 com manifestações pulmonares). A média de duração da doença na amostra foi de 9,1 anos. A análise dos índices compostos de atividade da doença (ICAD's), HAQ e escalas visuais analógicas podem ser vistos nos gráficos 2,3 e tabela 4, respectivamente.

GRÁFICO 2: Índices compostos de atividade de doença calculados na amostra de 67 pacientes com AR

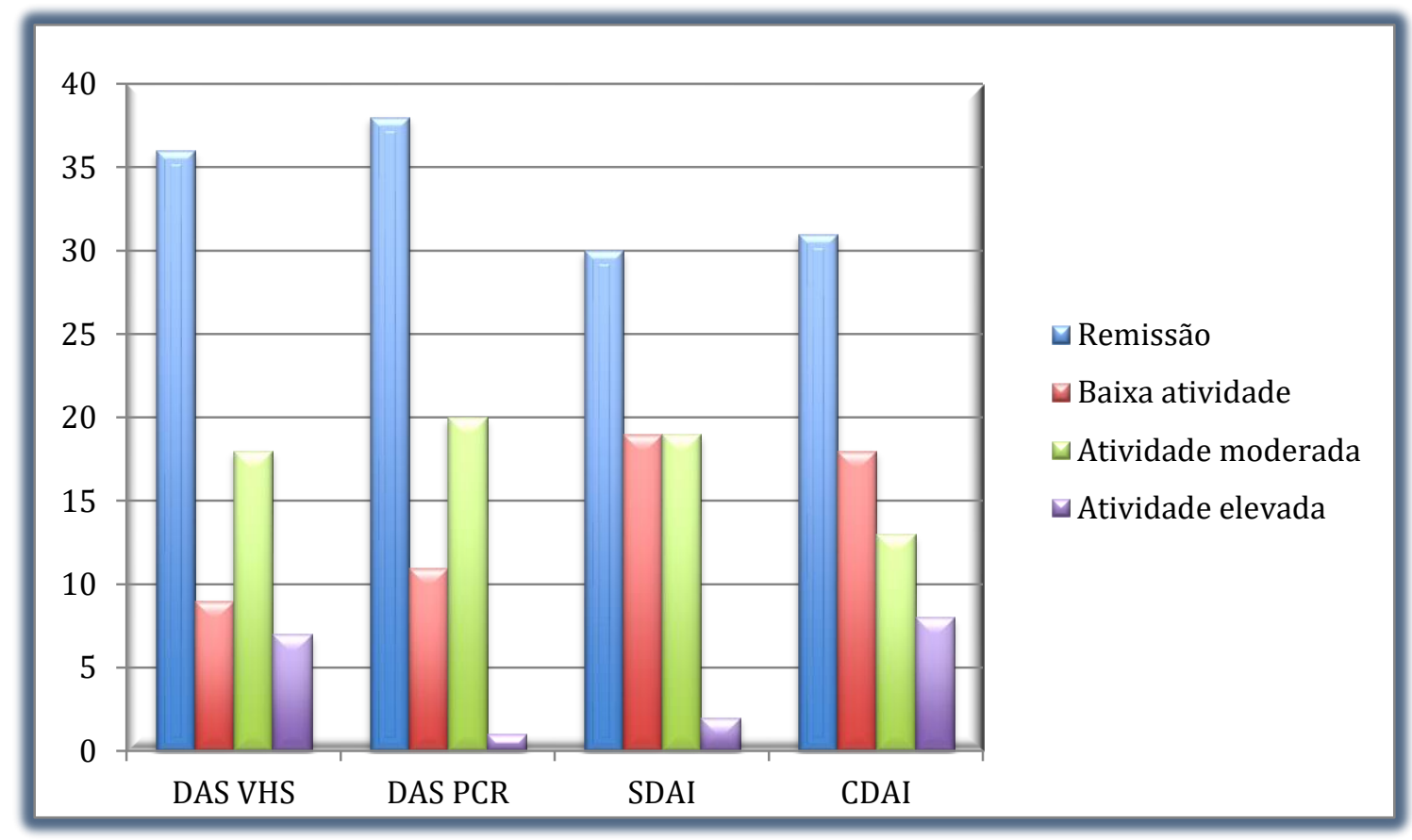


GRÁFICO 3: Avaliação de incapacidade através do HAQ de 67 pacientes com artrite reumatoide

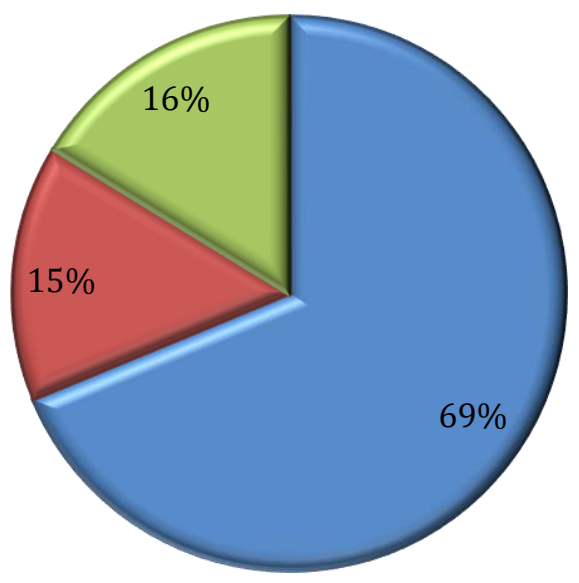

⿴囗ncapacidade leve ou ausente $(\mathrm{HAQ}=0-1)$

回 Incapacidade moderada $(\mathrm{HAQ}>1-2)$

QIncapacidade grave $(\mathrm{HAQ}>$ 2-3)

TABELA 4: Escala visual analógica (valor: 0-100) de pacientes com artrite reumatoide avaliados no estudo.

\begin{tabular}{l|l|c}
\hline ESCALA VISUAL ANALÓGICA & MÉDIA & DESVIO PADRÃO \\
\hline Dor & 16.09 & 22.602 \\
\hline Fadiga & 20.72 & 27.936 \\
\hline Atividade de doença nos últimos 6 meses & 16.56 & 19.279 \\
\hline Atividade de doença hoje & 14.38 & 19.828 \\
\hline Saúde geral hoje & 17.19 & 19.549 \\
\hline
\end{tabular}




\section{3) RESULTADOS DAS ANÁLISES EM AMOSTRA FECAL}

Quanto ao resultado do exame parasitológico de fezes, foram constatadas alterações em 8 (11.9\%) pacientes, sendo a presença de protozoários verificada em todos eles. A distribuição do tipo de protozoário foi a seguinte: 5 pacientes $(7.4 \%)$ apresentaram cistos de Endolimax nana, 2 (3\%) apresentaram cistos de Entamoeba histolytica/ Entamoeba dispar e 1 paciente (1.5\%) com Entamoeba Coli. Não foi observada positividade para helmintíase nesta amostra. Adicionalmente a presença de sangue oculto nas fezes foi verificada em 3 pacientes (4.5\%) e gordura fecal em 5 pacientes $(7.5 \%)$, sem concomitância de parasitas nestes casos.

\section{4) ANÁLISE ESTATÍSTICA}

$\mathrm{Na}$ análise bivariada observou-se uma associação estatisticamente significativa entre a presença de parasitose e as seguintes variáveis: ausência de fadiga na escala visual analógica ( $R P=8,13$; IC $95 \%$ : 1,06 - 62,49) e melhor estado atual de saúde hoje (nota 0 na escala visual analógica; RP = 5,04; IC 95\%: 1,1023,08). A análise bivariada completa pode ser vista na tabela 5 . 
TABELA 5: Prevalência de parasitose conforme variáveis estudadas em pacientes com AR $(n=67)$

\begin{tabular}{|c|c|c|c|}
\hline Variáveis & $\begin{array}{c}\text { Frequência } \\
\text { (Porcentagem) } \\
(\mathrm{n}=67)\end{array}$ & $\begin{array}{c}\text { Prevalência } \\
\text { de } \\
\text { Parasitose } \\
\text { (\%) }\end{array}$ & IC $95 \%$ \\
\hline \multicolumn{4}{|l|}{ Idade } \\
\hline$\leq 40$ & $10(14,93)$ & 30,00 & 0,$85 ; 59,15$ \\
\hline$>40$ & $57(85,07)$ & 8,77 & 1,$23 ; 16,31$ \\
\hline \multicolumn{4}{|l|}{ Anos de Estudo } \\
\hline$\leq 8$ & $34(50,75)$ & 8,82 & 0,$00 ; 18,61$ \\
\hline$>8$ & $33(49,25)$ & 15,15 & 2,$60 ; 27,71$ \\
\hline \multicolumn{4}{|l|}{ Classe Econômica } \\
\hline$B$ & $16(23,88)$ & 18,75 & 0,$00 ; 38,38$ \\
\hline$C, D$ e $E$ & $59(76,12)$ & 9,80 & 1,$43 ; 18,18$ \\
\hline \multicolumn{4}{|l|}{ Tempo de Doença } \\
\hline$\leq 10$ & $35(52,24)$ & 11,43 & 0,$61 ; 22,25$ \\
\hline$>10$ & $32(47,76)$ & 12,50 & 0,$74 ; 24,26$ \\
\hline \multicolumn{4}{|l|}{ AR SOROPOSITIVA } \\
\hline Não & $15(22,39)$ & 20,00 & 0,$00 ; 40,78$ \\
\hline Sim & $52(77,61)$ & 9,61 & 1,$39 ; 17,84$ \\
\hline \multicolumn{4}{|l|}{ IMC } \\
\hline Peso normal & $34(50,75)$ & 14,71 & 2,$49 ; 26,92$ \\
\hline Peso alterado & $33(49,25)$ & 9,09 & 0,$00 ; 19,16$ \\
\hline \multicolumn{4}{|l|}{ Rigidez Matinal } \\
\hline Não & $32(47,76)$ & 18,75 & 4,$87 ; 32,63$ \\
\hline Sim & $35(52,24)$ & 5,71 & 0,$00 ; 13,61$ \\
\hline \multicolumn{4}{|l|}{ EVA - dor } \\
\hline Ausência & $25(37,31)$ & 12,00 & 0,$00 ; 25,07$ \\
\hline
\end{tabular}




\begin{tabular}{|c|c|c|c|}
\hline Presença & $42(62,69)$ & 11,90 & 1,$85 ; 21,96$ \\
\hline \multicolumn{4}{|l|}{ EVA - fadiga } \\
\hline Ausência & $31(46,27)$ & 22,58 & 7,$47 ; 37,69$ \\
\hline Presença & $36(53,73)$ & 2,78 & 0,$00 ; 8,29$ \\
\hline \multicolumn{4}{|c|}{ EVA - atividade hoje } \\
\hline Ausência & $28(41,79)$ & 17,86 & 3,$30 ; 32,42$ \\
\hline Presença & $39(58,21)$ & 7,69 & 0,$00 ; 16,28$ \\
\hline \multicolumn{4}{|c|}{ EVA - atividade 6 meses } \\
\hline Ausência & $24(35,82)$ & 16,67 & 1,$36 ; 31,97$ \\
\hline Presença & $43(64,18)$ & 9,30 & 0,$39 ; 18,21$ \\
\hline \multicolumn{4}{|l|}{ EVA - saúde hoje } \\
\hline Ausência & $25(37,31)$ & 24,00 & 6,$82 ; 41,18$ \\
\hline Presença & $42(62,69)$ & 4,76 & 0,$00 ; 11,37$ \\
\hline \multicolumn{4}{|l|}{ EVA - médico } \\
\hline Ausência & $24(35,82)$ & 12,50 & 0,$00 ; 26,08$ \\
\hline Presença & $43(64,18)$ & 11,63 & 1,$79 ; 21,46$ \\
\hline \multicolumn{4}{|l|}{ DAS 28 - VHS } \\
\hline Remissão & $34(50,75)$ & 14,71 & 2,$49 ; 26,92$ \\
\hline Não Remissão & $33(49,25)$ & 9,09 & 0,$00 ; 19,16$ \\
\hline \multicolumn{4}{|l|}{ DAS 28 - PCR } \\
\hline Remissão & $36(53,73)$ & 13,89 & 2,$29 ; 25,48$ \\
\hline Não Remissão & $31(46,27)$ & 9,68 & 0,$00 ; 20,36$ \\
\hline \multicolumn{4}{|l|}{ SDAI } \\
\hline Remissão & $29(43,28)$ & 10,34 & 0,$00 ; 21,72$ \\
\hline Não Remissão & $38(56,72)$ & 13,16 & 2,$13 ; 24,19$ \\
\hline \multicolumn{4}{|l|}{ CDAI } \\
\hline Remissão & $30(44,78)$ & 10,00 & 0,$00 ; 21,02$ \\
\hline Não Remissão & $37(55,22)$ & 13,51 & 2,$21 ; 24,82$ \\
\hline
\end{tabular}


As seguintes variáveis foram incluídas, inicialmente, no modelo multivariado por apresentarem um $\mathrm{p}<0,25$ : idade, rigidez matinal, EVA fadiga, EVA atividade hoje e EVA saúde hoje. A análise multivariada final indicou que a presença de parasitose é 5,90 vezes maior em pacientes com ausência fadiga pela EVA do que em pacientes com presença de fadiga $(p=0,0488)$ e 7,53 vezes maior em pacientes com melhor índice de saúde hoje pela EVA ( $p=0,0012)$.

O indicador de tolerância para multicolinearidade variou de 0,60 a 0,95 indicando que não existe forte multicolinearidade entre as variáveis independentes no multivariado final.

A análise multivariada está sumarizada na tabela 6.

\section{TABELA 6:}

Distribuição das variáveis de estudo de acordo com as razões de prevalência bruta e ajustada conforme modelo de regressão de Poisson com variância robusta e seus respectivos intervalos de $95 \%$ de confiança.

\begin{tabular}{l|r|r|r|r}
\hline & \multicolumn{2}{|c|}{ RP Bruta } & \multicolumn{2}{c}{ RP Ajustada* } \\
\hline \multicolumn{1}{c|}{ Variáveis } & RP (IC 95 \%) & p-valor & $\begin{array}{c}\text { RP (IC } \\
\text { 95\%) }\end{array}$ & $\begin{array}{c}\text { p- } \\
\text { valor }\end{array}$ \\
\hline Idade & & 0,0565 & & \\
\hline$\leq 40$ & $3,42(0,97 ;$ & 0,0565 & & \\
\hline$>40$ & $12,10)$ & & & \\
\hline Anos de Estudo & 1 & - & & \\
\hline$\leq 8$ & $1,72(0,45 ;$ & 0,4321 & & \\
\hline$>8$ & $6,62)$ & & & \\
\hline Classe Econômica & 1 & - & & \\
\hline B & $1,91(0,51 ;$ & 0,3344 & & \\
\hline C, D e E & $7,13)$ & & & \\
\hline Tempo de Doença & 1 & - & & \\
\hline$\leq 10$ & & 0,8926 & & \\
\hline
\end{tabular}




\begin{tabular}{|c|c|c|c|c|}
\hline$>10$ & $\begin{array}{r}1,09(0,30 \\
4,01)\end{array}$ & 0,8926 & & \\
\hline AR & & 0,2736 & & \\
\hline Não & $\begin{array}{r}2,08(0,56 ; \\
7,72) \\
\end{array}$ & 0,2736 & & \\
\hline Sim & 1 & & & \\
\hline IMC & $\begin{array}{r}3,91(1,84 ; \\
8,33)\end{array}$ & 0,4846 & & \\
\hline Baixo Peso e Normal & $\begin{array}{r}1,62(0,42 \\
6,23)\end{array}$ & 0,4846 & & \\
\hline Sobre Peso e Obesidade & 1 & - & & \\
\hline Rigidez Matinal & & 0,1272 & & \\
\hline Não & $\begin{array}{r}3,28(0,71 ; \\
15,10)\end{array}$ & 0,1272 & & \\
\hline Sim & 1 & & & \\
\hline EVA - dor & & 0,9907 & & \\
\hline Ausência & $\begin{array}{r}1,01(0,26 ; \\
3,86) \\
\end{array}$ & 0,9907 & & \\
\hline Presença & 1 & - & & \\
\hline EVA - fadiga & & 0,0440 & & 0,0488 \\
\hline Ausência & $\begin{array}{r}8,13(1,06 \\
62,49)\end{array}$ & 0,0440 & $\begin{array}{r}5,90(1,01 \\
39,87)\end{array}$ & 0,0488 \\
\hline Presença & 1 & - & 1 & - \\
\hline EVA - atividade 6 meses & & 0,3767 & & \\
\hline Ausência & $\begin{array}{r}1,79(0,49 \\
6,53) \\
\end{array}$ & 0,3767 & & \\
\hline Presença & 1 & - & & \\
\hline EVA - saúde hoje & & 0,0372 & & 0,0012 \\
\hline Ausência & $\begin{array}{r}5,04(1,10 ; \\
23,08) \\
\end{array}$ & 0,0372 & $\begin{array}{r}7,53(2,23 ; \\
25,45) \\
\end{array}$ & 0,0012 \\
\hline Presença & 1 & - & 1 & - \\
\hline EVA - médico & & 0,9158 & & \\
\hline Ausência & $\begin{array}{r}1,07(0,28 \\
4,11)\end{array}$ & 0,9158 & & \\
\hline Presença & 1 & - & & \\
\hline DAS 28 - VHS & & 0,4846 & & \\
\hline Remissão & $\begin{array}{r}1,62(0,42 \\
6,23) \\
\end{array}$ & 0,4846 & & \\
\hline Não Remissão & 1 & - & & \\
\hline DAS 28 - PCR & & 0,5995 & & \\
\hline Remissão & $1,43(0,37$ & 0,5995 & & \\
\hline
\end{tabular}




\begin{tabular}{l|r|r|l|l}
\hline & $5,53)$ & & & \\
\hline Não Remissão & 1 & - & & \\
\hline SDAl & & 0,7264 & & \\
\hline Remissão & 1 & - & & \\
\hline Não Remissão & $1,27(0,33 ;$ & 0,7264 & & \\
& $4,89)$ & & & \\
\hline CDAl & 1 & 0,6615 & & \\
\hline Remissão & - & & \\
\hline Não Remissão & $1,35(0,35 ;$ & 0,7264 & & \\
& $5,20)$ & & & \\
\hline
\end{tabular}

\section{DISCUSSÃO}

As características sócio-demográficas da amostra estudada (idade de início da $A R$, sexo, etc) são semelhantes às encontradas em outros trabalhos com a população brasileira. (75-78) Em relação aos dados referentes à doença, observamos que a maioria da amostra foi de mulheres soropositivas em relação ao fator reumatoide e com a doença em remissão.

Quando analisado o exame parasitológico de fezes, 11.9\% apresentaram positividade para protozooses. Esta prevalência foi semelhante à encontrada por do Casavechia et al em estudo recente, no qual foi detectada positividade de protozoários em $15.1 \%$ da amostra estudada. (79)

Os subtipos encontrados Endolimax nana e Entamoeba Coli são considerados comensais do intestino humano e portanto não patogênicos. A despeito de não causarem doenças, cabe ressaltar que sugerem má qualidade da água e/ou contaminação fecal. (80) Em trabalho realizado no Distrito Federal (DF) no ano de 2013, Pereira et al. avaliaram a prevalência de parasitas intestinais e comensais em trabalhadores de coleta de lixo e encontraram $80 \%$ de positividade para helmintíases e protozooses, ficando clara a relação com ambientes contaminados. (81). O mesmo grupo de pesquisadores, avaliou a presença de parasitos em hortaliças comercializadas em feiras nas regiões administrativas no DF e constatou que todas as feiras forneceram hortaliças contaminadas por alguns helmintos, protozoários, e/ou artrópodes. Os parasitos intestinais encontrados foram 
Entamoeba sp., E. coli, Strongyloides sp., Ascaris sp., Enterobius vermicularis e Ancylostomidae. Também foram verificados outros nematoides (ovos, larvas, machos e fêmeas) e artrópodes (insetos e ácaros) que não foram identificados. Neste trabalho as amostras foram coletadas após a lavagem das hortaliças com água e auxílio de escova de dentes. O método utilizado para análise foi a sedimentação espontânea. Os autores concluíram que há alto risco de contaminação por este tipo de alimento em nosso meio e que as hortaliças comercializadas em feiras do DF estão fora dos padrões higiênicos exigidos pela legislação. Ressaltam a necessidade de medidas específicas para a higiene dos alimentos para a reduçao deste risco. (82)

Em nosso estudo, todos os pacientes se declararam moradores de zona urbana e com água encanada, mas eram de baixa renda e possivelmente com condições sanitárias inadequadas. Este achado pode indicar a necessidade de maior atenção com o tratamento hídrico, higienização dos alimentos e de orientações específicas para que os pacientes em tratamento reumatológico, principalmente aqueles em uso de imunossupressor, tenham maior cuidado com a água utilizada. Por outro lado, na literatura verificamos um número crescente de estudos sobre a possível participação de bactérias da microbiota intestinal na etiopatogenia da AR. Em relação aos parasitas comensais, há uma grande lacuna no conhecimento e portanto um campo promissor para pesquisas futuras.

A Entamoeba histolytica é a causadora da amebíase, doença transmitida por alimentos e água contaminadas e a segunda protozoose de maior mortalidade após a malária. Embora existam muitos casos assintomáticos, como os indivíduos deste estudo, pode se manifestar como síndrome diarréica, ulcerações intestinais e até abscesso hepático, sendo este último considerado grave complicação extraintestinal. (80,83-84) Em nosso estudo encontramos 2 casos positivos de Entamoeba histolytica/dispar, espécies morfologicamente idênticas e portanto sem possibilidade de diferenciação pela metodologia utilizada. Apesar disso, acreditamos que este é um dado relevante que merece atenção na prática clínica.

A ausência de helmintos na amostra estudada merece discussão. Embora estudos na população brasileira sejam escassos, em artigo de revisão de 2015, Serra et al compararam as prevalências de parasitoses intestinais em 2 períodos: 
1992-1996 e 2010-2011. Os autores concluíram que houve redução de $81.3 \%$ para 23.8\% das infecções parasitárias em geral e sugeriram a hipóstese de uma provável melhoria das condições sanitárias em geral. A despeito de uma possível redução dos casos de enteroparasitoses, a ausência de casos de helmintíase em nosso meio pode ter sido decorrente da não realização de técnicas mais específicas realizadas no EPF e a coleta única do material fecal, as quais foram limitações deste trabalho. O tamanho amostral poderá ser aumentado em futuros estudos para melhor avaliação do assunto.

Os indivíduos que participaram desta pesquisa, não apresentavam sintomatologia de síndrome de má absorção, ainda assim a presença de gordura fecal foi encontrada em 5 casos (7.5\%) da amostra. Não encontramos na literatura outros relatos de eliminação de gordura fecal em pacientes com AR e esta possível associação deverá ser melhor estudada. Outro achado deste estudo foi a presença de sangue oculto em 3 pacientes (4.5\%). Este fato deve merecer atenção dos reumatologistas no manejo do paciente com $A R$, tendo em vista a possibilidade de sangramento do trato gastrointestinal secundário ao uso de medicamentos ou outras patologias concomitantes.

Em nosso estudo, houve associação estatisticamente significativa entre a presença de parasitose com a ausência de fadiga e melhor estado atual de saúde pela EVA.

A fadiga é um sintoma frequente, que pode ser definido como um cansaço físico e/ou mental resultante do esforço, incluindo as atividades de vida diária e que pode gerar incapacidade de manter uma atividade com o mesmo desempenho. Da mesma forma, a fadiga pode ser definida como uma sensação intensa de exaustão e cansaço. Trata-se de uma queixa subjetiva e que pode ser influenciada por fatores diversos como por exemplo a dor, qualidade do sono, inatividade física e depressão. $(86,87)$. Na AR, a fadiga é considerada um problema comum e incapacitante, relatado entre 40 e $80 \%$ dos pacientes, podendo alcançar até $90 \%$ de prevalência em alguns trabalhos. (87-89). Em pesquisa recente realizada por Diniz et al, com a mesma população estudada nesta dissertação (pacientes com AR em tratamento no HUB), foi encontrada uma prevalência de $71,25 \%$ de fadiga, a qual foi mensurada por diversos instrumentos de avaliação. Dentre as ferramentas utilizadas no referido 
estudo, a EVA apresentou bom desempenho de avaliação no grupo de fadiga de leve a moderada.

A percepção do estado atual de saúde e sua mensuração pela EVA é uma avaliação subjetiva e sujeita a interferência de fatores emocionais, culturais e ambientais. Apesar disso, vem sendo largamente utilizada em estudos e demonstrado ser um bom instrumento quando comparado a outras escalas unidimensionais. $(92,93)$

A relação entre melhores parâmetros de EVA fadiga e EVA estado atual de saúde com protozooses não foi encontrada em outros estudos na literatura. $\mathrm{Na}$ artrite reumatoide, não há até o momento trabalhos de prevalência de parasitoses e portanto, não temos parâmetros de comparação dos dados encontrados nesta população. Um possível papel protetor dos protozoários em pacientes com AR pode ser suspeitado, o que explicaria os achados deste trabalho, mas ainda não foi relatado na literatura. Por outro lado, um efeito de proteção dos helmintos na AR vem sendo pesquisado em diversos estudos e confirmado por vários autores. (49$62)$.

Em artigo publicado durante a realização deste projeto, nosso grupo fez uma revisão literária de possíveis mecanismos nos quais ações de produtos derivados dos helmintos poderiam modular e até reduzir o processo inflamatório na AR (94). Em relação às protozooses, são necessárias novas pesquisas para confirmar nossos achados, bem como sua significância clínica.

O trabalho realizado apresentou algumas limitações. A amostra selecionada foi de número reduzido e proveniente de um hospital terciário com características próprias. Estes fatores permitem considerar os resultados encontrados apenas para a população estudada não permitindo extrapolação. O delineamento transversal do mesmo também não permite mensuração de causa e efeito. A ausência de técnicas específicas na realização do EPF foi outro fator limitante. Entretanto a sedimentação espontânea vem sendo largamente utilizada em trabalhos científicos devido ao baixo custo e facilidade de realização. As escalas visuais analógicas são medidas unidimensionais e subjetivas. A despeito do exposto, este foi o primeiro trabalho de prevalência de parasitoses na $A R$ até o momento e poderá embasar futuras pesquisas na área. 


\section{CONCLUSÃO}

O presente estudo verificou uma prevalência de $11.9 \%$ de parasitoses em pacientes com artrite reumatoide.

Todos os casos encontrados foram de protozoários com a seguinte distribuição por espécie: 5 pacientes $(7.4 \%$ ) apresentaram cistos de Endolimax nana, $2(3 \%)$ apresentaram cistos de Entamoeba histolytica e 1 paciente (1.5\%) com Entamoeba Coli. Não foram encontrados casos de helmintíase.

Não foi constatada relação dos casos positivos de parasitoses com classe social específica.

Adicionalmente, foi verificada associação dos casos de protozooses com menores níveis de fadiga e melhor estado de saúde atual pela escala visual analógica.

\section{ARTIGOS}

\subsection{ARTIGOS PUBLICADOS}

\subsection{1}

Parasitoses intestinais: efeito protetor na artrite reumatoide?

1) Sandra Maximiano de Oliveira - médica residente em Reumatologia no Hospital Universitário de Brasília

2) Ana Paula Monteiro Gomides - pós-graduanda em Ciências Médicas pela Faculdade de Medicina da Universidade de Brasília 
3) Lícia Maria Henrique da Mota - doutora em Ciências Médicas pela Faculdade de Medicina da Universidade de Brasília e orientadora do Programa de Pós-graduação da Faculdade de Medicina da Universidade de Brasília

4) Caliandra Maria Bezerra Luna Lima - doutora em Produtos Naturais e Sintéticos Bioativos pela Universidade Federal da Paraíba e colaboradora do Programa de Pós-graduação Interdisciplinar em Modelos de Decisão e Saúde da Universidade Federal da Paraíba

5) Francisco Airton Castro Rocha - professor associado da Faculdade de Medicina da Universidade Federal do Ceará

- Instituição de origem do trabalho: Serviço de Reumatologia do Hospital Universitário de Brasília

- Autor para correspondência: Sandra Maximiano de Oliveira, SQS 205 bloco B apartamento 301, CEP 70235020, Asa Sul - Brasília/DF, sandramaximianoo@gmail.com

- Os autores declaram não haver conflitos de interesse.

Título resumido - Helmintíases: efeito protetor na artrite reumatoide?

\section{Parasitoses intestinais: efeito protetor na artrite reumatoide?}

\section{Resumo}

A artrite reumatoide (AR) é uma doença inflamatória autoimune, sistêmica, de curso progressivo, caracterizada por exuberante sinovite crônica, que pode gerar deformidades e incapacidade funcional, cujo tratamento precoce minimiza o dano às juntas. Sua etiopatogenia ainda não está completamente elucidada, mas compreende respostas imunológicas com a participação de células $T$ auxiliares (Th1). Uma aparente menor gravidade da AR em pacientes de regiões com menor renda poderia estar associada a maior prevalência de parasitoses intestinais, especialmente as helmintíases. A rigor, um desvio na resposta imune para o 
predomínio de células T auxiliares (Th2), decorrente da exposição crônica a helmintos, modularia negativamente a inflamação em doentes com AR, levando a menor gravidade e dano articular. A revisão de aspectos da influência da reposta imunológica nas parasitoses intestinais, especialmente as helmintíases, em pacientes com artrite reumatoide é o objetivo desse trabalho.

Palavras-chave: artrite reumatoide; parasitoses intestinais; imunomodulação.

\section{Abstract}

Rheumatoid arthritis (RA) is a systemic autoimmune inflammatory disease, with progressive course, characterized by chronic synovitis that may evolve with deformities and functional disability, whose early treatment minimizes the damage to the joints. Its etiopathogeny is not fully elucidated, but comprises immunologic responses mediated by $\mathrm{T}$ helper cells (Th1). An apparent minor severity of RA in patients from regions with lower income could be associated with a higher prevalence of gut parasites, especially helminths. Strictly, a shift in the immune response towards the predominance of $\mathrm{T}$ helper cells (Th2), due to the chronic exposure to helminthes, could modulate negatively the inflammation in RA patients, resulting in lower severity and joint injury. The interaction between the immunological responses of parasitic helminths in rheumatoid arthritis patients is the purpose of this paper.

Keywords: rheumatoid arthritis; helminth infections; immunomodulation.

\section{Introdução}

A artrite reumatoide $(A R)$ é uma doença autoimune sistêmica, inflamatória, de caráter crônico e progressivo, caracterizada pelo comprometimento simétrico da membrana sinovial das articulações periféricas, com dano e destruição articular. ${ }^{1}$ Sua prevalência é estimada em $0,2-1 \%$ da população brasileira, ${ }^{2}$ com predomínio em mulheres e maior incidência na faixa etária de 30-50 anos. ${ }^{1}$ É uma doença multifatorial, de etiologia desconhecida, com a contribuição de fatores genéticos (HLA-DR1 e HLA-DR4) e ambientais (exposição a infecções e tabagismo, entre outros) para a perda da tolerância e dano orgânico. ${ }^{3}$ A doença, se não adequadamente tratada, pode levar à limitação funcional com deformidades irreversíveis e redução na expectativa de vida. ${ }^{1} \mathrm{O}$ impacto da AR é significativo 
tanto para o paciente (morbimortalidade e piora da qualidade de vida) como para a sociedade (prejuízo funcional com queda da produtividade e menor capacidade de participação no mercado de trabalho). ${ }^{2}$

As doenças parasitárias intestinais abrangem infecções causadas por protozoários e helmintos com grande morbimortalidade. Sua prevalência é estimada em $30 \%$ da população das Américas. ${ }^{4,5}$

Apesar da morbidade e, menos comum, mortalidade que pode estar associada às parasitoses, especificamente no caso de helmintíases, infestações subclínicas ocorrem, como a denunciar uma adaptação do hospedeiro ao parasita, contendo os danos e permitindo a sobrevida de ambos. Essa adaptação parasita/hospedeiro está relacionada a componentes da resposta imune inata e, no caso da resposta imune adaptativa, ao predomínio de resposta Th2, com maior liberação de citocinas ditas anti-inflamatórias como as interleucinas (IL) 4, 10 e $13 .^{5}$

Há relatos da menor prevalência e/ou gravidade da $A R$ em populações da África subsaariana e, em nosso meio, embora abordando pacientes com lúpus eritematoso sistêmico, um estudo em Natal/RN encontrou gravidade similar de pacientes lúpicos, comparados a populações de regiões com maior poder econômico. ${ }^{6}$ Mais recentemente, estudando crianças portadoras de artrite idiopática juvenil, em um centro terciário no estado do Ceará, observou-se que cerca de dois terços dos pacientes podiam atingir remissão da doença usando metotrexato e/ou leflunomida, mesmo havendo predomínio do subtipo poliarticular, que teria pior prognóstico. ${ }^{7} \mathrm{O}$ retardo no diagnóstico e no início do tratamento, bem como a baixa escolaridade familiar e renda, que ocorrem na nossa população, são fatores considerados agravantes do prognóstico em doenças autoimunes, portanto, é curioso que a evolução a longo prazo desses pacientes seja no mínimo semelhante, senão menos grave, à encontrada em populações com melhores índices socioeconômicos. Essa boa resposta em pacientes potencialmente mais graves, quando comparada a casuísticas de países ricos do hemisfério norte, abre a possibilidade de que fatores ambientais estejam atuando no curso clínico de doenças autoimunes.

O objetivo desse trabalho é elucidar o potencial efeito protetor que a infecção concomitante por enteroparasitas, especialmente os helmintos, poderia conferir aos doentes com AR. No período de maio a julho de 2015, foi realizada revisão da 
literatura por meio das bases de dados Pubmed (1970-2015) e Scopus, nos idiomas inglês e português, com as seguintes palavras-chave: 'artrite reumatoide', 'helmintíases', 'imunopatogenia' e 'hipótese higiênica'.

\section{Imunopatogenia da artrite reumatoide}

A sinóvia ou membrana sinovial é considerada o tecido onde se inicia e se perpetua $O$ processo inflamatório na $A R$, ocorrendo infiltrado inflamatório predominantemente mononuclear, hiperplasia da sinóvia e proliferação vascular, associada à produção de citocinas pró-inflamatórias. Essa sinóvia hiperplástica constitui o pannus sinovial que, por invasão do osso subcondral e cartilagem subjacentes, bem como tendões e ligamentos, leva à destruição articular. ${ }^{3,8}$ Propõese, como um mecanismo básico, a perda da tolerância imunológica a antígenos próprios, em indivíduo geneticamente susceptível, desencadeando-se a sinovite. ${ }^{3}$ Em relação aos mecanismos de resposta imune inata, neutrófilos, macrófagos, mastócitos e células natural killer participam nessa resposta inflamatória na membrana sinovial. ${ }^{3}$ Os macrófagos participam tanto como células apresentadoras de antígeno quanto como células efetoras, via liberação de citocinas ditas próinflamatórias (p.ex.: fator de necrose tumoral (TNF)- $\square$ e IL-1, IL-6, IL-12, IL-15, IL-18 e IL-23), espécies reativas de oxigênio, produção de prostanoides e metaloproteinases da matriz extracelular. ${ }^{3}$ Admite-se que o TNF tenha um papel central na patogênese da $A R$, promovendo a liberação de outros mediadores inflamatórios (como citocinas com ação autócrina e parácrina) e a ativação de linfócitos e macrófagos que contribuem para intensificar a sinovite; além de ativar diretamente osteoclastos, que induzem a reabsorção óssea. ${ }^{3}$

A AR é classicamente descrita como uma doença imune mediada por células $\mathrm{T}$, especialmente linfócitos efetores Th1 e Th17. ${ }^{5,8}$ A diferenciação de monócitos em osteoclastos é promovida indiretamente pelo TNF, por ativação do ligante do receptor ativador de fator nuclear $\square\left[\square\left(\right.\right.$ RANKL), membro da superfamília de TNF. ${ }^{9}$ Essa ação do TNF acaba por implicá-lo na reabsorção óssea inflamatória da AR, uma vez que o resultado da ativação do RANKL estimula a diferenciação e ativação de osteoclastos, além de inibir a apoptose dessas células. ${ }^{10}$ Ainda, a produção de IL-17 pelos linfócitos Th17, presente em altos níveis na sinóvia de indivíduos portadores de AR, regula a expressão de RANKL, contribuindo para a 
osteoclastogênese e progressão do dano articular. ${ }^{9}$ Embora a frequência de células T regulatórias $C D 4^{+} C D 25^{+}$, responsáveis por inibir a proliferação e produção de citocinas pelas células $T$ efetoras, esteja aumentada no líquido sinovial de pacientes com AR, não está claro se essas células estão ativadas nesse ambiente, visto que há perda da autotolerância a antígenos próprios, contribuindo para a persistência do processo inflamatório articular. ${ }^{9}$ Além disso, a apoptose de células $\mathrm{T}$ encontra-se inibida, provavelmente devido ao alto nível de citocinas antiapoptóticas, como IL-2, IL-4, IL-15, presentes precocemente na AR. ${ }^{9}$

Também há contribuição da resposta imune humoral na AR, por meio da diferenciação e proliferação de células $B$, que produzem citocinas e podem funcionar como células apresentadoras de antígeno de classe II, colaborando para a perpetuação da sinovite. ${ }^{9} \mathrm{~A}$ presença de autoanticorpos dirigidos contra a porção Fc de moléculas de lgG, como o fator reumatoide, que ilustra o componente humoral na $A R$, é detectável em $70-80 \%$ dos pacientes, mas também pode estar presente em indivíduos saudáveis e em portadores de outras doenças sistêmicas. ${ }^{9}$ Anticorpos contra autoantígenos modificados por citrulinação através da deaminação de arginina (anti-peptídeos citrulinados cíclicos) podem estar presentes em até $70 \%$ dos pacientes e aparecem precocemente na $A_{R}{ }^{9} \mathrm{O}$ papel exato desses autoanticorpos na patogenia da doença ainda não está claro, mas sabe-se que pacientes soropositivos em altos títulos para esses antígenos tendem a apresentar doença mais agressiva, com maior dano articular e erosão óssea e presença de manifestações extra-articulares. ${ }^{3,5}$

\section{Imunopatogenia das parasitoses intestinais}

Parasitas como os helmintos podem modular a resposta imune, propiciando um ambiente anti-inflamatório que favoreça sua sobrevivência dentro do organismo do hospedeiro, ou seja, suprimem respostas imunes pró-inflamatórias para manterem seu ciclo vital. ${ }^{3,11}$ As infecções parasitárias intestinais são crônicas, sendo a re-infestação comum, e tais organismos, além das alterações inibitórias que ocasionam nas respostas imunes inata e adaptativa, também possuem mecanismos de evasão à resposta imunitária do hospedeiro através da redução de sua imunogenicidade. ${ }^{5}$ Helmintos geralmente sobrevivem dentro do organismo hospedeiro provocando infecções persistentes aparentemente porque a resposta 
imune inata contra eles é reduzida. ${ }^{5,12}$ A ação combinada de mastócitos e eosinófilos contribui para a contenção dos parasitas intestinais. ${ }^{5}$ Tais parasitas são resistentes à fagocitose e aos mecanismos citocidas de macrófagos e neutrófilos. ${ }^{5}$ Alguns helmintos podem ainda ativar a via alternativa do sistema complemento e são resistentes à lise mediada pelas proteínas desse sistema. ${ }^{5}$

$\mathrm{Na}$ infecção por helmintos, os parasitas induzem a produção de IL-10 e citocinas Th2 (IL-4, 5, 9 e 13), modificando a estimulação dos macrófagos para fenótipo ativado alternativo, o que favorece a resposta anti-inflamatória de células Th2 e a resposta eosinofílica. ${ }^{3,12}$ Eles também inibem IFN- $\square$, IL-1 $\square$ e IL-17, suprimindo a resposta imune inflamatória de células Th1 e Th17.,12,13 Helmintos secretam produtos excretórios-secretórios, como a ES-62, que são glicosilados e agem induzindo citocinas Th2 e expansão de células T regulatórias. ${ }^{13}$ Ademais, a quantidade de células $\mathrm{T}$ regulatórias $\left(\mathrm{CD} 4^{+} \mathrm{CD} 25^{+} \mathrm{FOXP3^{+ }}\right)$ que produzem $\mathrm{IL}-10$ e TGF- $\square$ aumenta após a infecção por helmintos, ${ }^{3,11}$ contribuindo para sua permanência dentro do organismo hospedeiro.

A homeostase gerada por essas respostas imunes previne uma reação exagerada contra os parasitas que também prejudicaria o hospedeiro, garantindo a sobrevivência dos helmintos. ${ }^{11,13}$

\section{Efeito protetor das helmintíases na artrite reumatoide}

Greenwood, em 1970, observou que indivíduos de vilas nigerianas, apesar de alta incidência de fator reumatoide positivo, apresentavam doença reumática de curso benigno, com bom prognóstico e sem sinais radiológicos de gravidade ${ }^{14}$ Dada a alta prevalência de doenças infecciosas parasitárias naquela população, foi sugerido que a resposta do hospedeiro a múltiplas parasitoses deveria interferir de algum modo no curso das doenças autoimunes. ${ }^{14} \mathrm{O}$ atraso no diagnóstico, as dificuldades de acesso ao especialista, pouca adesão ao tratamento e falha ou atraso na indicação de drogas modificadoras da doença impactam negativamente a prevalência e gravidade das doenças autoimunes. ${ }^{15}$ Logo, pacientes oriundos de países subdesenvolvidos deveriam apresentar maiores morbidade e mortalidade. ${ }^{15}$ Porém, a AR é menos comum em certas áreas de países tropicais em que a incidência de doenças infecciosas, especialmente as parasitárias, é alta. ${ }^{16}$ No nordeste brasileiro, também observou-se menor gravidade da doença reumática 
autoimune, em parte devido possivelmente a infestações parasitárias endêmicas. ${ }^{17}$ Em 1989, Strachan propôs a teoria da "hipótese higiênica": a redução da exposição a patógenos comuns, como os helmintos, aumentou a prevalência de doenças alérgicas e autoimunes em áreas onde as condições sanitárias melhoraram. ${ }^{3,6,12,13,18-21}$

Os parasitas intestinais são supressores da resposta imunológica próinflamatória, o que os permite viver em equilíbrio com o sistema imune do hospedeiro. ${ }^{3,12}$ Sendo assim, além de causarem doença, também são potentes moduladores do sistema imunológico. ${ }^{3}$ Os parasitas relacionados a efeitos protetores da agressividade da doença na AR, descritos na literatura, são Schistosoma mansoni, Schistosoma japonicum, Ascaris suum, Heligmosomoides polygyrus bakeri e Hymenolepsis diminuta. ${ }^{3,12,20,21}$ Tais patógenos inibem a secreção de citocinas Th1/Th17, induzem células dendrtitícas tolerantes e promovem a proliferação de células $\mathrm{T}$ regulatórias. ${ }^{21} \mathrm{~A}$ infecção pelo Schistosoma mansoni ou japonicum pode modificar a função de células dendríticas, macrófagos, células NK e células $B$, levando à expansão de células Th2 e $T$ regulatórias responsáveis por manter a autotolerância. ${ }^{11,18} \mathrm{~A}$ infecção de camundongos com Schistosoma japonicum previamente à indução de artrite pelo colágeno (intervalo de 02 semanas) atenuou significativamente os sinais clínicos da artrite, com redução da hiperplasia sinovial, do infiltrado de células mononucleares sinoviais, da angiogênese na sinóvia inflamada, da ativação de osteoclastos e da destruição articular. ${ }^{11}$ Ocorre diminuição na produção de IFN- $\square$ e aumento na produção de IL-4 e 10, além de queda nos níveis de citocinas pró-inflamatórias (TNF- $\square$, IL-1 $\square, 6$ e 17, IFN- $\square$, RANKL), sugerindo predominância de resposta Th2 e redução de resposta Th1. ${ }^{11,18}$ Essa mudança no perfil imunológico explicaria a menor agressividade e até mesmo a ausência de doença articular nos modelos estudado. ${ }^{11,18}$ No entanto, a infecção dos camundongos com Schistosoma japonicum após indução de artrite pelo colágeno não pôde reverter a resposta imunológica já instalada e a lesão articular subsequente. ${ }^{11}$

Estudos com extratos de Ascaris suum (não patogênico para o ser humano), fornecidos tanto por via oral quanto parenteral, para camundongos modelos de artrite induzida por zymosan e pelo colágeno, demonstraram efeitos antiinflamatórios do extrato, com redução da hiperalgesia e do dano na cartilagem 
articular. $^{15,17} \mathrm{O}$ mecanismo observado associado à resposta ao extrato do helminto foi a redução na liberação de mediadores inflamatórios - óxido nítrico, IL-1 $\square$ e IL-10 - na articulação dos camundongos. ${ }^{17}$ Não houve alteração nos níveis de TNF- $\square \square^{17}$

No indivíduo portador de uma doença reumática autoimune como a $A R$, a infecção por helmintos poderia potencialmente aliviar os sintomas e melhorar o curso progressivo da doença devido à indução de uma resposta imunológica por células Th2 que antagoniza a resposta por células Th1 presente na doença autoimune. ${ }^{6,19}$ Além da inibição de citocinas Th1, a indução de citocinas regulatórias (IL-10 e TGF- $\square$ ), a produção de células T regulatórias FOXP3 e a atividade de macrófagos ativados alternativamente também influenciariam no efeito protetor da infecção por helmintos em indivíduos com AR. ${ }^{20}$

Diante da hipótese de que indivíduos infectados por helmintos seriam menos suscetíveis a outras doenças inflamatórias, a infecção parasitária poderia influenciar no tratamento de doenças mediadas por células Th1. ${ }^{20}$

As infecções por helmintos e os produtos derivados de helmintos (como a ES-62) são ferramentas valiosas para compreender as respostas imunológicas provocadas por esses parasitas, que podem ajudar a identificar novos alvos terapêuticos clinicamente relevantes. ${ }^{13}$ Produtos imunomodulatórios de helmintos, purificados ou sintetizados, devem ser pesquisados a fim de serem utilizados clinicamente. $^{15,19}$ O grande desafio será identificar e caracterizar antígenos específicos de um determinado helminto que dirija a reposta protetora e os antígenos/moléculas que serviriam como indicadores no desenvolvimento de novos imunobiológicos para o tratamento de uma série de doenças, ${ }^{20}$ entre elas a AR.

\section{Conclusão}

A AR é uma doença sistêmica dolorosa e debilitante, cuja imunopatogenia envolve mecanismos imunes inatos e adaptativos, especialmente a ação de células Th1 e a liberação de citocinas inflamatórias como o TNF- $\square$. O tratamento precoce pode modificar seu curso agressivo e incapacitante. Terapias biológicas eficazes estão disponíveis para o tratamento da $A R$, dirigidas ao bloqueio de citocinas inflamatórias específicas. Presume-se que a geração de um ambiente equilibrado imunologicamente como resultado da infecção por helmintos possa reduzir a gravidade de uma doença reumática autoimune concomitante. A melhor 
compreensão das vias de modulação da ação anti-inflamatória proporcionada pela infecção por helmintos, ou por seus produtos secretórios, pode gerar novas estratégias de tratamento (que inibam de modo mais abrangente as citocinas inflamatórias) e ampliar o arsenal terapêutico atualmente disponível para a AR.

\section{Referências bibliográficas}

1. Mota LMH, Cruz BA, Brenol CV, Pereira IA, Rezende-Fronza LS, Bertolo MB et al. Consenso 2012 da Sociedade Brasileira de Reumatologia para o tratamento da artrite reumatoide. Revista Brasileira de Reumatologia. 2012; 52(2):135-174.

2. Azevedo $A B C$, Ferraz MB, Ciconelli RM. Indirect costs of rheumatoid arthritis in Brazil. International Society for Pharmacoeconomics and Outcomes research. 2008; 11(5):869-877.

3. Anaya JM, Shoeenfeld Y, Rojas-Villarraga A, Levy RA, Cervera R. Autoimmunity from bench to bedside. 1st ed. Bogotá: El Rosario University Press, 2013.

4. Braz AS, Andrade CAF, Mota LMH, Lima CMBL. Recomendações da Sociedade Brasileira de Reumatologia sobre diagnóstico e tratamento das parasitoses intestinais em pacientes com doenças reumáticas autoimunes. Revista Brasileira de Reumatologia. 2015; (doi: 10.1016/j.rbr.2014.10.010.)

5. Abbas AK, Lichtman AH, Pillai S. Cellular and molecular immunology. 7th ed. Philadelphia: Elsevier, 2012.

6. Bezerra ELM, Vilar MJP, Barbosa OFC, Santos SQ, Castro MA, Trindade MC et al. Lúpus eritematoso sistêmico (LES): perfil clínico-laboratorial dos pacientes do Hospital Universitário Onofre Lopes (UFRN-Natal/Brasil) e índice de dano nos pacientes com diagnóstico recente. Rev Bras Reumatol. 2005; 45(6):339-42.

7. Alcântara AC, Leite CA, Leite AC, Sidrim JJ, Silva FS Jr, Rocha FA. A longterm prospective real-life experience wiht leflunomide in juvenile idiopathic arthritis. $J$ Rheumatol. 2014; 41(2):338-44.

8. Ortiz-Flores AM, Ledesma-Soto $\mathrm{Y}$, Calleja EA, Rodríguez-Sosa M, Juárez I, Terrazas LI. Taenia crassiceps infection does not infleunce the development of experimental rheumatoid arthritis. BioMed Research International. 2012; 2013: article ID 316980. 
9. Andersson AK, Li C, Brennan FM. Recent developments in the immunobiology of rheumatoid arthritis. Arthritis Research \& Therapy. 2008; 10(2): article 204.

10.Schett G, Hayer S, Zwerina J, Redlich K, Smolen JS. Mechanisms of disease: the link between RANKL and arthritic bone disease. Nat Clin Pract Rheumatol. 2005; $1(1): 47-54$.

11.Song X, Shen J, Wen H, Zhong Z, Luo Q, Chu D et al. Impact of Schistosoma japonicum infection on collagen-induced arthritis in DBA/1 mice: a murine model of human rheumatoid arthritis. PLoS ONE. 2011; 6(8): article e23453.

12. McSorley HJ, Maizels MR. Helminth infections and host immune regulation. Clinical Microbiology Reviews. 2012; 25(4):585-608.

13. Pineda MA, Al-Riyami L, Harnett W, Harnett MM. Lessons from helminth infections: ES-62 highlights new interventional approaches in rheumatoid arthritis. Clinical and Experimental Immunology. 2013; 177:13-23.

14. Greenwood BM, Herrick EM, Voller A. Can parasitic infection suppress autoimune disease? Proc Roy Soc Med. 1970; 63:19-20.

15. Rocha FAC, Leite AKRM, Pompeu MML, Cunha TM, Jr WAV, Soares FM et al. Protective effect of an extract from Ascaris suum in experimental arthritis models. Infection and Immunity. 2008; 76(6):2736-2745.

16. Mattsson L, Larsson P, Erlandsson-Harris H, Klareskog L, Harris RA. Parasitemediated down regulation of collagen-induced arthritis (CIA) in DA rats. Clinical and Experimental Immunology. 2000; 122:477-483.

17. Rocha FAC. Protective role of helminthiasis in the development of autoimune diseases. Clinical \& Developmental Immunology. 2006; 13(2-4):159-162.

18. He Y, Li J, Zhuang W, Yin L, Chen C, Li J et al. The inhibitory effect against collagen-induced arthritis by Schistosoma japonicum infection is infection stagedependent. BioMed Central Immunology. 2010; 11(28).

19. Osada Y, Kanazawa T. Parasitic helminths: new weapons against immunological disorders. Journal of Biomedicine and Biotechnology. 2009; 2010: article ID 743758.

20. Matisz CE, McDougall JJ, Sharkey KA, McKay DM. Helminth parasites and the modulation of joint inflammation. Journal of Parasitology research. 2011; 2011: article ID 942616. 
21. Versini M, Jeandel PY, Bashi T, Bizzaro G, Blank M, Shoenfeld Y. Unraveling the Hygiene hypothesis of helminthes and autoimmunity: origins, pathophysiology, and clinical applications. BioMed Central M 
Review article

\section{Intestinal parasites infection: protective effect in rheumatoid arthritis?}

\section{Sandra Maximiano de Oliveira ${ }^{a, *}$, Ana Paula Monteiro Gomides ${ }^{b}$, Lícia Maria Henrique da Mota ${ }^{b, c}$, Caliandra Maria Bezerra Luna Lima ${ }^{d, e}$, Francisco Airton Castro Rocha ${ }^{f}$}

a Hospital Universitário de Brasília (HUB), Brasília, DF, Brazil

${ }^{b}$ Medicine School, Universidade de Brasilia (UnB), Brasília, DF, Brazil

c Post-Graduate Program, Medicine School, Universidade de Brasília (UnB), Brasília, DF, Brazil

d Universidade Federal da Paraíba (UFPB), João Pessoa, PB, Brazil

e Interdisciplinary Post-Graduate Program in Decision and Health Models, Universidade Federal da Paraíba (UFPB), João Pessoa, PB, Brazil

${ }^{\mathrm{f}}$ Medicine School, Universidade Federal do Ceará, Fortaleza, CE, Brazil

\section{A R T I C L E I N F O}

\section{Article history:}

Received 16 September 2015

Accepted 3 April 2016

Available online $\mathrm{xxx}$

\section{Keywords:}

Rheumatoid arthritis

Helminth infections

Immunomodulation

Palauras-chave:

Artrite reumatoide

Parasitoses intestinais

Imunomodulação

\begin{abstract}
A B S T R A C T
Rheumatoid arthritis (RA) is a systemic autoimmune inflammatory disease, with a pro gressive course, characterized by chronic synovitis that may evolve with deformities and functional disability, and whose early treatment minimizes joint damage. Its etiopathogenesis is not fully elucidated but comprises immunologic responses mediated by $\mathrm{T}$ helper cells (Th1). An apparent minor severity of RA in patients from regions with lower income could be associated with a higher prevalence of gut parasites, especially helminths. Strictly, a shift in the immune response toward the predominance of T helper cells (Th2), due to the chronic exposure to helminths, could modulate negatively the inflammation in RA patients, resulting in lower severity/joint injury. The interaction between the immunological responses of parasitic helminths in rheumatoid arthritis patients is the purpose of this paper

๑) 2016 Elsevier Editora Ltda. This is an open access article under the CC BY-NC-ND license (http://creativecommons.org/licenses/by-nc-nd/4.0/)
\end{abstract}

\section{Parasitoses intestinais: efeito protetor na artrite reumatoide?}

R E S U M O

A artrite reumatoide (AR) é uma doença inflamatória autoimune, sistêmica, de curso progressivo, caracterizada por exuberante sinovite crônica, que pode gerar deformidades e incapacidade funcional, cujo tratamento precoce minimiza o dano às juntas. Sua etiopatogenia ainda não está completamente elucidada, mas compreende respostas imunológicas com a participação de células $\mathrm{T}$ auxiliares (Th1). Uma aparente menor gravidade da AR

\footnotetext{
Study conducted at the Rheumatology Department, Hospital Universitário de Brasília (HUB), Brasília, DF, Brazil. Corresponding author.

E-mail: sandramaximianoo@gmail.com (S.M. Oliveira).

http://dx.doi.org/10.1016/j.rbre.2016.06.004

2255-5021/@ 2016 Elsevier Editora Ltda. This is an open access article under the CC BY-NC-ND license (http://creativecommons.org/ licenses/by-nc-nd/4.0/)
} 


\subsection{2}

\section{GUT PARASITES IN RHEUMATOID ARTHRITIS: IMMINENT THREAT OR PROTECTIVE EFFECT?}

AUTHOR : Ana Paula Monteiro Gomides

Universidade de Brasília (UnB), Brasília, DF, Brazil

CO-AUTHORS:

Caliandra Maria Bezerra Luna Lima

Universidade Federal da Paraíba, João Pessoa, PB, Brazil

Francisco Airton Castro Rocha

Universidade Federal do Cerará, Fortaleza, CE, Brazil

Licia Maria Henrique da Mota

Universidade de Brasília (UnB), Brasília, DF, Brazil

Sandra Maximiniano de Oliveira

Hospital Universitário de Brasília (HuB), Brasília, DF, Brazil

Corresponding author at: SEPS 709/909 Sala 123 A,

Asa Sul, 70.390-095. Brasília- DF, Brasil.

Tel: 55- 61- 3263-9439

E-mail: anapmgomides@terra.com.br 


\section{ABSTRACT}

Gut parasites are among the oldest and most common infections in humans. Alterations in the host defense alterations caused by autoimmune diseases or immunosuppressive drugs can cause modifications of the symptoms: indolent parasites can be reactivated, asymptomatic patients may experience new symptoms, or mild or moderate symptoms can become serious and, rarely, may lead to death. In recent years, new drugs have been used in the treatment of rheumatoid arthritis (RA), causing a greater level of immunosuppression and therefore more concerns regarding the risk of serious parasitic diseases. Of note, experimental studies have demonstrated that the immunomodulation induced by infection with helminths can minimize the occurrence and severity of rheumatoid arthritis. Products derived from helminths (such as glycoprotein ES-62) can exert favorable effects in RA patients via their anti-inflammatory actions. Greater knowledge of these substances may serve as a basis for the development of new treatments for RA. The full impact of parasitic diseases on patients with rheumatoid arthritis remains controversial, and further studies are warrented.

KEY WORDS: helminths, parasitic infections, rheumatoid arthritis, immunomodulation 


\section{INTRODUCTION}

Intestinal parasites (protozoa and helminths) are among the most common infections in humans and have been reported since antiquity. Studies have revealed the presence of intestinal parasites in Egyptian mummies and other substances taken from mummified bodies dating back approximately 7000 years. For exampe, eggs of Ascaris lumbricoides were found in intestinal tissue sections from an Egyptian mummy fragment from 170 BC housed in a art museum in Philadelphia. The prehistoric evidence of this type of worm infestation and the growing interest in research on parasites in ancient materials resulted in the development of a new branch of study called Paleoparasitology. [1] [2]

It is estimated that approximately $25 \%$ of the world population carries a form of parasitic infections although this prevalence is markedly influenced by the data from countries with a lower development index. It is estimated that approximately 1 billion people are infected with Ascaris, with slightly smaller numbers infested by Trichuris trichiura and the hookworms. It has also been estimated that millions of individuals are carriers of Entamoeba histolytica,

Entamoeba dispar and Giardia lamblia. [1] [2] [3]

The helminths and protozoa are distributed according to the climate characteristics of the population and the region. They are more common in places with tropical and subtropical climates, and in underdeveloped or developing countries. However, even the developed countries with adequate sanitation are not exempt from these diseases. 
The most common forms of contamination occur following the ingestion of contaminated water and food or direct contamination through the skin (by the penetration of larvae from the soil). There may also be sexual transmission, although this is much rarer. Housing conditions, sanitation and personal hygiene are key factors association with the higher prevalence of parasitic diseases in populations with poor economic conditions. The lack of knowledge about the basic principles of hygiene and a lack of proper care in food preparation favor re-infection, another common problem in endemic areas. [3] [4] [5]

The actual prevalence of intestinal parasites is still not well-known. In Europe and the United States, the data for these diseases are very limited, most likely due to the low prevalence and the fact that health authorities are not always alerted to infections. In Brazil, the Ministry of Health published the National Plan for Surveillance and Control of Enteroparasitosis in 2005 in order to obtain information about the prevalence of these infections and to define better control measures. However, the available data are still insufficient and restricted. Studies published in the literature are generally related to specific population groups, such as school-age and pre school children, residents of rural areas, the elderly and people living in institutions such as nursing homes and day care centers. In an attempt to obtain higher nationwide data, a study was conducted in 10 Brazilian states in the late 1980 s, in which the prevalence of enteroparasites infections was found to be $44.2 \%$ in the state of Minas Gerais and the prevalence of schistosomiasis was $10.1 \%$ in the country. However, the data from that study probably does not represent the current status in Brazil because the project evaluated only school-aged children who were 714 years old. [4] [5] [6] [7] [8] [9] 
The clinical picture of patients with parasitic infections is extremely varied. In most cases, the patients are asymptomatic or only mildly symptomatic. However, serious and even fatal cases are occasionally observed, especially in individuals with disorders of their mechanisms of defense against microorganisms (those who are immunosuppressed, malnourished children, the elderly) and who have a high parasite load. [10] [11] [12]

The most common symptoms of parasitic infections are generally nonspecific including changes in bowel habits, nausea, vomiting, anorexia and asthenia. However, they may also result in malnutrition, anemia, intestinal blockage and malabsorption syndromes. Therefore, parasitic diseases are responsible for high morbidity and mortality, resulting in a major impact on public health. [10] [11] [12]

Regarding the concomitante occurrence of parasitic and rheumatic diseases, the data available in the literature are scarce and confined mostly to case reports. There have been serious cases of intestinal parasites reported in patients with lupus erythematosus and rheumatoid arthritis (RA). [13] [14] [15] [16] [17] On the other hand, some parasites, especially helminths, may exert a protective effect against rheumatic autoimmune disorders, reducing their severity. We herein discuss the impact of parasitic infections on rheumatoid arthritis and the results of the treatment of RA on parasitic infections.

\section{METHODS}

A literature review was performed using the following electronic databases:

Scientific Electronic Library Online (SciELO), Medical Literature Analysis and Retrieval System Online (MEDLINE/PubMed), and Latin American and Caribbean Health Sciences (LILACS). The descriptors used in the literature review were: 
rheumatoid arthritis and parasitic infections or helminths, ES-62. The findings were classified by the GRADE system ("Grading of Recommendations, Assessment, Development and Evaluation"). [18] Studies were selected that were conducted from 1950 to 2015 .

\section{RESULTS AND DISCUSSION}

3.1) Parasitic risks in patients with rheumatic diseases

The host immune response against parasites has been studied mainly in experimental models such as zymosan-induced arthritis. [19] Although the body's defense mechanisms are still not fully understood, there is evidence that the barrier of the intestinal mucosa, and the humoral and cellular responses are affected to varying degrees depending on the type of infection. [20]

In parasitic infections, as in other diseases, the efficiency of the immune system is crucial to the outcome. Therefore, alteration of the host defense may lead to a modification of the symptoms of previously existing parasitic infections: indolent organisms can be reactivated, asymptomatic patients may experience new symptoms, and mild or moderate symptoms can become serious and may rarely lead to death. [20] [21]

A high parasite load, favored by an ineffective immune response, and the nutritional status of the patient are factors that favor the worsening of the infectious process, autoinfection and even cases of hyperinfection (as in the case of strongyloidiasis). Thus, there is significant concern about the development or aggravation of parasitic diseases in patients with various forms of congenital or 
acquired immunosuppression due to disease and/or treatment. In this context, there is a particular need for greater care in patient with rheumatic diseases.

In the field of rheumatology, there is a variety of diseases that are associated with profound changes in the immune response compared to the normal population. Furthermore, the treatment used to induce or maintain the remission of such diseases can cause immunosuppression that favors infectious processes. In recent years, in addition to corticosteroids and traditional DMARDs (disease-modifying antirheumatic drugs), new "biologic" drugs are being used mainly in the treatment of rheumatoid arthritis. These drugs include cytokine inhibitors (TNF -alpha antagonists and/or blockers of cytokine receptors) and immunomodulators. In most cases, these therapies have been well tolerated, but have been shown to increase the risk of infections, probably by inhibiting molecules essencial for the host defense against viruses, bacteria, fungi and parasites. [22] [23] Because these new drugs have become essential in the management of $\mathrm{RA}$, it has been recommended that professional track and monitor of infectious processes in this population. It has also been suggestions of "screening" should be performed to detect diseases such as tuberculosis, hepatitis and HIV before starting to use immunosuppressants and biological therapy. [24]

There is currently a dearth of information regarding the risk of new or worsening parasite infections in patients with rheumatoid arthritis receiving immunosuppressive therapy, and the prevalence of helminth infections in this population is currently unclear. Nevertheless, due to the greater risk and potential increased severity of parasitic infections in patients with RA, some rheumatology societies, such as the Brazilian Society, the Italian Society and the Spanish Society, are preparing documents based on expert consensus and literature reviews to direct research and 
treatment of these diseases, especially the use of biopharmaceuticals. [25] [26] However, studies are needed to provide sufficient epidemiological data on the subject to inform decisions and future reserach.

3.1.2) Difficulties in the diagnosis of intestinal parasites in immunocompromised patients

Knowledge concerning the epidemiology of intestinal parasites in RA patients is critical to provide suggestions regarding the proper management of these patients in clinical practice. However, there are several factors that may make diagnosing parasites difficult in these patients.

Stool testing to confirm the presence of parasites remains the method of choice. However, it should be carefully performed to minimize the risk of false negative findings. The collection and preservation of material should be undertaken properly, and the choice of technique used in the analysis should be carefully made. Preferably, one should use various techniques in combination and should examined more than one fecal specimen. The shortage of experienced microscopists in this type of examination can be another limiting factor. [1] In addition, the fact that infected individuals do not continuously shed cysts, further complicates the diagnosis. For example, in patients with giardiasis, there may be an intermittent disposal of fecal cysts during what is known as a "negative" period, which can last up to 10 days. [27]

Immunosuppression can also cause diagnostic difficulties due to changes in laboratory parameters. Eosinophilia, a typical change noted in patients infected with intestinal parasites, may be absent. On the other hand, this parameter cannot be 
consider in patients receiving systemic corticosteroids, as it is a result of the treatment. Additionally, in many cases, the symptoms of parasitic diseases can mimic manifestations of the underlying disease, preventing or delaying its diagnosis. Several cases in the literature describe symptoms of a parasitic infection that were misdiagnosed as part of the underlying disease. There is an increasing use of immunosuppressive drugs, which can resulting in catastrophic outcomes, such as hyperinfection and death. Several cases of widespread parasitic disease, particularly strongyloidiasis, have been published in recent decades. [15] [28] [29] [30] [31] [32] [33] [34] [35] The simultaneous infection of patients with diseases rheumatic with strongyloidiasis is probably an important fator that should be consider before prescribing corticosteroids. Some researchers suggest that these drugs may have direct actions on the parasites, causing maturation of larvae and even stimulating latent adult females. [36]

Faced with all these difficulties, a high level of suspicion for parasitic infection is required, but this may lead to a delay in the diagnosis and treatment in immunocompromised patients. Research is needed to provide more epidemiological data on the subject to allow physicians to make informed decisions and to provide future directions for research and treatment.

3.1) Protective effects of parasitic diseases against rheumatic diseases

The participation of microorganisms, especially the Enterobacteriaceae and viroses, in the pathogenesis of rheumatic diseases has been described for decades. The possible influence of parasitic infections on the evolution of a rheumatic disease was first described in 1970 when Greenwood et al reported that patients with 
rheumatoid arthritis in Nigerian villages had mild disease and correlated this with the high prevalence of parasitic diseases in that group. [37] In 1974, Pearson at al. found that infection by the nematode Syphacia oblevata reduced the incidence of induced arthritis in rats. [38] Since then, various studies have attempted to demonstrate a reduction in new cases and the severity of imune-mediated diseases in experimental animals and individuals infected by intestinal parasites. [19] [39] [40] [41] In 1989, Strachan proposed the theory of the "hygiene hypothesis", where the reduction of a person's contact with common organisms such as helminths increased the prevalence of allergic and autoimmune diseases, reinforcing the arguments of other researchers.

Other aspects that have been investigated include the differences in disease severity factors in diferente regions. There is a tendency for there to be a higher incidence of $A R$ and a greater severity of the disease in developed countries. It would be expected that the difficulties in the diagnosis (due to delayed access to an expert, for example) and in the treatment of rheumatoid arthritis in underdeveloped or developing countries, would lead to a worse clinical outcome but his does not occur in practice. [42] These finds have reinforced the hypothesis that an environmental factors may have a protective roles in countries with unfavorable economic conditions. Researchers have been trying to determine whether helminth infections can minimize the appearance and severity of rheumatoid arthritis.

In 2006, Rock. et al reported that patients in the Northeast region of Brazil, where there is a high prevalence of helminth infections, may presente a better evolution of RA than patients in São Paulo, the most developed region. [42] Similar findings were reported by Panda et. al, who indicated that RA patients had no infections with 
nematodes in Odisha India, a region with a high very prevalence of Wuchereria bancrofti. [43]

The inverse relationship between parasitic infections and rheumatic diseases such as RA can be ascertained based on an understanding of the mechanisms of action of the parasites.

\subsection{1) Parasitic immunomodulation}

The mechanisms of action of the parasites in the host have been widely studied. It is believed that parasites generally have the ability to modulate the immune response, ensuring their prolonged survival in the host. This would be possible by the production of biologically active substances such as ES (excretory-secretory) molecules that cause changes in the host inflammatory response. Several experimental studies have shown several actions of parasites that culminate with an anti-inflammatory response. [44]

The prevalence of the Th2 immune response may be the most important mechanism in this process. It has been shown that substances produced by helminths, especially ES-62, induce a shift from the Th1 to the Th2 response, culminating in the production of a high levels of IL-4, IL-10 and TGF $\square \square \square$ in addition to the reduction of proinflammatory cytokines ( TNF- $\square$, IL-1 $\square$, IL-6 and IL-17, IFN- $\square$ and RANKL). Additionally, there may be alterations in the functions of dendritic cells, macrophages, NK cells and B cells, leading to the expansion of regulatory $\mathrm{T}$ responsible for maintaining self-tolerance. All of these effects would be desirable in 
patients with autoimmune diseases, especially rheumatoid arthritis, in which these would lead to an improvement or inhibition of disease progression. [44]

\subsection{1) Perspectives in the treatment of RA}

Based on the accumulating knowledge of the immunological actions of products derived from helminths (mainly ES-62) and a better understanding of the mechanisms of action thereof, experimental studies are being perfored in an attempt to test their effects on rheumatoid arthritis. There is an expectation that such products can form the basis of new drugs and new lines of treatment for RA and other immunological diseases.

The major studies that have been performed so far are summarized in the table below (Table. 1):

\section{CONCLUSIONS}

The actual impact of parasitic diseases on patients with rheumatoid arthritis remains controversial. First, there may be an increased risk of severe and disseminated parasitic infections due to the changes in the immune response generated by the underlying disease or immunosuppressive therapy. However, there is a growing body of evidence suggesting that helminths produce substances capable of attenuating the inflammatory disease process. These principles can be viewed in Figure 1. Further studies are essential to elucidated this subject. 


\section{Financial disclosure}

The authors have no financial relationships relevant to this article to disclose.

\section{Conflict of interest}

The authors have no conflicts of interest to disclose.

\section{REFERENCES}

[1] Chapter L, M Head CW. Intestinal parasites. Rev Bras Med 1995; 51: 126-32.

[2] Ferreira LF, Reinhard KJ AAA. Fundamentals of paleoparasitology. Topics In Health Ed Fiocruz in 2011.

[3] MU Ferreira, Ferreira CS MC. Secular trends of intestinal parasites in children in the city of São Paulo (1984-1996). Rev Public Health 2000; 34 (suppl 6): 73-82.

[4] Elisabeth Campos de Andrade EC, ECG Milk, Rodrigues VO CM. Intestinal parasites: a review of its social, epidemiological, clinical and therapeutic. Rev APS, Juiz de Fora 2010; 13: 231-40.

[5] DP N. Human Parasitology. 2005.

[6] Peruzzi S, Gorrini C, Piccolo G, Calderaro A, L Dettori, Chezzi C. Prevalence of intestinal parasites in the area of Parma During the year 2005. Acta Biomed 2006; 77: $147-51$.

[7] Pellon IT AB. Geographical distribution of schistosomiasis in Brazil. Ministry of Educ. and Health, Dep. Nat. Health Div. Organ. Health. 11th Congregation. Bras. Hig., 1950. 
[8] Pellon IT AB. Helmintológico School survey in five states of Eastern regions, South, and Midwest. Dep. Nat. Health Div. Organ. Health. VIIlo Congregation. Bras. Hig., 1953.

[9] Campos R BW. Multicenter survey of intestinal parasites in Brazil. The final results. Rev Soc Bras Med Trop 2002; 35: 597-600.

[10] Melo MCB, Klem VGQ, Mota JAC PF. Intestinal parasites. Rev Med Minas Gerais 2004; 14: 3-12.

[11] A. Cunha intestinal parasitosis. Gastroenterol. clinical Dani, R. Castro, LP, 1993, p. 971-91.

[12] L. Rodrigues clinical and laboratory diagnosis of intestinal parasites. 1983.

[13] NK Shrestha, Khanal B, Sharma SK, Dhakal SS KR. Primary amoebic meningoencephalitis in a patient with systemic lupus erythematosus. Scand J Infect Dis 2003 ; 35: $514-6$.

[14] Shirwadkar GC Samant R Sankhe M, Deshpande R, S Yagi, FL Schuster et al. Acanthamoeba encephalitis in patient with systemic lupus, India. Emerg Infect Dis 2006; 12: 984-986.

[15] Buonfrate D Requena-Mendez A, Angheben A, Munoz J, Gobbi F, Van Den Ende J, et al. Severe strongyloidiasis: a systematic review of case reports. BMC Infect Dis 2013; 13: 78. doi: 10.1186 / 1471-2334-13-78.

[16] Of P, Raghu P, Dinda AK GP. Strongyloides hyperinfection in rheumatoid arthritis. J Surg Pathol 2007; 15: 391-2.

[17] Altintop L, Cakar B, Hokelek M, Bektas A, L Yildiz, Karaoglanoglu M. Strongyloides stercoralis hyperinfection in a patient with rheumatoid arthritis and bronchial asthma: a case report. Antimicrob Ann Clin Microbiol 2010; 9: 27. 
[18] Pollock A, Farmer SE, Brady MC, Langhorne P, Mead GE, Mehrholz J, et al. An algorithm was developed to assign GRADE levels of evidence to comparisons Within systematic reviews. J Clin Epidemiol 2015.

[19] Rock FAC, AKRM Milk, Pompey MML, Cunha TM, the Verri W., Soares FM, et al. Protective effect of an extract from Ascaris suum in experimental arthritis models. Infect Immun 2008; 76: 2736-45.

[20] Evering T, Weiss LM. The immunology of parasite infections in immunocompromised hosts. Parasite Immunol 2006; 28: 549-565.

[21] Port MAF, Muniz A, Junior OJ, Carvalho M. clinical and immunological implications of the association between HTLV-1 and strongyloidiasis Clinical and immunological consequências of the association between HTLV-1 and strongyloidiasis. Rev Soc Bras Med Trop 2002; 35: 641-9.

[22] Fabiani S, F Bruschi, Heumatology EXR, Fabiani S BF. Patients Undergoing Rheumatological parasitic diseases and immunosuppressive treatments: a review of the literature cases of clinical perspectives and to screen and follow-up active and latent chronic infections. Clin Exp Rheumatol 2014; 32: 587-96.

[23] Favalli EG, Desiati F, Atzeni F, Sarzi-Puttini P, R Caporali, Pallavicini FB, Gorla R, M Filippini MA. Serious infections During anti-TNFalpha treatment in rheumatoid arthritis Patients. Autoimunn Rev 2009; 8: 266-73.

[24] Faucherre M, B Pazar, So RB. TNF-alpha inhibitors: infection risks? Practical recommendations. Rev Med Suisse 2011; 7: 75-6,78-9.

[25] Braz AS, CAF De Andrade, LMH Da Mota, Lima CMBL. Recommendations of the Brazilian Society of Rheumatology for diagnosis and treatment of intestinal parasites in patients with autoimmune rheumatic diseases. Bras J Rheumatol 2014; 55: $368-80$. 
[26] Bartalesi F Bartoloni A, Z SM Bisoffi at al., Bartalesi F Bartoloni A, Z SM Bisoffi at al. The emerging problem of biological treatment in migrant and traveling Populations: It is time to extend guidelines for the screening of infectious diseases. Ann Rheum Dis 2014; 73: 794-6.

[27] MD et al. Giardiasis: general aspects. Mod Pediatr 2009; 45.

[28] Ibarra-Gonzalez F, Chevli P L Schachter, Kaur M, Eivaz-Mohammadi S, Tashtoush B, et al. Strongyloidiasis and Diffuse Alveolar Hemorrhage in a Patient with Systemic Lupus Erythematosus. Case Rep Med 2014; 2014: 1-3.

[29] Souza JN, Agnes EJ, Santiago M, Teixeira MC SN. . Strongyloides stercoralis infection in systemic lupus erythematosus Patients with: diagnosis and prevention of severe strongyloidiasis. Int J Rheum Dis 2015; doi: 10:11.

[30] Yung EE, Lee CM, J Boys, DJ Grabo, Buxbaum JL CP. Strongyloidiasis hyperinfection in a patient with a history of systemic lupus erythematosus. Am J Trop Med Hyg 2014; 91: 806-9.

[31] The Rajadhyaksha, K. S Mehra Rajadhyaksha A, S Mehra, Kawale. Disseminated Strongyloides in systemic lupus erythematosus and antiphospholipid antibody syndrome: a case report. Int J Rheum Dis 2012; 15: e159-61.

[32] Caramaschi P, Marocco S, M Gobbo, La Verde V, Volpe A, Bambara L BD. Systemic lupus erythematosus and strongyloidiasis: a multifaceted connection. Lupus. Lupus 2010; 19: 872-4.

[33] Fardet L, T Généreau, Poirot JL, Guidet B, Kettaneh CJ. Severe strongyloidiasis in corticosteroid-treated Patients: series and literature review case. J Infect 2007; 57: 18-27.

[34] CS Lam, Tong MK, SY Chan KM. Disseminated strongyloidiasis: a retrospective study of clinical course and outcome. Eur J Clin Microbiol Infect Dis 2006; 25: 14-8. 
[35] Arsic-Arsenijević V, Dzamić A, Dzamić Z, Milobratović D TD. Fatal Strongyloides stercoralis infection in a young woman with lupus glomerulonephritis. J Nephrol 2005; 18: 787-90.

[36] Keiser PB NT. Strongyloides stercoralis in the Immunocompromised Population. Clin Microbiol Rev 2004; 17: 208-17.

[37] Greenwood BM, Herrick IN VA. Can parasitic infection suppress autoimmune disease? Proc Roy Soc Med 1970; 63: 18-20.

[38] Pearson DJ TG. The influence of the nematode Syphacia oblevata on adjuvant arthritis in the rat. Immunology 1975; 29: 391-6.

[39] Osada Y, Shimizu S, Kumagai T, Yamada S KT. Schistosoma mansoni infection angiograms severity of collagen-induced arthritis via down-regulation of proinflammatory mediators. Int J Parasitol 2009; 39: 457-64.

[40] Shi M, Wang A, D Prescott et al. Infection with an intestinal helminth parasite angiograms Freund's complete adjuvant-induced monoarthritis in mice. Arthritis Rheum 2011; 63: 434-44.

[41] Itami MD, Oshiro TM, CA Araujo, Perini A, Martins MA, MS Macedo M-SM. Modulation of murine experimental asthma by Ascaris suum components. Clin Exp Allergy 2005; 35: 873-9.

[42] Rock FAC, FAC Rock. Protective Role of Helminthiasis in the Development of Autoimmune Diseases. Dev Clin Immunol 2006; 13: 159-62.

[43] AK Panda, Ravindran B DB. Rheumatoid arthritis Patients are free of filarial infection in an area where filariasis is endemic: comment on the article by Pineda et al. Arthritis Rheum 2013; 65: 1402-3.

[44] DW Dunne, Cooke A. A worm's eye view of the immune system: consequências for evolution of human autoimmune disease. Nat Rev Immunol 2005; 5: 420-6. 
[45] Rzepecka J, Pineda MA, Al-Riyami L, Rodgers DT, Huggan JK, Lumb FE, et al. Prophylactic and therapeutic treatment with a synthetic analogue of a parasitic worm product arthritis and inhibits IL-1 $\beta$ Prevents experimental production via NRF2mediated counter-regulation of the inflammasome. Autoimmun J 2015; 60: 59-73. [46] Al-Riyami L, Rodgers DT, Rzepecka J, Pineda MA, CJ Suckling, Harnett MM, et al. Protective effect of small molecule analogues of the Acanthocheilonema viteae secreted product ES-62 on oxazolone-induced ear inflammation. Exp Parasitol 2015. [47] Aprahamian TR, Zhong X, Amir S, Binder CJ, Chiang LK, Al-Riyami L, et al. The immunomodulatory product parasitic worm ES-62 lupus-associated angiograms accelerated atherosclerosis in a mouse model. Int J Parasitol 2015; 45: 203-7.

[48] Rodgers DT, McGrath MA, MA Pineda, Al-Riyami L Rzepecka J, F Lumb et al. The parasitic worm product ES-62 targets myeloid differentiation factor 88dependent effector mechanisms to suppress antinuclear antibody production and proteinuria in MRL / Ipr mice. Arthritis Rheumatol (Hoboken, NJ) 2015; 67: 1023-35. [49] Rzepecka J. Coates ML Saggar M, Al-Riyami L, Coltherd J, Tay HK, et al. Small molecule analogues of the immunomodulatory parasitic helminth product ES-62 antiallergy properties have. Int J Parasitol 2014; 44: 669-74.

[50] Al-Riyami L, W. Harnett immunomodulatory properties of ES-62, the phosphorylcholine-containing glycoprotein secreted by Acanthocheilonema viteae. Endocr Metab Immune Disord Drug Targets 2012; 12: 45-52.

[51] Egan CA, Houston KM, Alcocer MJC, Solovyova A, Tate R, Lochnit G, et al. Lack of immunological cross-reactivity between parasite-derived and recombinant forms of ES-62, a secreted protein of Acanthocheilonema viteae. Parasitology 2006; 132: $263-74$. 
[52] Nagayama Y, Watanabe K, Niwa M, McLachlan SM, Rapoport B. Schistosoma mansoni and alpha-galactosylceramide: prophylactic effect of Th1 Immune suppression in a mouse model of Graves' hyperthyroidism. J Immunol 2004; 173: 2167-73.

[53] La Flamme AC, Ruddenklau K Bäckström BT. Decreases schistosomiasis central nervous system inflammation and alters the progression of experimental autoimmune encephalomyelitis. Infect Immun 2003; 71: 4996 to 5004.

[54] Mattsson L, Larsson P, Erlandsson-Harris H, Klareskog L, Harris RA. Parasitemediated down-regulation of collagen-induced arthritis $(C I A)$ in DA rats. Clin Exp Immunol 2000; 122: 477-83.

[55] Cooke T, Tonks P, Jones FM, O'Shea M, P Hutchings, Fulford AJ, et al. Infection with Schistosoma mansoni Prevents insulin dependent diabetes in nonobese diabetic mice. Parasite Immunol 1999; 21: 169-76.

[56] Ben-Ami Shor D, Bashi T, Lachnish J, Fridkin M, Bizzaro G, Barshak I, Blank M, Shoenfeld Y. Phosphorycholine-tuftsin compound prevents development of dextransulfate-sodium-salt induced murine colitis: implications for treatment of human inflammatory bowel disease. J Autoimmun. 2015 Jan; 56:111-7. 
Table 1. Studies on the effects of products derived from parasites in autoimmune diseases

\begin{tabular}{|c|c|c|c|}
\hline Authors/ & Studies & Year & Model \\
\hline $\begin{array}{l}\text { Rzepecka J, Pineda MA, } \\
\text { Al-Riyami L at. Al [45] }\end{array}$ & $\begin{array}{l}\text { Prophylactic and } \\
\text { therapeutic treatment with } \\
\text { a synthetic analogue of a } \\
\text { parasitic worm product } \\
\text { prevents experimental } \\
\text { arthritis and inhibits IL-1ß } \\
\text { production via NRF2- } \\
\text { mediated counter- } \\
\text { regulation of the } \\
\text { inflammasome. }\end{array}$ & 2015 & $\begin{array}{c}\text { Experimental } \\
\text { rheumatoid } \\
\text { arthritis }\end{array}$ \\
\hline $\begin{array}{l}\text { Al-Riyami L, Rodgers DT, } \\
\text { Rzepecka J, Pineda MA, } \\
\text { Suckling CJ, Harnett MM, } \\
\text { Harnett W. [46] }\end{array}$ & $\begin{array}{l}\text { Protective effect of small } \\
\text { molecule analogues of the } \\
\text { Acanthocheilonema viteae } \\
\text { secreted product ES-62 on } \\
\text { oxazolone-induced ear } \\
\text { inflammation. }\end{array}$ & 2015 & $\begin{array}{c}\text { Contact } \\
\text { dermatitis }\end{array}$ \\
\hline $\begin{array}{l}\text { Aprahamian TR, Zhong } \\
\text { X, Amir S, Binder CJ, } \\
\text { Chiang LK at al. [47] }\end{array}$ & $\begin{array}{l}\text { The immunomodulatory } \\
\text { parasitic worm product ES- } \\
62 \text { reduces lupus- } \\
\text { associated accelerated } \\
\text { atherosclerosis in a mouse } \\
\text { model. }\end{array}$ & 2015 & $\begin{array}{c}\text { Sistemic lupus } \\
\text { erythematosus } \\
\text { (atherosclerosi } \\
\text { s) }\end{array}$ \\
\hline $\begin{array}{l}\text { Rodgers DT, McGrath } \\
\text { MA, Pineda MA, Al- } \\
\text { Riyami L, Rzepecka J, } \\
\text { Lumb F, Harnett W, } \\
\text { Harnett MM. [48] }\end{array}$ & $\begin{array}{l}\text { The parasitic worm product } \\
\text { ES-62 targets myeloid } \\
\text { differentiation factor } 88 \text { - } \\
\text { dependent effector } \\
\text { mechanisms to suppress } \\
\text { antinuclear antibody } \\
\text { production and proteinuria } \\
\text { in MRL/Ipr mice. }\end{array}$ & 2015 & $\begin{array}{c}\text { Sistemic lupus } \\
\text { erythematosus } \\
\text { (nephritis) }\end{array}$ \\
\hline $\begin{array}{l}\text { Rzepecka J, Coates ML, } \\
\text { Saggar M, Al-Riyami L, } \\
\text { Coltherd J at al.[49] }\end{array}$ & $\begin{array}{l}\text { Small molecule analogues } \\
\text { of the immunomodulatory } \\
\text { parasitic helminth product }\end{array}$ & 2014 & $\begin{array}{c}\text { Asthma/Allergi } \\
\text { es }\end{array}$ \\
\hline
\end{tabular}




\begin{tabular}{|c|c|c|c|}
\hline & $\begin{array}{l}\text { ES-62 have anti-allergy } \\
\text { properties. }\end{array}$ & & \\
\hline $\begin{array}{l}\text { Al-Riyami L, Harnett } \\
\text { W.[50] }\end{array}$ & $\begin{array}{l}\text { Immunomodulatory } \\
\text { properties of ES-62, a } \\
\text { phosphorylcholine- } \\
\text { containing glycoprotein } \\
\text { secreted by } \\
\text { Acanthocheilonema viteae. }\end{array}$ & 2012 & $\begin{array}{c}\text { Autoimmune } \\
\text { diseases/Aller } \\
\text { gies }\end{array}$ \\
\hline $\begin{array}{l}\text { Egan CA, Houston KM, } \\
\text { Alcocer MJ, Solovyova A, } \\
\text { Tate R, Lochnit G, } \\
\text { Mclnnes IB, Harnett MM, } \\
\text { Geyer R, Byron O, } \\
\text { Harnett W [51] }\end{array}$ & $\begin{array}{l}\text { Lack of immunological } \\
\text { cross-reactivity between } \\
\text { parasite-derived and } \\
\text { recombinant forms of ES- } \\
62, \text { a secreted protein of } \\
\text { Acanthocheilonema viteae. }\end{array}$ & 2006 & \\
\hline $\begin{array}{l}\text { Francisco Airton Castro } \\
\text { Rocha at al } \\
{[19]}\end{array}$ & $\begin{array}{l}\text { Protective Effect of an } \\
\text { Extract from Ascaris suum } \\
\text { in Experimental Arthritis } \\
\text { Models }\end{array}$ & 2008 & $\begin{array}{c}\text { Experimental } \\
\text { Arthritis }\end{array}$ \\
\hline $\begin{array}{l}\text { Nagayama, Y., } \\
\text { Watanabe, K., Niwa, } \\
\text { M.,McLachlan, S. M. \& } \\
\text { Rapoport [52] }\end{array}$ & $\begin{array}{l}\text { B. Schistosoma mansoni } \\
\text { and } \square \text {-galactosylceramide: } \\
\text { prophylactic effect of } \mathrm{T}_{\mathrm{H}}{ }^{1} \\
\text { immune suppression in a } \\
\text { mouse model of Graves' } \\
\text { hyperthyroidism }\end{array}$ & 2004 & $\begin{array}{c}\text { Graves'diseas } \\
\text { e }\end{array}$ \\
\hline $\begin{array}{l}\text { La Flamme, A. C., } \\
\text { Ruddenklau, K. \& } \\
\text { Backstrom, B. T.[53] }\end{array}$ & $\begin{array}{l}\text { Schistosomiasis decreases } \\
\text { central nervous system } \\
\text { inflammation and alters the } \\
\text { progression of } \\
\text { experimental autoimmune } \\
\text { encephalomyelitis. }\end{array}$ & 2003 & $\begin{array}{l}\text { Experimental } \\
\text { autoimmune } \\
\text { encephalomye } \\
\text { litis }\end{array}$ \\
\hline $\begin{array}{l}\text { Mattsson, L., Larsson, P., } \\
\text { Erlandsson-Harris, H., } \\
\text { Klareskog, L. \& Harris, R. } \\
\text { A. [54] }\end{array}$ & $\begin{array}{l}\text { Parasite-mediated down- } \\
\text { regulation of collagen- } \\
\text { induced arthritis (CIA) in } \\
\text { DA rats. }\end{array}$ & 2000 & $\begin{array}{l}\text { Collagen- } \\
\text { induced } \\
\text { arthritis }\end{array}$ \\
\hline
\end{tabular}




$\begin{array}{lll}\text { Cooke, A. et al.[55] } & \text { Infection with Schistosoma } \\ & \text { mansoni prevents insulin } \\ & \text { dependent diabetes } \\ & \text { mellitus in non- obese } \\ & \text { diabetic mice }\end{array}$

Figure 1 : Proposed mechanisms for the participation of parasites in general (left) and helminths specifically (right) in patients with autoimmune diseases.

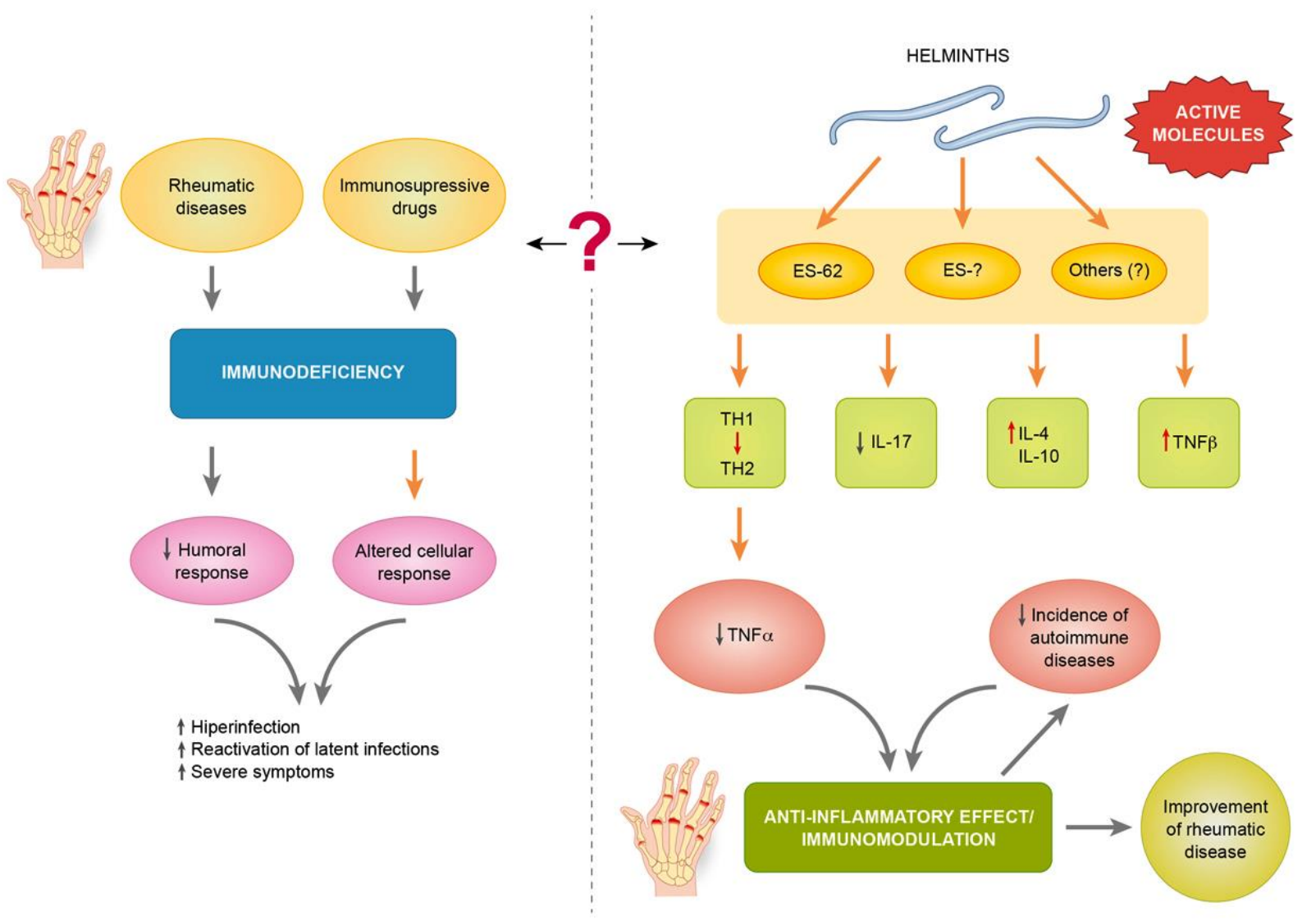


REVIEW ARTICLE

\title{
Parasites in Rheumatoid Arthritis: Imminent Threat or Protective Effect?
}

\author{
Ana Pạula Monteiro Gomides ${ }^{1}$, Caliandra Maria Bezerra Luna Lima ${ }^{2}$, Françisco Airton Castro \\ Rocha $^{3}$, Licia Maria Henrique da Mota ${ }^{4}$ and Sandra Maximiano de Oliveira
}

${ }^{1}$ Universidade de Brasilia (UnB), Brasilia, DF, Brazil; ${ }^{2}$ Universidade Federal da Paraíba, João Pessoa, PB, Brazil; ${ }^{3}$ Universidade Federal do Cerará, Fortaleza, CE, Brazil: ${ }^{4}$ Universidade de Brasilia (UnB), Brasilia, DF, Brazil; ${ }^{5}$ Hospital Universitário de Brasília (HuB), Brasilia, DF, Brazil

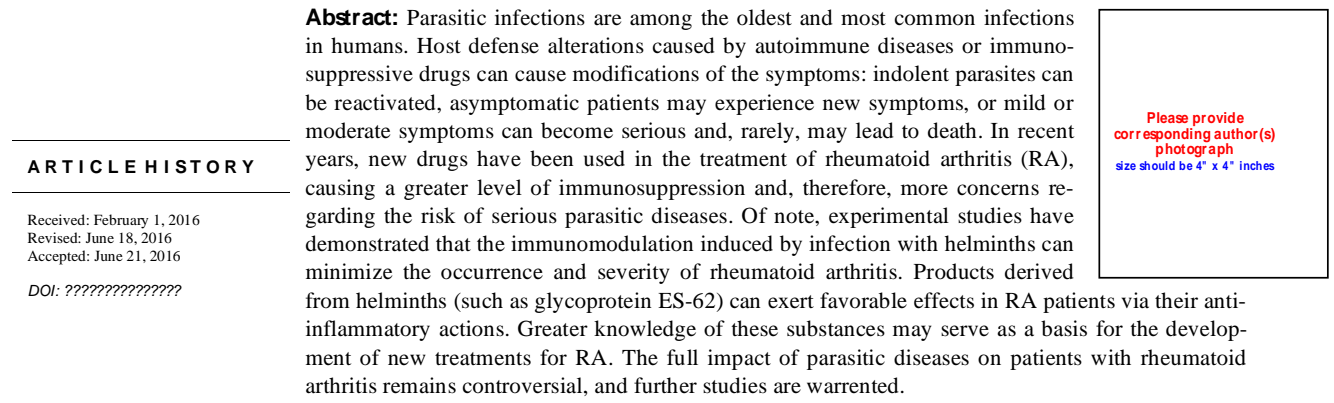

Keywords: Helminths, parasitic infections, rheumatoid arthritis, immunomodulation.

\section{INTRODUCTION}

The parasites (protozoa and helminths) are among the most common causes of infections in humans and have been reported since antiquity. Studies have revealed the presence of intestinal parasites in Egyptian mummies and other substances taken from mummified bodies dating back approximately 7000 years. For example, eggs of Ascaris lumbricoideswere found in intestinal tissue sections from an Egyptian mummy fragment from $170 \mathrm{BC}$ housed in an art museum in Philadelphia. The prehistoric evidence of this type of worm infestation and the growing interest in research on parasites in ancient materials resulted in the development of a new branch of study called Paleoparasitology $[1,2]$.

It is estimated that approximately $25 \%$ of the world population carries a form of parasitic infection although this prevalence is markedly influenced by the data from countries with a lower development index. It is estimated that approximately 1 billion people are infected with Ascaris, with slightly smaller numbers infested by Trichuris trichiura and the hookworms. It has also been estimated that millions of individuals are carriers of Entamoeba histolytica, Entamoeba dispar and Giardia lamblia [1-3]

Address correspondence to this author at the SEPS 709/909 Sala $123 \mathrm{~A}$ Asa Sul, 70.390-095. Brasília- DF, Brasil; Tel: 55- 61- 3263-9439; E-mail: anapmgomides@terra.com.br
The helminths and protozoa are distributed according to the climate characteristics of the population and the region. They are more common in places with tropical and subtropical climates, and in underdeveloped or developing countries. However, even the developed countries with adequate sanitation are not exempted from these diseases.

The most common forms of contamination occur following the ingestion of contaminated water and food or direct contamination through the skin (by the penetration of larvae from the soil). There may also be sexual transmission, although this is much rarer. Housing conditions, sanitation and personal hygiene are key factors associated with the higher prevalence of parasitic diseases in populations with poor economic conditions. The lack of knowledge about the basic principles of hygiene and a lack of proper care in food preparation favor re-infection, another common problem in endemic areas [3-5]

The actual prevalence of parasites is still not well-known. In Europe and the United States, the data for these diseases are very limited, most likely due to the low prevalence and the fact that health authorities are not always alerted to infections. In Brazil, the Ministry of Health published the National Plan for Surveillance and Control of Enteroparasitosis in 2005 in order to obtain information about the prevalence of these infections and to define better control measures. However, the available data are still insufficient and re- 


\section{REFERÊNCIAS}

1. Cox FEG. History of Human Parasitology. Clin Microbiol Rev. 2002 Oct; 15(4): 595-612.

2. Ferreira LF, Reinhard KJ, Araújo A. Adauto. Fundamentos da paleoparasitologia. In: Temas em saúde. Editora Fiocruz, 2011.

3. World Health Organization. Deworming for health and development. Report of the Third Global Meeting of the Partners for Parasite Control. Geneva: World Health Organization; 2014.

4. Neves DP. Parasitologia Humana. 11a ed. São Paulo: Atheneu; 2005. p. 494 .

5. Andrade EC, Cristina I, Leite $G$ et al. Intestinal parasitic diseases: a review of social, epidemiologic, clinical and therapeutic aspects. Rev APS, Juiz Fora. 2010;13(2):231-40.

6. Belo VS, Oliveira RB, Fernandes CP, Castro CL, Santos WB, Silva ES., Fatores associados à ocorrência de parasitoses intestinais em uma população de crianças e adolescentes. Revista Paulista de Pediatria, São Paulo, v. 30, n. 2, p. 195-201, 2012.

7. Santos IP, Isaac RMF. Comparação das parasitoses mais encontradas em dois municípios da região Sul de Goiás. Revista da Universidade Vale do Rio Verde, Três Corações, v. 13, n. 2, p. 344-355, 2015.

8.Ferreira MU, Ferreira CS, e Monteiro CA. Tendência secular das parasitoses intestinais na infância na cidade de São Paulo (1984-1996). Rev Saúde Pública 2000;34(6 Supl):73-82.

9. Elisabeth Campos de Andrade EC, Leite ECG, Rodrigues VO, Cesca MG. Parasitoses intestinais: uma revisão sobre seus aspectos sociais, epidemiológicos, clínicos e terapêuticos. Rev. APS, Juiz de Fora 201013 (2): 231-240.

10. Peruzzi S, Gorrini C, Piccolo G, Calderaro A, Dettori G, Chezzi C. Prevalence of intestinal parasites in the area of Parma during the year 2005. Acta Biomed. 2006 Dec; 77(3):147-51.

11. Pellon AB, Teixeira I. Distribuição geográfica da esquis- tossomose mansônica no Brasil. Ministério da Educação e Saúde, Departamento Nacional de Saúde, 
Divisão de Organização Sanitária. In: 110 Congresso Brasileiro de Higiene. Rio de Janeiro; 1950.

12. Pellon $A B$, Teixeira I. Inquérito Helmintológico Escolar em cinco estados das regiões Leste, Sul, e Centro-Oeste. Departamento Nacional de Saúde, Divisão de Organiza- ção Sanitária. In: VIIlo Congresso Brasileiro de Higiene. Curitiba; 1953.

13. Campos $R$, Briques $W$. Levantamento multicêntrico de parasitoses intestinais no Brasil. Os resultados finais. Rhodia: São Paulo; 1988. In: Carvalho OS. Prevalência de helmintos intrestinais em três mesorregiões do Estado de Minas Gerais. Rev Soc Bras Med Trop. 2002; 35(6):597-600.

14. Mathers CD, Gore FM, Pattom GC, Ferguson J, Sawyer SM. Global burden of disease in young people aged 10-24 years: authors' reply. Lancet. 2012; 379 (9810) : 377.

15. Barry MA, Simon GG, Mistry N, Hotez PJ. Global trends in neglected tropical disease control and elimination: impact on child health. Arch Dis Child. 2013. 98 (8): 635- 41.

16. Addum FM; Serra CG; Sessa KS; Izoton LM; SANTOS T B. Planejamento local, Saúde Ambiental e Estratégia Saúde da Família: uma análise do uso de ferramentas de gestão para a redução do risco de contaminação por enteroparasitoses no município de Venda Nova do Imigrante. Physis. 2011. 21 (3): 955- 978.

17. Busato MA.; Antoniolli MA. Relação de parasitoses intestinais com as condições de saneamento básico. Cienc Cuid Saude. 2014; 13(2): 357- 363.

18. Cimerman B, Cimerman S. Parasitologia humana e seus fundamentos gerais. 2. ed. São Paulo: Atheneu, 2010.

19. Melo MCB, Klem VGQ, Mota JAC, Penna FJ. Parasitoses intestinais. Rev Med Minas Gerais. 2004 Jan/Fev; 14(1):3-12.

20. Cunha, AS. Parasitoses intestinais. In: Dani, R. \& Castro, LP. Gastroenterologia clínica, 3. ed, Guanabara Koogan, Rio de Janeiro, 1993. p.971-91.

21. Rodrigues, LD. Diagnóstico clínico e laboratorial das parasitoses intestinais. 3. ed. São Paulo, Sarvier, 1983. p.200-3.

22. Chapter L, Cabeça M, Catapani WR. Parasitoses intestinais. Rev Bras Med, 1995, 51: 126-32.

23. Fabiani S, Bruschi F. Rheumatological patients undergoing immunosuppressive treatments and parasitic diseases: a review of the literature of clinical cases and 
perspectives to screen and follow-up active and latent chronic infections. Clin Exp Rheumatol 2014; 32: 587-596.

24. McSorley HJ, Maizels MR. Helminth infections and host immune regulation. Clinical Microbiology Reviews. 2012; 25(4):585-608.

25. DW Dunne, Cooke A. A worm's eye view of the immune system: consequências for evolution of human autoimmune disease. Nat Rev Immunol 2005; 5: 420-6.

26. Pineda MA, Al-Riyami L, Harnett W, Harnett MM. Lessons from helminth infections: ES-62 highlights new interventional approaches in rheumatoid arthritis. Clinical and Experimental Immunology. 2013; 177:13-23.

27. Greenwood BM, Herrick EM, Voller A. Can parasitic infection suppress autoimune disease? Proc Roy Soc Med. 1970; 63:19-20.

28. Rocha FAC, Leite AKRM, Pompeu MML, Cunha TM, Jr WAV, Soares FM et al. Protective effect of an extract from Ascaris suum in experimental arthritis models. Infection and Immunity. 2008; 76(6):2736-2745.

29. Mattsson L, Larsson P, Erlandsson-Harris H, Klareskog L, Harris RA. Parasitemediated down regulation of collagen-induced arthritis (CIA) in DA rats. Clinical and Experimental Immunology. 2000; 122:477-483.

30. Rocha FAC. Protective role of helminthiasis in the development of autoimune diseases. Clinical \& Developmental Immunology. 2006; 13(2-4):159-162.

31. He Y, Li J, Zhuang W, Yin L, Chen C, Li J et al. The inhibitory effect against collagen-induced arthritis by Schistosoma japonicum infection is infection stagedependent. BioMed Central Immunology. 2010; 11(28).

32. Osada Y, Kanazawa T. Parasitic helminths: new weapons against immunological disorders. Journal of Biomedicine and Biotechnology. 2009; 2010: article ID 743758.

33. Rzepecka J. Coates ML Saggar M, Al-Riyami L, Coltherd J, Tay HK, et al. Small molecule analogues of the immunomodulatory parasitic helminth product ES-62 antiallergy properties have. Int J Parasitol 2014; 44: 669-74.

34. Matisz CE, McDougall JJ, Sharkey KA, McKay DM. Helminth parasites and the modulation of joint inflammation. Journal of Parasitology research. 2011; 2011: article ID 942616.

35. Porto MAF, Muniz A, Júnior JO, Carvalho EM. Implicações clínicas e imunológicas da associação entre o HTLV-1 e a estrongiloidíase . Revista Brasileira de Medicina Tropical. 200235 (6): 641-649. 
36. Altintop L, Cakar B, Hokelek M, Bektas A, Yildiz L, Karaoglanoglu M. Strongyloides stercoralis hyperinfection in a patient with rheumatoid arthritis and bronchialasthma: a case report. Ann Clin Microbiol Antimicrobials. 2010;9:27.

37. Braz AS, et al. Recomendações da Sociedade Brasileira de Reumatologia sobre diagnóstico e tratamento das parasitoses intestinais em pacientes com doenças reumáticas autoimunes. Rev Bras Reumatol. 2015.

38. T. Evering and L. M. Weiss. The immunology of parasite infections in immunocompromised hosts.

Parasite Immunol. 2006 November ; 28(11): 549-565.

39. Porto MAF, Muniz A, Júnior JO, Carvalho EM. Implicações clínicas e imunológicas da associação entre o HTLV-1 e a estrongiloidíase . Revista Brasileira de Medicina Tropical. 200235 (6): 641-649.

40. Fabiani S, Bruschi F. Rheumatological patients undergoing immunosuppressive treatments and parasitic diseases: a review of the literature of clinical cases and perspectives to screen and follow-up active and latent chronic infections. Clin Exp Rheumatol 2014; 32: 587-596.

41. Favalli EG, Desiati $F$, Atzeni $F$ et al.: Serious infections during anti-TNF alpha treatment in rheumatoid arthritis patients. Autoimunn Rev 2009; 8: 266-73.

42. Faucherre M, Pazar B, So A, Rozier B. TNF alpha-inhibitors: infection risks? Pratical recommendations. Rev Med Suisse 2011; 7: 75-6, 78-9.

43. Shrestha NK, Khanal B, Sharma SK, Dhakal SS, Kanungo R. Primary amoebic meningoencephalitis in a patient with systemic lupus erythematosus. Scand $J$ Infect Dis. 2003;35(8):514-6.

44. Shirwadkar CG, Samant R, Sankhe M, Deshpande R, Yagi S, Schuster FL, et al. Acanthamoeba encephalitis in patient with systemic lupus, India. Emerg Infect Dis. 2006;12(6):984-6.

45. Buonfrate D, Mendez AD ,Angheben A, Gobbi FM, Ende JVD, et al. Severe strongyloidiasis: a systematic review of case reports. BMC Infectious Diseases. 2013;13(78):1.

46. Das $P$, Raghu $P$, Dinda AK, Garg P. Strongyloides hyperinfection in rheumatoid arthritis. Int J Surg Pathol. 2007;15(4):391-2. 
47. Altintop L, Cakar B, Hokelek M, Bektas A, Yildiz L, Karaoglanoglu M. Strongyloides stercoralis hyperinfection in a patient with rheumatoid arthritis and bronchialasthma: a case report. Ann Clin Microbiol Antimicrobials. 2010;9:27.

48. Bartalesi F, Bartoloni A, Bisoffi Z, Spinicci M at al. The emerging problem of biological treatment in migrant and travelling populations: it is time to extend guidelines for the screening of infectious diseases. Ann Rheum Dis 2014;73:794-796 49. Rzepecka J, Pineda MA, Al-Riyami L, Rodgers DT, Huggan JK, Lumb FE, et al. Prophylactic and therapeutic treatment with a synthetic analogue of a parasitic worm product prevents experimental arthritis and inhibits IL-1 $\beta$ production via NRF2mediated counter-regulation of the inflammasome. J Autoimmun 2015;60:59-73.

50. Al-Riyami L, Rodgers DT, Rzepecka J, Pineda MA, Suckling CJ, Harnett MM, et al. Protective effect of small molecule analogues of the Acanthocheilonema viteae secreted product ES-62 on oxazolone-induced ear inflammation. Exp Parasitol 2015. 51. Aprahamian TR, Zhong X, Amir S, Binder CJ, Chiang L-K, Al-Riyami L, et al. The immunomodulatory parasitic worm product ES-62 reduces lupus-associated accelerated atherosclerosis in a mouse model. Int J Parasitol 2015;45:203-7.

52. Rodgers DT, McGrath MA, Pineda MA, Al-Riyami L, Rzepecka J, Lumb F, et al. The parasitic worm product ES-62 targets myeloid differentiation factor 88dependent effector mechanisms to suppress antinuclear antibody production and proteinuria in MRL/lpr mice. Arthritis Rheumatol (Hoboken, NJ) 2015;67:1023-35.

53. Rocha FAC, Leite AKRM, Pompeu MML, Cunha TM, Verri W a., Soares FM, et al. Protective effect of an extract from Ascaris suum in experimental arthritis models. Infect Immun 2008;76:2736-45.

54. Egan CA, Houston KM, Alcocer MJC, Solovyova A, Tate R, Lochnit G, et al. Lack of immunological cross-reactivity between parasite-derived and recombinant forms of ES-62, a secreted protein of Acanthocheilonema viteae. Parasitology 2006;132:26374.

55. Greenwood BM, Herrick EM VA. Can parasitic infection suppress autoimune disease? Proc Roy Soc Med 1970;63:18-20.

56. Osada Y, Shimizu S, Kumagai T, Yamada S KT. Schistosoma mansoni infection reduces severity of collagen-induced arthritis via down-regulation of proinflammatory mediators. Int J Parasitol 2009;39:457-64. 
57. Itami DM, Oshiro TM, Araujo CA, Perini A, Martins MA, Macedo MS M-SM. Modulation of murine experimental asthma by Ascaris suum components. Clin Exp Allergy 2005;35:873-9.

58. Da Rocha FAC, Rocha FAC. Protective Role of Helminthiasis in the Development of Autoimmune Diseases. Clin Dev Immunol 2006;13:159-62.

59. Nagayama Y, Watanabe K, Niwa M, McLachlan SM, Rapoport B. Schistosoma mansoni and alpha-galactosylceramide: prophylactic effect of Th1 Immune suppression in a mouse model of Graves' hyperthyroidism. J Immunol 2004;173:2167-73.

60. La Flamme AC, Ruddenklau K, Bäckström BT. Schistosomiasis decreases central nervous system inflammation and alters the progression of experimental autoimmune encephalomyelitis. Infect Immun 2003;71:4996-5004.

61. Mattsson L, Larsson P, Erlandsson-Harris H, Klareskog L, Harris RA. Parasitemediated down-regulation of collagen-induced arthritis $(\mathrm{CIA})$ in DA rats. Clin Exp Immunol 2000;122:477-83.

62. Cooke A, Tonks P, Jones FM, O'Shea H, Hutchings P, Fulford AJ, et al. Infection with Schistosoma mansoni prevents insulin dependent diabetes mellitus in nonobese diabetic mice. Parasite Immunol 1999;21:169-76.

63. Arnett FC, Edworthy SM, Bloch DA, McShane DJ, Fries JF, Cooper NS et al. The American Rheumatism Association 1987 revised criteria for the classification of rheumatoid arthritis. Arthritis Reum 1988; 31:315.

64. Aletaha D, Neogi T, Silman AJ, Funovits J, Felson DT, Bingham CO, et al. 2010 Rheumatoid Arthritis Classification Criteria. An American College of Rheumatology/European League Against Rheumatism Collaborative Initiative. Arthritis Rheum 2010;62:2569-81.

65. De Carli, Geraldo Attilio. Parasitologia clínica: seleção de métodos e técnicas de laboratório para o diagnóstico das parasitoses humanas. 2ª edição. São Paulo: Atheneu, 2007

66. Masamune O, Takahashi T, Nagasaki A, Iwabuchi J, Ishikawa M. Diagnostic significance of the sudan III staining for fecal fat. Tohoku J Exp Med. 1977 Aug; 122 (4): 397-402.

67. Khouri MR, Huang G, Shiau YF. Sudan stain of fecal fat: new insight into an old test. Gastroenterology. 1989 Feb; 96 (2 Pt 1): 421-7. 
68. Nagata M, Tanaka T. Detection of fecal blood by colloidal gold agglutination using an anti-human hemoglobin monoclonal antibody. J Immunol Methods. 1992 Aug 30;153(1-2):185-92.

69. Aletaha D, Smolen JS.The Simplified Disease Activity Index (SDAI) and the Clinical Disease Activity Index (CDAI): a review of their usefulness and validity in rheumatoid arthritis. Clin Exp Rheumatol 2005; 23(Suppl. 39):S100-8.

70. Ferraz MB. Tradução para o português e validação do questionário para avaliar a capacidade funcional "Stanford Health Assessment Questionnaire" Doutorado [Tese]. São Paulo: Universidade Federal de São Paulo; Escola Paulista de Medicina; 1990.

71. Hosmer D.W, Lemeshow S (2000). Applied logistic regression $\left(2^{\text {nd }}\right)$. Chapter 4 pag. 95 John Wiley: New York

72. Barros AJ, Hirakata VN: Alternatives for logistic regression in crosssectional studies: an empirical comparison of models that directly estimate the prevalence ratio. BMC Med Res Methodol 2003, 3:21.

73. Allison P.D. (1999). Logistic Regression Using SAS - Theory and Application. North Caroline: SAS Institute. Chapter 3 pag. 48-51.

74. Marques-Neto JF, Goncalves ET, Langen LFOB, Cunha MFL, Radominski S, Oliveira SM et al. Multicentric study of the prevalence of adult rheumatoid arthritis in Brazilian population samples. Rev Bras Reumatol 1993; 33:169-73.

75. da Mota LM, dos Santos Neto LL, Burlingame R, Menard HA, Laurindo IM. Laboratory characteristics of a cohort of patients with early rheumatoid arthritis. Rev Bras Reumatol. Jul-Aug 2010;50(4):375-388.

76. da Mota LM, Laurindo IM, dos Santos Neto LL. Prospective evaluation of the quality of life in a cohort of patients with early rheumatoid arthritis. Rev Bras Reumatol. May-Jun 2010;50(3):249-261 .

77. da Mota LM, Laurindo IM, dos Santos Neto LL. Demographic and clinical characteristics of a cohort of patients with early rheumatoid arthritis. Rev Bras Reumatol. May-Jun 2010;50(3):235-248.

78. Silva CR, Costa TF, de Oliveira TT, Muniz LF, da Mota LM. Physical activity among patients from the Brasilia cohort of early rheumatoid arthritis. Rev Bras Reumatol. Sep-Oct 2013;53(5):394-399. 
79. Casavechia MT1, Lonardoni MV, Venazzi EA, Campanerut-Sá PA, da Costa Benalia HR, Mattiello MF el al. Prevalence and predictors associated with intestinal infections by protozoa and helminths in southern Brazil. Parasitol Res. 2016 Jun;115(6):2321-9.

80. Elisabeth Campos de Andrade EC, Leite ECG, Rodrigues VO. Parasitoses intestinais: uma revisão sobre seus aspectos sociais, epidemiológicos, clínicos e terapêuticos. Rev APS, Juiz Fora. 2010;13(2):231-40.

81. Pereira IGS, Rodrigues CS , Gurgel-Gonçalves R, Machado ER. Frequency of intestinal parasites and commensals in street waste pickers from two cooperatives in the Brazilian Federal District. Rev Patol Trop Vol. 2015; 44 (4): 432-440.

82. Maciel DF, Gurgel- Gonçalves R, Marchado ER. Ocorrência de parasitos intestinais em hortaliças comercializadas em feiras no Distrito Federal. Rev Patol Trop Vol. 2014; 43 (3): 351-359.

83. JA. W. Problems in recognition and diagnosis of amebiasis: estimation of the global magnitude of morbidity and mortality. Rev Infect Dis. 1986;8(2):228-38.

84. Santos FLN, Soares NM. Mecanismos fisiopatogênicos e diagnóstico laboratorial da infecção causada pela Entamoeba histolytica. J Bras Patol Med Lab. 2008; 44 (4): 249-261.

85. Scher JU, Littman DR, Abramson SB. Microbiome in Inflammatory Arthritis and Human Rheumatic Diseases. Arthritis Rheum 2016; 68(1): 35-45.

86. Evans WJ, Lambert CP. Physiological basis of fatigue. Am J Phys Med Rehabil 2007;86(1):529-46.

87. Norheim KB, Jonsson G, Omdal R. Biological mechanisms of chronic fatigue. Rheumatology 2011;50:1009-18.

88. Balsamo S, Diniz LR, Santos-Neto LLS, da Mota LMH. Exercise and Fatigue in Rheumatoid Arthritis. IMAJ 2014;16:57-60.

89. Rat A-C, Pouchot J, Fautrel B, Boumier P, Goupille P, Guillemin F. Factors associated with fatigue in early arthritis: results from a multicenter national French cohort study. Arthritis Care Res (Hoboken). 2012;64:1061-9.

90. Minnock P, Kirwan J, Bresnihan B. Fatigue is a reliable, sensitive and unique outcome measure in rheumatoid arthritis. Rheumatology (Oxford). 2009;48:1533-36 91. Rios Diniz, Leonardo. Fadiga em pacientes da coorte Brasília de artrite reumatoide $(A R)$-Estudo da prevalência e comparação entre diferentes instrumentos 
de avaliação. UNB, 2016. 164p. Dissertação (Mestrado)- Programa de Pós Graduação em Ciências Médicas, Faculdade de Medicina, Universidade de Brasília, Brasília, 2016.

92. Kievit W, Welsing PM, Adang EM, Eijsbouts AM et al. Comment on the use of self-reporting instruments to assess patients with rheumatoid arthritis: the longitudinal association between the DAS28 and the VAS general health. Arthritis Rheum. 2006 Oct 15; 55(5):745-50.

93. Voutilainen A Pitkäaho T, Kvist T, Vehviläinen-Julkunen K. How to ask about patient satisfaction? The visual analogue scale is less vulnerable to confounding factors and ceiling effect than a symmetric Likert scale. J Adv Nurs. 2016 Apr;72 (4):946-57.

94. Oliveira SM, Gomides AP, Mota LM, Lima CM, Rocha FA. Intestinal parasites infection: protective effect in rheumatoid arthritis? Rev Bras Reumatol. 2016 Jun 26. pii: S0482-5004(16)30035-3. doi: 10.1016/j.rbr.2016.04.002. 


\title{
ANEXO 1
}

\section{TERMO DE CONSENTIMENTO LIVRE E ESCLARECIDO HOSPITAL UNIVERSITÁRIO DE BRASÍLIA}

\begin{abstract}
Participação no Projeto: "Prevalência e fatores associados a enteroparasitoses em pacientes com artrite reumatoide"
\end{abstract}

\section{I - DADOS DE IDENTIFICAÇÃO DO SUJEITO DA PESQUISA}

Nome:

Identidade № :

Sexo: M F Nasc: I

Endereço:

Bairro: Cidade:

CEP: Telefone:

Convido você a participar do estudo chamado "Prevalência e fatores associados a enteroparasitoses em pacientes com artrite reumatoide" .

Trata-se de um estudo que vai avaliar a presença de parasitoses (verminoses) em pessoas com artrite reumatoide. O objetivo é tentar verificar quantas pessoas (pacientes) tem sintomas relacionados ao trato gastrointestinal (estômago e intestino), quantas pessoas tem os testes positivos para parasitoses (verminoses) e como isso afeta suas vidas. Para isso, o paciente terá que preencher questionários, realizar exames de sangue e fezes.

Os procedimentos do estudo serão coletas de informações à doença e realização dos exames (alguns deles já fazem parte da avaliação médica e 
seguimento de rotina com o seu médico). Todas as avaliações serão realizadas no Hospital Universitário de Brasília, sem qualquer custo para o paciente.

Não existe risco em participar deste estudo, pois as informações serão coletadas apenas através de questionários. As informações obtidas neste estudo provavelmente não terão relação direta com a sua doença ou com seu tratamento, mas poderão servir para compreender melhor a evolução das doenças autoimunes. Assim, estas informações poderão trazer benefícios para todos os pacientes com artrite reumatoide.

As informações obtidas serão de uso científico e não serão divulgadas para outros fins. Todos os dados referentes aos pacientes são confidenciais. Em nenhum momento haverá liberação de identidade ou quaisquer dados que possam levar à sua identificação.

A sua participação neste estudo é totalmente voluntária, e a sua recusa em participar não afetará de nenhuma maneira o relacionamento com o seu médico. Uma vez que você aceite participar do estudo, permanecerá com o direito de retirar seu consentimento a qualquer momento.

Para qualquer dúvida ou esclarecimento adicional, você posso entrar em contato com a pesquisadora Ana Paula Monteiro Gomides Reis, pelos telefones 3547-9493 ou 9339-9494, ou contatá-lo diretamente no endereço SGAN 604/605, Avenida L2 Norte, Hospital Universitário de Brasília, Ambulatório de Reumatologia, CEP:70919970. Ele poderá ser encontrado no corredor laranja, sala D, às quartasfeiras, das $8 \mathrm{~h}$ às 12 horas.

Declaro que recebi uma cópia deste termo de consentimento para ler antes de assiná-lo, que os detalhes do projeto foram explicados e que manterei uma cópia deste consentimento em meu pod

\section{Assinatura do sujeito da pesquisa / Data}

\section{Assinatura do pesquisador / Data}




\section{ANEXO 2 \\ ROtINA PARA TRATAMENTO DE PACIENTES COM DIAGNÓSTICO DE ARTRITE REUMATOIDE, ACOMPANHADOS NA COORTE BRASÍLIA DE ARTRITE REUMATOIDE.FACULDADE DE MEDICINA. HOSPITAL UNIVERSITÁRIO DE BRASÍLIA. SERVIÇO DE REUMATOLOGIA COORTE BRASÍLIA DE ARTRITE REUMATOIDE}

O tratamento da artrite reumatoide será clínico, fisioterápico e cirúrgico, quando necessário.

\section{Tratamento clínico:}

Os pacientes serão avaliados mensalmente, nos primeiros 6 meses de acompanhamento, e trimestralmente, após. Reavaliações mais frequentes poderão ser necessárias, a depender da condição clínica do paciente.

O tratamento medicamentoso consistirá de uso simultâneo de drogas antiinflamatórias de ação rápida, associado a drogas que modificam o curso evolutivo da doença. A escolha e a sequência do uso de drogas serão individualizadas a critério do médico assistente, mas seguirá preferencialmente as recomendações a seguir. Atentar desde início para sinais de pior prognóstico (elevado número de articulações acometidas, erosões radiográficas na fase inicial da doença e fator reumatóide e/ou anti-CCP em altos títulos). As doses da medicação em uso serão ajustadas ou o esquema terapêutico será trocado/ajustado a cada avaliação, caso o paciente não atinja a resposta terapêutica almejada (período máximo de 6 meses para definir ausência de resposta à primeira linha de tratamento instituída) ou apresente efeitos adversos decorrentes da terapia.

Objetivo do tratamento é que o paciente atinja, preferencialmente, remissão (DAS28 <2,6; SDAI $\leq 5$ e CDAI $\leq 2,8$ ), ou pelo menos um estado de baixa atividade de doença (DAS28 < 3,2, 5> SDAl $\leq 20$ e $2,8>$ CDAl $\leq 10$ ). A terapia 
medicamentosa será ajustada com a finalidade de se alcançar essa meta. Alvo almejado é o de boa resposta, ou seja, queda $>1,2$ no DAS28 com DAS-28 < 3,2; queda de 17 pontos no SDAI ou de 14 pontos no CDAI. Pode-se julgar aceitável, em alguns casos, o alvo de uma moderada resposta - queda de 0,6-1,2 pontos no DAS28 com declínio da atividade da doença de alta para moderada ou de moderada para baixa atividade; ou queda de 7 pontos no SDAI ou 6 pontos no CDAI.

O tratamento deverá ser otimizado também no caso de evolução radiográfica (importante solicitar radiografias articulares convencionais anualmente) ou atividade de doença ao Power-Doppler (caso ecografia com PD disponível).

Importante monitorar a cada consulta também a capacidade funcional do paciente (HAQ) e atentar para manifestações extra-articulares (nódulos reumatoides, doença pulmonar intersticial, serosites, inflamação ocular, vasculite, etc), comorbidades (HAS, DM, doença cardiovascular, osteoporose, depressão, fibromialgia, etc), infecções e efeitos colaterais das medicações para intervir nesses aspectos. Avaliar internação no caso de urgências relacionadas à doença, principalmente: escleromalácea perfurante, mielopatias, mononeurite múltipla, vasculite e gravidez em pacientes em uso de drogas teratogênicas.

\section{DROGAS ANTI-INFLAMATÓRIAS DE AÇÃO RÁPIDA:}

A opção por qualquer AINE dependerá da idade, da tolerância do paciente e do padronizado no HUB ou na rede de saúde pública. Deve-se ter a máxima cautela quanto a efeitos adversos.

\section{DROGAS ANALGÉSICAS:}

Utilizadas em todas as fases. Opção e doses conforme perfil do paciente e disponibilidade.

\section{ESTERÓIDES:}

Preferencialmente em doses baixas (até $15 \mathrm{mg} / \mathrm{dia}$ de prednisona ou equivalente), principalmente no início do tratamento e em períodos de atividade de 
doença enquanto ajustes medicamentosos são atingidos. Utilizar pelo menor tempo possível e, quando a dose exceder $5 \mathrm{mg} / \mathrm{dia}$, com uma previsão de uso superior a 3 meses, associar medidas de profilaxia para perda de massa óssea (cálcio, vitamina D e, em situações de maior risco, bisfosfonatos por via oral). Pode-se utilizar ainda corticoides por via parenteral (IM) ou infiltração intra-articular.

Os esteroides poderão ser usados como droga auxiliar em caso de artrite reumatoide grave com febre, tendência precoce à deformidades, grande proliferação sinovial, vasculite e envolvimento extra-articular.

Em caso de manifestações extra-articulares graves, incluindo manifestações pulmonares e vasculite reumatoide, poderá ser utilizada dose de prednisona ou equivalente de $1 \mathrm{mg} / \mathrm{kg} / \mathrm{dia}$, ou pulsoterapia com metilprednisolona.

DROGAS QUE MODIFICAM O CURSO EVOLUTIVO DA DOENÇA (DMCD): antimaláricos, metotrexato, sulfassalazina, leflunomida e sais de ouro.

O MTX deve ser a DMCD de primeira escolha. Havendo contraindicação, sulfassalazina ou leflunomida podem ser utilizadas como primeira opção. O uso de antimaláricos (difosfato de cloroquina e sulfato de hidroxicloroquina) pode ser indicado apenas para pacientes com doença leve ou artrite indiferenciada com baixo potencial erosivo. Em casos excepcionais, como pacientes com hipersensibilidade a outras DMCD ou com hepatite viral, sais de ouro podem ser utilizados.

O MTX deve ser prescrito preferencialmente em monoterapia, no início do tratamento, via oral, iniciando com 10-15 mg/sem até dose máxima de $25 \mathrm{mg} / \mathrm{sem}$. Fazer via parenteral se intolerância ou inabilidade de utilizar a medicação pela via oral (IM disponível no hospital). Fazer ácido fólico $5 \mathrm{mg}$ após 24-48 horas do MTX (aumentar dose caso eventos adversos) preferencialmente.

Após 3 meses, não havendo a resposta clínica objetivada (remissão ou baixa atividade da doença) com dose máxima tolerada de MTX ou na presença de efeitos adversos, recomenda-se o uso de combinações de DMCD ou a sua troca por outra DMCD em monoterapia.

As combinações mais utilizadas com MTX são: 
- leflunomida: dose 20 mg/dia. Primeira opção de combinação pela eficácia e comodidade posológica em relação à associação com SSZ. Reduzir dose do MTX quando associar Leflunomide pela potencial hepatotoxicidade e aumentar progressivamente conforme necessidade e tolerância (atentar se elevação de transaminases acima de 3 vezes o valor de referência, caso em que deverá ser suspenso; se elevação em até 3 vezes das transacionados, reduzir a dose). Caso toxicidade, fazer, para reversão farmacológica da leflunomida, $50 \mathrm{~g}$ de carvão ativado oral $6 / 6$ horas por $24 \mathrm{~h}$ e uso da coletivamente.

- sulfassalazina: $1 \mathrm{~g} /$ dia por 30 dias com elevação de 1 grama por mês até um máximo de $3 \mathrm{~g} /$ dia (segunda opção, ou primeira caso desejo de engravidar nos próximos 2 anos- período ideal sugerido sem LEF para gestação planejada).

- Avaliar terapia tripla (MTX 15-25 mg/sem+ HCLQ 400 mg/dia + SSZ 1 $\mathrm{g} /$ dia $\rightarrow 6$ sem $\rightarrow 2 \mathrm{~g} / \mathrm{dia}$ ) em caso de falha de terapia dupla ou fatores de mau prognóstico.

Caso antimaláricos sejam utilizados ( cloroquina e hidroxicloroquina), durante a gravidez/lactação, por exemplo, utilizar as doses: difosfato de cloroquina 4 $\mathrm{mg} / \mathrm{kg} / \mathrm{dia}$ (250 mg = $150 \mathrm{mg}$ de cloroquina base) e sulfato de hidroxicloroquina 6 $\mathrm{mg} / \mathrm{kg} / \mathrm{dia}$ (400 mg = 309,6 mg de hidroxicloroquina base). Fazer avaliações oftalmológicas de rotina para avaliar toxicidade ocular.

DROGAS MODIFICADORAS DA RESPOSTA BIOLÓGICA (DMCDs BIOLÓGICOS): Infliximabe, etanercepte, adalimumabe, rituximabe, abatacepte, golimumabe, certolizumabe pegol e tocilizumabe

Os agentes biológicos ficarão reservados para os pacientes que não responderem ao esquema terapêutico com drogas sintéticas nas doses recomendadas no período de 3-6 meses. Excepcionalmente, podem ser introduzidos precocemente se sinais de pior prognóstico, preferencialmente, associados ao metotrexato (dose mínima de $7,5 \mathrm{mg} / \mathrm{sem}$ ). $\mathrm{Na}$ impossibilidade do uso do MTX, avaliar associação com outra droga sintética, como leflunomida, 
sulfassalazina ou hidroxicloroquina. $\mathrm{Na}$ impossibilidade de uso concomitante com droga sintética, avaliar monoterapia (principalmente com tocilizumabe).

A sequência das drogas utilizadas dependerá da avaliação do médico assistente. Preferencialmente, após falha ao esquema terapêutico habitual com DMCD sintética, utilizar-se-á um agente anti-fator de necrose tumoral-TNF (infliximabe, etanercepte, adalimumabe, certolizumabe pegol e golimumabe) ou abatacepte ou tocilizumabe. Rituximabe como primeira escolha apenas quando contra-indicados outros biológicos (anti-TNF, abatacepte e tocilizumabe) e em casos especiais, principalmente se soropositivos para fator reumatoide e anti-CCP (linfoma associado, doenças neurológicas periféricas, neoplasias nos últimos 5 anos, vide preferências posteriormente).

Havendo ocorrência de efeitos adversos ou falha terapêutica do biológico (considerar período de 3-6 meses), trocar o biológico por: outro agente anti-TNF, abatacepte, rituximabe ou tocilizumabe.

Os pacientes que não responderem a esta terapêutica proposta, terão sua doença discutida em reuniões do setor, para que sejam usadas medidas adicionais.

\section{- Regime de uso dos biológicos:}

○ Infliximabe: $3 \mathrm{mg} / \mathrm{kg} /$ dose- infusão IV - dose inicial + reinfusões após 2 e 6 semanas, e após, a cada 8 semanas. Otimizar dose para 5 mg/kg e/ou reduzir intervalo para 6 semanas se resposta insuficiente. Infusão deverá ocorrer em 2 horas, com uso de anti-histamínico antes; se reação cutânea leve, reduzir velocidade de infusão.

- Etanercepte: 50 mg SC semanalmente. Pode- se ainda optar pela dose de $25 \mathrm{mg} \mathrm{SC}$ duas vezes por semana.

- Adalimumabe: $40 \mathrm{mg}$ SC quinzenalmente.

- Rituximabe: infusão IV de 1000 mg (duas infusões com intervalo de 14 dias), com reinfusões a depender da necessidade (intervalo mínimo de 6 meses). Preceder infusões com 100 mg de metilprednisolona IV 60 minutos antes, $1 \mathrm{~g}$ de paracetamol e anti-histamínico para diminuir gravidade e frequência de reações infusionais. Velocidade de infusão lenta na primeira infusão em especial pelo maior risco de reações infusionais. 
- Abatacepte: infusão IV, durante 30 minutos, na dose de 500 mg nos pacientes com menos de $60 \mathrm{~kg}, 750 \mathrm{mg}$ nos pacientes entre 60 e 100 $\mathrm{kg}$ e $1.000 \mathrm{mg}$ nos com mais de $100 \mathrm{~kg}$. A dose seguinte deve ser administrada duas a quatro semanas após a dose inicial, depois a cada quatro semanas.

- Certolizumabe pegol: $400 \mathrm{mg}$ SC nas semanas 0, 2 e 4. Após, $200 \mathrm{mg}$ SC a cada duas semanas ou $400 \mathrm{mg}$ mensalmente.

- Golimumabe: $50 \mathrm{mg}$ SC mensalmente.

○ Tocilizumabe: 8 mg/kg (máximo 800 mg) IV mensalmente.

- Preferência para escolha de biológico:

- Infliximabe : má aderência

○ etanercepte: desejo de engravidar, infecções de repetição. Hepatite C e HIV (pela menor meia vida)

○ adalimumabe: infecções de repetição

- golimumabe: quando houver falha secundária a outro anti-TNF

- certolizumabe-pegol: necessidade de rápido início de ação, pacientes que desejam engravidar

- tocilizumabe: FR/anti-CCP (-), grande elevação de provas de atividade inflamatória, anemia relacionada à $A R$

- abatacepte: FR/anti-CCP (-), pacientes com maior risco de infecção (idosos, por exemplo), para os quais a segurança é um aspecto prioritário, doenças neurológicas

○ rituximabe: $\mathrm{FR} /$ anti-CCP(+), linfoma, doenças neurológicas periféricas, neoplasias nos últimos 5 anos. Risco de TB (único biológico não associado a uma maior incidência de TB).

- Peculiaridades contra o uso de determinado biológico (situações em que se deve evitar drogas específicas)

- Anti-TNFs: ICC classes III-IV segundo a NYHA, gravidez/lactação, doença desmielinizante (neurite óptica, etc), neoplasias nos últimos 5 anos, TB ou risco de TB, infecção ativa. Atentar para: infecções 
principalmente por bacilos intracelulares e fungos, fenômenos autoimunes, lesões psoriasiformes ou agravamento de psoríase.

- Tocilizumabe: dislipidemia, plaquetopenia, neutropenia, doença diverticular do colon ou histórico de úlceras intestinais, infecção ativa. Ajustar doses de medicamentos concomitantes que sejam metabolizados via CYP450 3A4, 1A2 ou 2C9 (ex: atorvastatina, bloqueadores de canal de cálcio, teofilina, varfarina, fenitoína, ciclosporina, benzodiazepínicos).

- Abatacepte: DPOC

- Rituximabe: hepatite $B$, infecção ativa, reações infusionais

\section{- Retirada de medicações com remissão sustentada:}

Após remissão sustentada e na ausência de artrite em outras articulações não incluídas no DAS28, avaliar reduzir/retirar medicações com cautela.

1) Ordem retirada das medicações: anti-inflamatório $\rightarrow$ corticóide $\rightarrow$ DMCD sintética após manter remissão sustentada sem corticóide. Quando uso de DMCD biológica, retirar biológico mantendo DMCD sintética.

2) Retirada dos biológicos: reduzir dose e não suspender de uma vez, mantendo a dose da DMCD sintética (reduzir apenas se contraindicação ou intolerância).

Possibilidades de tentativa de retirada da DMCD biológica, se o paciente mantiver remissão sustentada após 6 meses:

a. infliximabe $=>$ espaçar dose para $10 \mathrm{sem}=>$ após 3 meses $=>12 \mathrm{sem}$ => após 3 meses $=>$ suspender

b. adalimumabe $=>$ espaçar dose para 3 sem $\Rightarrow$ após 3 meses $=>$ espaçar para $4 \mathrm{sem}=>$ após 3 meses $=>6 \mathrm{sem}=>$ suspender

c. etanercepte $=>$ espaçar dose para $2 \mathrm{sem}=>$ após 3 meses $=>3 \mathrm{sem}$ => após 3 meses $=>$ suspender

d. golimumabe => espaçar dose para 2 meses $=>$ após 3 meses => espaçar dose para 3 meses => suspender 
e. certolizumabe-pegol => espaçar dose para 2 meses $=>$ após 3 meses => espaçar dose para 3 meses $=>$ suspender

f. tocilizumabe $=>$ espaçar dose para 2 meses $=>$ após 3 meses $=>$ espaçar dose para 3 meses $=>$ suspender

g. abatacepte $=>$ espaçar dose para 2 meses $=>$ após 3 meses => espaçar dose para 3 meses => suspender

h. rituximabe: conforme atividade

3) Após 1 ano sem biológicos e em remissão, reduzir dose da DMCD sintética progressivamente. Sugestão: MTX 2,5 -5mg a cada 2-3 meses, SSZ 500mg a cada 2-3 meses ou da LEF $10 \mathrm{mg}=20 \mathrm{mg}$ em dias alternados)

\section{OUTRAS DROGAS IMUNOSSUPRESSORAS:}

ciclosporina $A$, azatioprina e ciclofosfamida

Avaliar uso associadas à corticoterapia em dose alta para manifestações extra-articulares graves, como doença reumatóide do pulmão e vasculite reumatoide; ainda podem ser úteis na AlJ e ciclosporina para síndrome de ativação macrofágica. Uso limitado destas medicações em função de eventos adversos de longo prazo e da superioridade terapêutica dos outros DMCDs.

\section{ABORDAGENS ADICIONAIS:}

\section{A) FERTILIDADE, CONTRACEPÇÃO, GESTAÇÃO E AMAMENTAÇÃO}

a. Aconselhamento gestacional importante.

i. Aguardar controle de atividade de doença para melhores desfechos.

ii. Orientar uso de contraceptivos adequados (por exemplo: azatioprina reduz efeito do DIU não hormonal e cautela com estrogênios quando risco de trombose). 
iii. Informar sobre medicações que possam desencadear infertilidade: sulfassalazina - redução na espermatogênese por até 2 meses após suspensão; ciclofosfamida - risco de falência gonadal em ambos os sexos, sendo maior o risco de falência ovariana permanente em mulheres > 30 anos (quando possível, avaliar congelamento de óvulos); MTX em altas doses oligospermia; e AINEs- prejudicam implantação do óvulo.

iv. Aconselhado uso de ácido fólico $5 \mathrm{mg} /$ dia antes da concepção e até pelo menos o final do $1^{\circ}$ trimestre.

v. Suspender em prazo adequado medicações teratogênicas/abortivas e imunossupressores quando atividade de doença permitir e/ou fazer quando possível medidas minimizadoras do risco de desfecho desfavorável quando gestação não planejada ocorrer em vigência da droga proibida. Idealmente, suspender antes de conceber: leflunomide em 2 anos-mínimo 2 meses (se engravidou usando LEF: colestiramina $8 \mathrm{~g}$ de $8 / 8 \mathrm{~h}$ por 11 dias ou até indetectável no sangue $<0,02 \mathrm{~g} / \mathrm{ml}$ em 2 ocasiões com 14 dias de intervalo); metotrexato em 3 meses (se engravidou usando MTX: ácido fólico $10 \mathrm{mg} / \mathrm{d}$ ); micofenolato de mofetila em 6 meses; abatacepte em 10 semanas; tocilizumabe em 3 meses; e rituximabe em 6 meses. Ainda são proibidos: AINEs seletivos para COX-2, penicilamina, ciclofosfamida (pode ser cogitada no $2^{\circ}$ e $3^{\circ}$ trimestres quando risco de vida por manifestação extraregulamentar, talidomida, bosentana, varfarina (teratogênica da

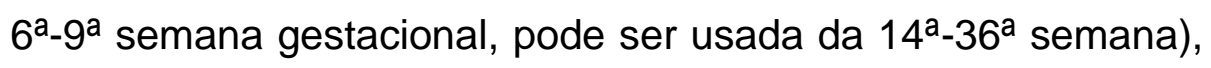
bisfosfonatos, colchicina, IECA, inibidores da angiotensina II, inibidor da endotelina e estatinas. Suspender a princípio biológicos imediatamente caso gestação não planejada, porém passagem transplacentária apenas com IG 12 semanas e antiTNF são categoria $B$, daí decisão compartilhada.

b. Gestação em curso. Pode: prednisona dose baixa (para parto aconselha-se hidrocortisona $100 \mathrm{mg} 8 / 8 \mathrm{~h}$ por 3 dias como proteção 
adrenal); sulfassalazina $\leq 2 \mathrm{~g} / \mathrm{d}$ associada a ácido fólico $5 \mathrm{mg} / \mathrm{d}$ (evitar nas últimas 2 semanas gestacionais pelo risco de icterícia neonatal); hidroxicloroquina; sais de ouro podem ser mantidos; paracetamol; AINEs (cautela principalmente no $3^{\circ}$ trimestre, em especial após a $32^{\underline{a}}$ semana). Anti-TNF devem ser evitados.

c. Puerpério e Amamentação: risco de reativação da doença. Permitidos cronicamente: paracetamol, ibuprofeno ou diclofenaco orais (preferencialmente pós-mamada ou pré-sono do bebê ou estocar leite no intervalo) ou tópico, corticóide, sulfassalazina, hidroxicloroquina ou cloroquina, sais de ouro, heparina e varfarina. Excepcionalmente, antiTNF e rituximabe permitidos. Evitar aleitamento com uso de: leflunomide, metotrexato, micofenolato, azatioprina, betametasona ou dexametasona, ciclofosfamida, penicilamina, pilocarpina, cevimelina, ciclosporina (possível), valdecoxibe e celocoxibe.

\section{B) VACINAÇÃO:}

a. Avaliar situação vacinal do paciente e atualizar cartão vacinal preferencialmente 2-4 semanas antes de iniciar terapia imunossupressora (4 semanas no caso do rituximabe). Encaminhar a centro de vacinação/imunização para: influenza sazonal e H1N1 anuais, antipneumocócica a cada 5 anos, HPV em adolescentes e mulheres jovens, antimeningocócica se asplenia ou deficiência de complemento, Haemophilus influenzae tipo B em adultos asplênicos, hepatite $A$ combinada com hepatite $B$ e tríplice acelular, além de vacinas específicas do calendário vacinal vigente na região.

b. Vacinas com componentes vivos atenuados a princípio estão contraindicadas durante 0 tratamento com fármacos imunossupressores. Exemplo: febre amarela, influenza intranasal, tríplice viral SCR, rotavírus, febre tifoide oral, pólio oral VOP, varicela e hérpes zoster.

c. Respeitar intervalo de descontinuidade de imunossupressores para utilização de vacinas vivas atenuadas, quando forem utilizadas em casos excepcionais como, por exemplo, viagem para determinada 
local com elevado risco de contágio, discutindo a decisão com o paciente (exceto: metotrexato, leflunomide, sulfassalazina e antimaláricos que não necessitam desse intervalo): 4 semanas para corticoides ( $\mathrm{se}>20 \mathrm{mg} / \mathrm{dia}$ ); 3 meses para antiproliferativos (azatioprina e ciclofosfamida) e inibidores de calcineurinas (ciclosporina e tacrolimus); cinco meias-vidas para os biológicos (5 dias para etanercepte, 9 dias para infliximabe, 13 dias para tocilizumabe, 14 dias para golimumabe, certolizumabe, adalimumabee abatacepte e 21 dias para belimumabe, ustequinumabe e canaquinumabe), exceto 6 meses no caso de rituximabe.

d. Checar anti-HBs 30-60 dias após terceira dose e anualmente. Quando não soroconversão, repetir esquema de 3 doses em 30-60 dias. Se segundo esquema falhar, considerar não-respondedor e fazer imunoglobulina caso exposição.

e. Avaliar situação vacinal dos contactantes se possível. Se utilizaram vacinas vivas, tentar evitar contato com imunossuprimido por 4 semanas. Indicadas aos contactantes: influenza, febre amarela, tríplice bacteriana dTPa, tríplice viral SCR e varicela (se rash pós-vacinal, afastar imunodeprimido até desaparecimento do sintoma). Ainda, hepatite A e B para contactantes de hepatopatas e rotavírus para crianças contactantes. Podem ser feitas ainda: herpes zoster (se rash pós-vacinal, afastar imunodeprimido até desaparecimento do sintoma) e febre tifoide oral. Contra-indicadas: pólio oral -VOP (fazer a inativada - VIP).

f. Recém-nascidos de mães que receberam biológicos na gestação, adiar vacinação com componentes vivos por 4 meses (etanercepte), cinco meses (adalimumabe) e seis meses (infliximabe, golimumabe e rituximabe).

C) TUBERCULOSE, HIV E HEPATITES B E C: avaliar sintomas sugestivos de doença e solicitar sorologias (HIV 1 e 2, HBsAg, anti-HBs, anti-HBc e anti$\mathrm{HCV}$ ), PPD e radiografia de tórax preferencialmente antes da imunossupressão, especialmente no caso de biológicos. 
a. TB. Se sintomáticos, exposição a doentes ou imagem radiográfica suspeita ou de sequela de TB com PPD reator ( $\geq 5 \mathrm{~mm}$ ), encaminhar para avaliação com especialista (pneumologista, infectologista ou médico do Programa de tuberculose da rede básica de saúde) antes do imunossupressor, principalmente com anti-TNF. Se sequela radiográfica de TB pulmonar (com PPD não reator) ou PPD reator (com radiografia de tórax normal), fazer quimioprofilaxia com Isoniazida $5-10 \mathrm{mg} / \mathrm{kg} / \mathrm{d}$ até $300 \mathrm{mg}$ por 6 meses (avaliar introdução do biológico após 1 mês, excepcionalmente concomitante quando doença grave). Repetir PPD a cada 2-3 anos se persistir imunossupressão ou reexposição a focos bacilíferos (não repetir exame com $<12$ meses para evitar efeito booster). Avaliar necessidade a cada caso de TC tórax, cultura específica de escarro ou lavado broncoalveolar e IGRA. O tratamento da TB ativa deverá ser completado antes dos biológicos, conforme recomendações do Ministério da Saúde: regime 2 RHZE na fase intensiva por 2 meses (rifampicina 150/ isoniazida 75/pirazinamida 400/ etambutol $275 \mathrm{mg}$; $50 \mathrm{~kg}=4$ comprimidos/dia, $2 \mathrm{~h}$ após café da manhã, com copo de água) e $4 \mathrm{RH}$ na fase de manutenção por 4 meses (rifampicina 150/ isoniazida 100; $>50 \mathrm{~kg}=2$ cápsulas/dia). Se desenvolveu TB na vigência do biológico, suspender biológico imediatamente e tratar conforme acima; sendo que $\mathrm{O}$ biológico só poderá ser reintroduzido após completado tratamento e afastada possível fonte de contato quando identificada.

b. Hepatite B: reativação do HBV pode ser fatal com anti-TNF. Se anti$\mathrm{HBc}$, monitorar e, se hepatite B oculta, avaliar profilaxia antiviral. Tratamento antiviral concomitante (1 semana antes do início do imunossupressor) e avaliação periódica da carga viral recomendados para todos os biológicos.

c. Hepatite C: casos de reativação do HCV, consultar com especialista e avaliação periódica da carga viral. Etanercepte e ciclosporina A seriam melhores opções. 
d. HIV. CD4> 200, considerar imunobiológico possível. Anti-TNF concomitante à terapia antiretroviral. Monitorar carga viral e CD4. Etanercepte preferível.

D) EDUCAÇÃO DO PACIENTE E FAMILIARES: a cada consulta orientar quanto a fontes seguras de informação e grupos de apoio. Ingestão e manipulação de alimentos, evitar exploração de cavernas, sótãos e porões, repelentes para insetos, observar micoses em pregas cutâneas, evitar contato com doentes, etc. Orientar atividade física regular e dieta apropriada.

E) OUTROS: Avaliar sinovectomia radioisotópica (radiossinoviórtese) em casos especiais. Terapia psicológica de forma individualizada para casos especiais. Abordagens de medicina alternativa carecem de evidência científica que as indiquem.

\section{Tratamento fisioterápico e terapia ocupacional:}

Será individualizado para cada paciente e para cada articulação, devendo ser estimulado e prescrito deste o início. Reabilitação, indicação de órteses e orientação quanto a proteção articular e conservação de energia.

\section{Tratamento cirúrgico}

Se DMCD sintética, preferencialmente, manter os imunossupressores, mas a decisão será individualizada. Se uso biológicos, no caso de cirurgias eletivas (ortopédicas ou não), suspendê-lo por 3-5 meias-vidas, porém considerando o risco de piora da atividade de doençasa: 2 semanas para etanercepte; 4-7 semanas para infliximabe; 8-10 semanas para adalimumabe, golimumabe, tocilizumabe e certolizumabe; 8-12 semanas para abatacepte; e 20-24 semanas para rituximabe (este também associado a risco maior de complicações em cirurgia de coluna). 


\section{ANEXO 3}

\section{FORMULÁRIO DE COLETA DE DADOS}

“"'Prevalência e fatores associados a enteroparasitoses em pacientes com artrite reumatoide"

Data:

Número de Registro na pesquisa:

Número de Registro no HUB:

\section{1) IDENTIFICAÇÃO}

Nome:

Data de nascimento:

Endereço:

Telefone:

Outras informações de contato:

\section{2) SEXO}

$\begin{array}{ll}\text { ( ) feminino } & \text { 2. ( ) masculino }\end{array}$

3) COR
( ) branco
2. ( ) negro
3. ( ) pardo
4. ( ) amarelo

4) ESCOLARIDADE:

5) ESTADO CIVIL
( ) solteiro 2.( ) casado
3. ( ) divorciado/separado
4. ( ) outros

6) PROFISSÃO/ OCUPAÇÃO: 
6.1) Possui vínculo de emprego atual ? :
1. ( ) Não
2. ( ) Sim
3. ( ) Autônomo
4. ( ) Aposentado

Se sim, especificar :
a) Local:
b) Tempo do vínculo trabalhista atual:
c) Outras informações relevantes sobre o trabalho:

6.2) Já teve afastamento do trabalho por doença?
1. ( ) Não
2. ( ) Sim
3. ( ) Não se aplica

Se sim, especificar:

a) Encontra-se afastado do trabalho atualmente?
1. ( ) Não
2. ( ) Sim

b) Número de vezes que já afastou do trabalho ?
1. ( ) 1 a 2 vezes
2. ( ) 3 a 5 vezes
3. ( $)>5$ vezes
c) Tempo máximo do afastamento:

6.3) Já houve reabilitação profissional ou mudança de função em virtude da doença ou sequelas?
1. ( ) Não
2. ( ) Sim

6.4) Com que frequência comparece ao trabalho mas percebe que não realizou sua função adequadamente?

1. ( ) Nunca 2. ( ) Raramente 3. ( ) Algumas vezes 4. ( ) Muito frequentemente

\section{7) CARACTERÍSTICAS DA RESIDÊNCIA:}


Número de residentes no domicílio: ( )1 ( ) 2 ( )3 ( ) ( ) Mais de 4 Construção: ( ) madeira ( ) alvenaria ( )condições insuficientes Localidade: ( ) urbana ( ) rural Número de cômodos: ( )1 ( ) 2 ( ) 3 ( ) 4 ( ) Mais de 4 Existe banheiro?: ( ) sim ( )não

Destino das fezes: ( ) rede de esgoto ( ) fossa ( ) céu aberto )outro

Procedência da água: ( ) água encanada ( ) filtrada ( ) pote ( ) outro

Presença de animais domésticos? ( )não ( )sim Qual?

\section{8) RENDA}

Renda mensal da família ou individual:

( ) menor que um salário ( )um salário ( ) mais que dois salários

\section{9) CARACTERÍSITCAS ALIMENTARES}

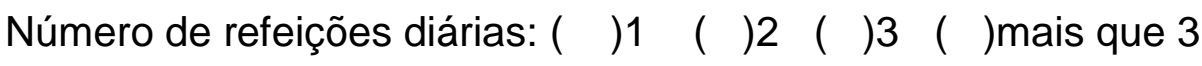

Tipo de alimentação:

Frutas: ( )não ( )sim

Verduras: ( )não ( )sim.

Carnes: ( ) não ( )sim Tipo: ( ) cozida ou assada ( ) crua

\section{0) MEDIDAS DE HIGIENE}

Realiza higienização das frutas e verduras?

( )não ( ) sim. Como?

Anda descalço: ( )não ( )sim

Lavagem das mãos:

( )depois de utilizar o banheiro

( ) antes de preparar os alimentos

( ) antes das refeições 


\section{1) MANIFESTAÇÕES CLÍNICAS RELACIONADAS A AR}

Data do início dos sintomas:

Data do diagnóstico:

Data do início do tratamento:

Forma de início dos sintomas: 1. ( ) agudo 2 ( ) insidioso

Critérios:

Acometimento articular:( ) monoarticular 2. ( ) oligoarticular 3.( ) poliarticular Sintomas atuais:

Duração da rigidez matinal:

Manifestações sistêmicas/extra-articulares: Qual (s):

1. ( ) Não

2. ( ) Sim

Outras manifestações:

( ) fadiga ( ) anemia ( ) fenômeno de Raynaud ( ) vasculite cutânea ( ) vasculite sistêmica ( ) úlceras de membros inferiores ( ) manifestações pulmonares ( ) manifestações oculares ( ) manifestações cardíacas ( ) neuropatia periférica ( ) fibromialgia ( ) sintomas depressivos ( ) síndrome sicca ( ) outra

Tratamentos realizados e tratamento atual:

12) HISTÓRIA PATOLÓGICA PREGRESSA

( )HAS ( )ICC ( ) DM ( )neoplasias ( )tuberculose ( ) Outras Qual (s): 
13) HÁBITOS DE VIDA

Tabagismo: 1. ( ) Não

2. ( ) Sim Quantidade:

Etilismo: 1. ( ) Não

2. ( ) Sim Quantidade:

Atividade física: 1. ( ) Não

2. ( ) Sim Tipo e frequência:

14) HISTÓRIA FAMILIAR

AR: $\quad$ 1. ( ) Não

2. ( ) Sim

Outras doenças autoimunes:

1. ( ) Não

2. ( ) Sim Qual (s) :

Outras:

15) EXAME Físıco

15.1) Sinais vitais

15.2) Exame físico geral

16.3) Avaliação osteoarticular

DOR ARTICULAR ARTRITE 


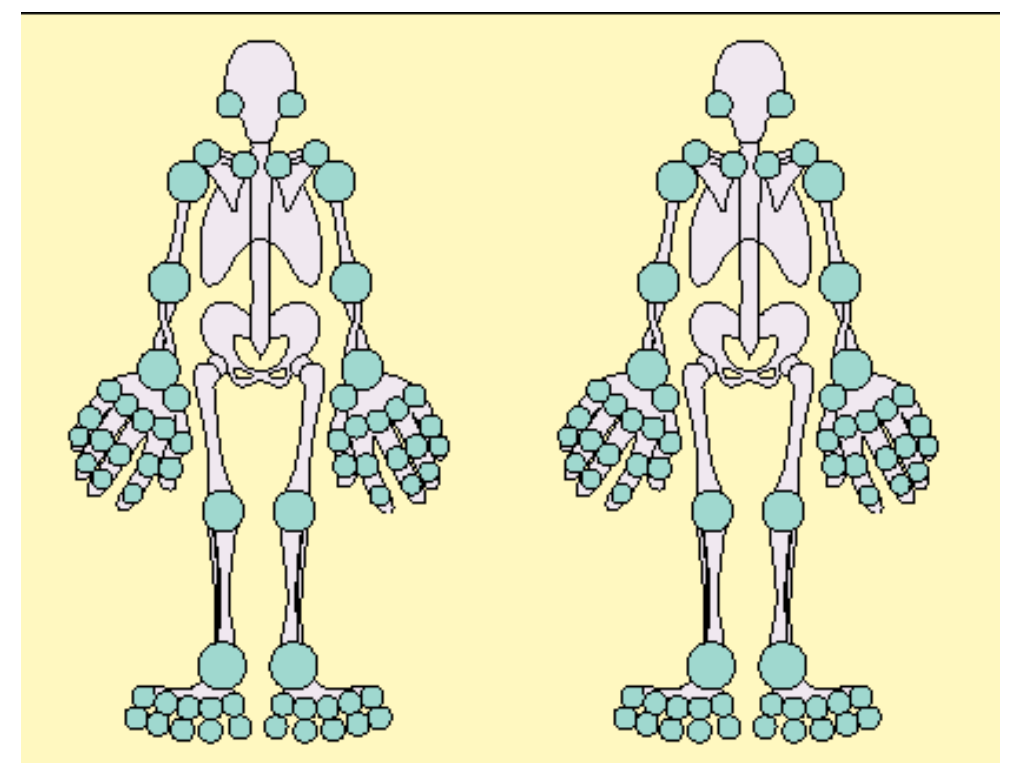

Contagem das Articulações Doloridas e Inflamadas (28 articulações)

\begin{tabular}{|c|c|c|c|c|c|}
\hline & \multicolumn{2}{|c|}{ Esquerdo } & \multicolumn{2}{|c|}{ Direito } \\
\hline & & Edema & Dor & Edema & Dor \\
\hline \multicolumn{6}{|c|}{ Ombro } \\
\hline \multicolumn{6}{|c|}{ Cotovelo } \\
\hline \multicolumn{6}{|c|}{\begin{tabular}{|l|} 
Punho \\
\end{tabular}} \\
\hline \multirow{5}{*}{$\begin{array}{l}\mathrm{MC} \\
\mathrm{F}\end{array}$} & 1 & & & & \\
\hline & 2 & & & & \\
\hline & 3 & & & & \\
\hline & 4 & & & & \\
\hline & 5 & & & & \\
\hline \multirow[t]{5}{*}{ IFP } & 1 & & & & \\
\hline & 2 & & & & \\
\hline & 3 & & & & \\
\hline & 4 & & & & \\
\hline & 5 & & & & \\
\hline \multicolumn{6}{|c|}{ Joelho } \\
\hline \multicolumn{6}{|c|}{ Subtotal } \\
\hline Tot & & Edema & & Dor & \\
\hline
\end{tabular}


16) AVALIAÇÃO NUTRICIONAL

Peso:

Altura:

IMC:

17) EXAMES COMPLEMENTARES

17.1) EXAMES LABORATORIAIS

HEMOGRAMA

VHS

PCR

FATOR REUMATÓIDE

ANTI- CCP

18) EXAME PARASITOLÓGICO DE FEZES

19) PESQUISA DE SANGUE OCULTO NAS FEZES E GORDURA FECAL 


\section{ANEXO 4}

\section{Critério de Classificação Econômica Brasil (CCEB) da Associação Brasileira de Empresas de Pesquisa (ABEP)}

\section{Modelo de Questionário sugerido para aplicação}

Entrevistador: "Agora vou fazer algumas perguntas sobre itens do domicilio para efeito de classificação econômica. Todos os itens de eletroeletrônicos que vou citar devem estar funcionando, incluindo os que estão guardados. Caso não estejam funcionando, considere apenas se tiver intenção de consertar ou repor nos próximos seis meses."

Vamos começar? No domicílio tem (LEIA CADA ITEM)

\begin{tabular}{|c|c|c|c|c|c|}
\hline & & & $\begin{array}{l}\text { UA } \\
\text { DE } \\
\text { DO }\end{array}$ & $\begin{array}{l}\text { ITII } \\
\text { QUI } \\
\text { SU }\end{array}$ & \\
\hline ITENS DE CONFORTO & $\begin{array}{l}\text { NÃO } \\
\text { POS } \\
\text { SUI }\end{array}$ & 1 & 2 & 3 & $\begin{array}{l}4 \\
+\end{array}$ \\
\hline $\begin{array}{l}\text { Quantidade de automóveis de passeio exclusivamente para } \\
\text { uso particular }\end{array}$ & & & & & \\
\hline $\begin{array}{l}\text { Quantidade de empregados mensalistas, considerando } \\
\text { apenas os que trabalham pelo menos cinco dias por semana }\end{array}$ & & & & & \\
\hline Quantidade de máquinas de lavar roupa, excluindo tanquinho & & & & & \\
\hline Quantidade de banheiros & & & & & \\
\hline $\begin{array}{l}\text { DVD, incluindo qualquer dispositivo que leia DVD e } \\
\text { desconsiderando DVD de automóvel }\end{array}$ & & & & & \\
\hline Quantidade de geladeiras & & & & & \\
\hline $\begin{array}{l}\text { Quantidade de freezers independentes ou parte da geladeira } \\
\text { duplex }\end{array}$ & & & & & \\
\hline Quantidade de microcomputadores, considerando & & & & & \\
\hline
\end{tabular}




\begin{tabular}{|l|l|l|l|l|}
\hline $\begin{array}{l}\text { computadores de mesa, laptops, notebooks e netbooks e } \\
\text { desconsiderando tablets, palms ou smartphones }\end{array}$ & & & \\
\hline Quantidade de lavadora de louças & & & & \\
\hline Quantidade de fornos de micro-ondas & & & \\
\hline $\begin{array}{l}\text { Quantidade de motocicletas, desconsiderando as usadas } \\
\text { exclusivamente para uso profissional }\end{array}$ & & & \\
\hline $\begin{array}{l}\text { Quantidade de máquinas secadoras de roupas, considerando } \\
\text { lava e seca }\end{array}$ & & & & \\
\hline
\end{tabular}

\begin{tabular}{|c|l|}
\hline \multicolumn{2}{|c|}{ A água utilizada neste domicílio é proveniente de? } \\
\hline ( ) 1 & Rede geral de distribuição \\
\hline ( ) 2 & Poço ou nascente \\
\hline ( ) 3 & Outro meio \\
\hline
\end{tabular}

Considerando o trecho da rua do seu domicílio, você diria que a rua é:

\begin{tabular}{|l|l|}
\hline ( ) 1 & Asfaltada/Pavimentada \\
\hline ( ) 2 & Terra/Cascalho \\
\hline
\end{tabular}

Qual é o grau de instrução do chefe da família? Considere como chefe da família a pessoa que contribui com a maior parte da renda do domicílio.

\begin{tabular}{|l|l|}
\hline Nomenclatura atual & Nomenclatura anterior \\
\hline ( ) Analfabeto / Fundamental I incompleto & Analfabeto / Primário Incompleto \\
\hline $\begin{array}{l}\text { ( ) Fundamental I completo / Fundamental II } \\
\text { incompleto }\end{array}$ & $\begin{array}{l}\text { Primário Completo / Ginásio } \\
\text { Incompleto }\end{array}$ \\
\hline ( ) Fundamental completo/Médio incompleto & $\begin{array}{l}\text { Ginásio Completo / Colegial } \\
\text { Incompleto }\end{array}$ \\
\hline ( ) Médio completo / Superior incompleto & $\begin{array}{l}\text { Colegial Completo / Superior } \\
\text { Incompleto }\end{array}$ \\
\hline ( ) Superior completo & Superior Completo \\
\hline
\end{tabular}




\section{Procedimentos da coleta de itens}

É importante e necessário que o critério seja aplicado de forma uniforme e precisa. Para tanto, é fundamental atender integralmente as definições e procedimentos citados a seguir.

Para aparelhos domésticos em geral:

Devem ser considerados todos os bens que estão dentro do domicílio em funcionamento (incluindo os que estão guardados) independente da forma de aquisição: compra, empréstimo, aluguel, etc. Se o domicílio possui um bem que emprestou a outro, este não deve ser contado pois não está em seu domicílio atualmente. Caso não estejam funcionando, considere apenas se tiver intenção de consertar ou repor nos próximos seis meses.

\section{Banheiro}

O que define o banheiro é a existência de vaso sanitário. Considerar todos os banheiros e lavabos com vaso sanitário, incluindo os de empregada, os localizados fora de casa e os da(s) suíte(s). Para ser considerado, o banheiro tem que ser privativo do domicílio. Banheiros coletivos (que servem a mais de uma habitação) não devem ser considerados.

\section{Empregados Domésticos}

Considerar apenas os empregados mensalistas, isto é, aqueles que trabalham pelo menos cinco dias por semana, durmam ou não no emprego. Não esqueça de incluir babás, motoristas, cozinheiras, copeiras, arrumadeiras, considerando sempre os mensalistas.

Note bem: o termo empregado mensalista se refere aos empregados que trabalham no domicílio de forma permanente e/ou continua, pelo menos cinco dias por semana, e não ao regime de pagamento do salário.

\section{Automóvel}

Não considerar táxis, vans ou pick-ups usados para fretes, ou qualquer veículo usado para atividades profissionais. Veículos de uso misto (pessoal e profissional) não devem ser considerados.

\section{Microcomputador}

Considerar os computadores de mesa, laptops, notebooks e netbooks. Não considerar: calculadoras, agendas eletrônicas, tablets, palms, smartphones e outros aparelhos. 


\section{Lava-Louça}

Considere a máquina com função de lavar as louças.

\section{Geladeira e Freezer}

No quadro de pontuação há duas linhas independentes para assinalar a posse de geladeira e freezer respectivamente. A pontuação será aplicada de forma independente:

Havendo uma geladeira no domićlio, serão atribuídos os pontos correspondentes a posse de geladeira;

$\mathrm{Se}$ a geladeira tiver um freezer incorporado - 2a porta - ou houver no domicílio um freezer independente serão atribuídos os pontos (2) correspondentes ao freezer. Dessa forma, esse domicílio totaliza 4 pontos na soma desses dois bens.

\section{Lava-Roupa}

Considerar máquina de lavar roupa, somente as máquinas automáticas e/ou semiautomática. O tanquinho NÃO deve ser considerado.

\section{DVD}

Considere como leitor de DVD (Disco Digital de Vídeo ou Disco Digital Versátil) o acessório doméstico capaz de reproduzir mídias no formato DVD ou outros formatos mais modernos, incluindo videogames, computadores, notebooks. Inclua os aparelhos portáteis e os acoplados em microcomputadores. Não considere DVD de automóvel.

\section{Micro-ondas}

Considerar forno micro-ondas e aparelho com dupla função (de microondas e forno elétrico).

\section{Motocicleta}

Não considerar motocicletas usadas exclusivamente para atividades profissionais. Motocicletas apenas para uso pessoal e de uso misto (pessoal e profissional) devem ser consideradas.

\section{Secadora de roupas}

Considerar a máquina de secar roupa. Existem máquinas que fazem duas funções, lavar e secar. Nesses casos, devemos considerar esse equipamento como uma máquina de lavar e como uma 


\section{ANEXO 5 DAS 28, SDAI e CDAI}

Contagem de articulações com edema (0-28)

Contagem de articulações com dor (0-28)

VHS $\left(\mathrm{mm} / 1^{\text {a }}\right.$ hora $)$

Avaliação da atividade da doença $(0-100 \mathrm{~mm})$

Cálculo do DAS $28=(0,56 \times \sqrt{ }$ dor $28+0,28 \times \sqrt{ }$ edema $28+0,70 \times$ VHS $+0,014 \times$ avaliação global do paciente)

VALORES DO DAS 28- ( 0 a 9,3 )

$>5,5$ - alta atividade

$>3,6$ e $\leq 5,5$ - moderada atividade

$>2,4$ e $\leq 3,6$ - baixa atividade

$\leq 2,4-$ remissão

Resultado SDAI=

Resultado CDAl= 


\section{ANEXO 6 ESCALAS VISUAIS ANALÓGICAS}

\section{Avaliação global da dor}

Em média, quanta dor você sentiu na última semana devido a sua doença?

Sem Dor

Dor Insuportável

Valor em mm:

\section{Avaliação global da fadiga}

Em média, quanta fadiga você sentiu na última semana?

Sem Fadiga

Fadiga Insuportável

Valor em $\mathrm{mm}$ :

Avaliação global da atividade da doença - Paciente

Considerando todas as formas como a artrite te afeta, em média, como você tem se sentido nos últimos 6 meses?

Sem atividade

Atividade máxima

Valor em $\mathrm{mm}$ :

Avaliação do estado geral de saúde hoje - Paciente

Considerando seu estado geral de saúde, como você tem se sentido na última semana? 
Valor em mm:

\section{Avaliação global da atividade da doença - Médico}

Como você avalia a atividade da artrite do seu paciente?

Sem atividade

Atividade máxima

Valor em mm:

\section{ANEXO 7}

Questionário de Capacidade Funcional - HAQ

\begin{tabular}{|l|l|l|l|l|}
\hline & $\begin{array}{l}\text { Sem } \\
\text { dificuldade }\end{array}$ & $\begin{array}{l}\text { Com } \\
\text { alguma } \\
\text { dificuldade }\end{array}$ & $\begin{array}{l}\text { Com } \\
\text { muita } \\
\text { dificuldade }\end{array}$ & $\begin{array}{l}\text { Incapaz } \\
\text { de fazer }\end{array}$ \\
\hline $\begin{array}{l}\text { 01. Vestir-se, inclusive amarrar os } \\
\text { cordões dos seus sapatos, } \\
\text { abotoar as suas roupas? }\end{array}$ & 0 & 1 & 2 & 3 \\
\hline $\begin{array}{l}\text { 02. Lavar a sua cabeça e seus } \\
\text { cabelos? }\end{array}$ & 0 & 1 & 2 & 3 \\
\hline $\begin{array}{l}\text { 03. Levantar-se de uma maneira } \\
\text { ereta de uma cadeira de encosto } \\
\text { reto e sem braços? }\end{array}$ & 0 & 1 & 2 & 3 \\
\hline
\end{tabular}




\begin{tabular}{|c|c|c|c|c|}
\hline $\begin{array}{l}\text { 04. Deitar-se e levantar-se da } \\
\text { cama? }\end{array}$ & 0 & 1 & 2 & 3 \\
\hline 05. Cortar um pedaço de carne? & 0 & 1 & 2 & 3 \\
\hline $\begin{array}{l}\text { 06. Levar a boca um copo ou uma } \\
\text { xícara cheia de café, leite ou } \\
\text { água? }\end{array}$ & 0 & 1 & 2 & 3 \\
\hline $\begin{array}{l}07 . \text { Abrir um saco de leite } \\
\text { comum? }\end{array}$ & 0 & 1 & 2 & 3 \\
\hline 08. Caminhar em lugares planos? & 0 & 1 & 2 & 3 \\
\hline 09. Subir cinco degraus? & 0 & 1 & 2 & 3 \\
\hline $\begin{array}{l}\text { 10. Lavar seu corpo inteiro e secá- } \\
\text { lo após o banho? }\end{array}$ & 0 & 1 & 2 & 3 \\
\hline 11. Tomar um banho de chuveiro? & 0 & 1 & 2 & 3 \\
\hline $\begin{array}{l}\text { 12. Sentar-se e levantar-se de um } \\
\text { vaso sanitário? }\end{array}$ & 0 & 1 & 2 & 3 \\
\hline $\begin{array}{l}\text { 13. Levantar os braços e pegar } \\
\text { um objeto de mais ou menos } 2,5 \\
\mathrm{Kg} \text {, que está posicionado um } \\
\text { pouco acima de sua cabeça? }\end{array}$ & 0 & 1 & 2 & 3 \\
\hline $\begin{array}{l}\text { 14. Curvar-se para pegar suas } \\
\text { roupas no chão? }\end{array}$ & 0 & 1 & 2 & 3 \\
\hline $\begin{array}{l}\text { 15. Segurar-se em pé no ônibus } \\
\text { ou no metrô? }\end{array}$ & 0 & 1 & 2 & 3 \\
\hline $\begin{array}{l}\text { 16. Abrir potes ou vidros de } \\
\text { conserva que tenham sido } \\
\text { previamente abertos? }\end{array}$ & 0 & 1 & 2 & 3 \\
\hline 17. Abrir e fechar torneiras? & 0 & 1 & 2 & 3 \\
\hline $\begin{array}{l}\text { 18. Fazer compras na redondeza } \\
\text { onde mora? }\end{array}$ & 0 & 1 & 2 & 3 \\
\hline 19. Entrar e sair de um ônibus? & 0 & 1 & 2 & 3 \\
\hline $\begin{array}{l}\text { 20. Realizar tarefas tais como } \\
\text { usar a vassoura para varrer e o } \\
\text { rodo para puxar a água? }\end{array}$ & 0 & 1 & 2 & 3 \\
\hline
\end{tabular}


Escores dos componentes:

Componente 1, perguntas 1 e 2 : Maior escore $=$

Componente 2, perguntas 3 e 4 : Maior escore $=$

Componente 3 , perguntas 5,6 e $7:$ Maior escore $=$ Componente 4, perguntas 8 e 9 : Maior escore $=$

Componente 5, perguntas 10, 11 e 12: Maior escore $=$

Componente 6, perguntas 13 e 14: Maior escore $=$ Componente 7, perguntas 15 e 16: Maior escore $=$ Componente 8, perguntas 18, 19 e 20: Maior escore $=$ 


\section{ANEXO 8}

universıaade ae srasıla

Faculdade de Medicina

Comitê de Ética em Pesquisa em Seres Humanos

Campus Universitário, Asa Norte - CEP 70910-9000 - Brasília, DF - Tel.: (061) 3307-2520 / 3273-4069

\section{ANÁLISE DE PROJETO DE PESQUISA}

Registro de projeto: CEP-FM 028/2007

Título: "Artrite reumatóide inicial: avaliação prospectiva de possíveis marcadores sorológicos de atividade, determinantes prognósticos funcionais radiográficos."

Pesquisador responsável: Licia Maria Henrique da Mota

Documentos analisados: Folha de rosto, carta de encaminhamento, declaração de Responsabilidade, protocolo de pesquisa, termo de consentimento livre e esclarecido, cronograma, bibliografia pertinente e currículo(s) de pesquisador(es)

Data de entrada: $\quad 15 / 06 / 2007$

Proposição do(a) relator(a)

( x ) Aprovação

( ) Não aprovação

Data da primeira análise pelo CEP-FM/UnB: 22/08/2007

Data do parecer final do projeto pelo CEP-FM/UnB: 22/08/2007

\section{PARECER}

Com base na Resolução CNS/MS No 196/96, que regulamenta a matéria, a Coordenação do Comitê de Ética em Pesquisa da Faculdade de Medicina da Universidade de Brasília decidiu APROVAR na reunião ordinária de 22/08/2007, conforme parecer do(a) relator(a), o projeto de pesquisa acima especificado, quanto aos seus aspectos éticos.

1 - Modificações no protocolo devem ser submetidas ao CEP, assim como a notificação imediata de eventos adversos graves;

2 - O(s) pesquisador(es) deve(m) apresentar relatórios periódicos do andamento da pesquisa ao CEP-FM.

Brasília, 24 de agosto de 2007.

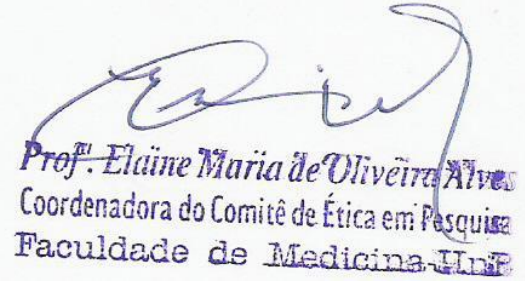


